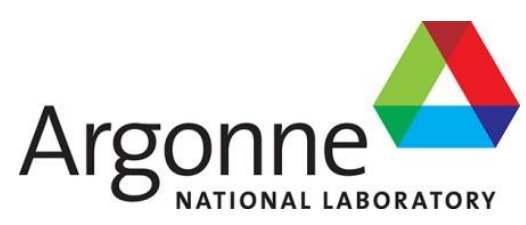

ANL-15/15

\title{
Measuring and Monitoring KIPT Neutron Source Facility Reactivity
}

Nuclear Engineering Division 


\section{About Argonne National Laboratory}

Argonne is a U.S. Department of Energy laboratory managed by UChicago Argonne, LLC under contract DE-AC02-06CH11357. The Laboratory's main facility is outside Chicago, at 9700 South Cass Avenue, Argonne, Illinois 60439. For information about Argonne

and its pioneering science and technology programs, see www.anl.gov.

\section{DOCUMENT AVAILABILITY}

Online Access: U.S. Department of Energy (DOE) reports produced after 1991 and a growing number of pre-1991 documents are available free via DOE's SciTech Connect (http://www.osti.gov/scitech/)

\section{Reports not in digital format may be purchased by the public from the} National Technical Information Service (NTIS):

U.S. Department of Commerce

National Technical Information Service

5301 Shawnee Rd

Alexandria, VA 22312

www.ntis.gov

Phone: (800) 553-NTIS (6847) or (703) 605-6000

Fax: (703) 605-6900

Email:orders@ntis.gov

Reports not in digital format are available to DOE and DOE contractors from the Office of Scientific and Technical Information (OSTI):

U.S. Department of Energy

Office of Scientific and Technical Information

P.O. Box 62

Oak Ridge, TN 37831-0062

www.osti.gov

Phone: (865) 576-8401

Fax: (865) 576-5728

Email: reports@osti.gov

\section{Disclaimer}

This report was prepared as an account of work sponsored by an agency of the United States Government. Neither the United States Government nor any agency thereof, nor UChicago Argonne, LLC, nor any of their employees or officers, makes any warranty, express or implied, or assumes any legal liability or responsibility for the accuracy, completeness, or usefulness of any information, apparatus, product, or process disclosed, or represents that its use would not infringe privately owned rights. Reference herein to any specific commercial product, process, or service by trade name, trademark, manufacturer, or otherwise, does not necessarily constitute or imply its endorsement, recommendation, or favoring by the United States Government or any agency thereof. The views and opinions of document authors expressed herein do not necessarily state or reflect those of the United States Government or any agency thereof, Argonne National Laboratory, or UChicago Argonne, LLC. 
ANL-15/15

\section{Measuring and Monitoring KIPT Neutron Source Facility Reactivity}

by

Yan Cao, Yousry Gohar and Zhaopeng Zhong

Nuclear Engineering Division, Argonne National Laboratory

August 2015 


\title{
MEASURING AND MONITORING KIPT NEUTRON SOURCE FACILITY REACTIVITY
}

\author{
$\underline{\text { Table of Contents }}$
}

Page

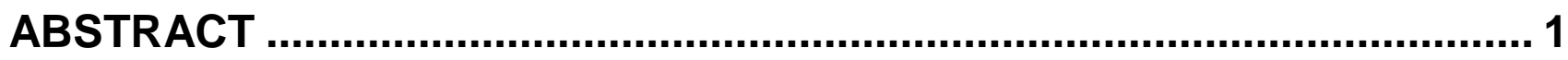

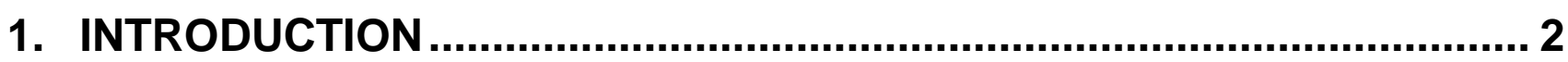

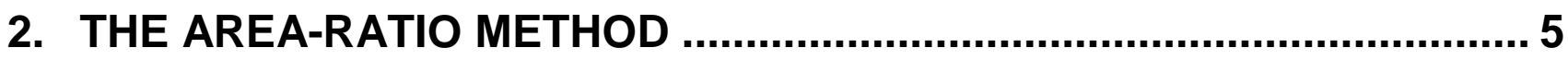

A. THEORY

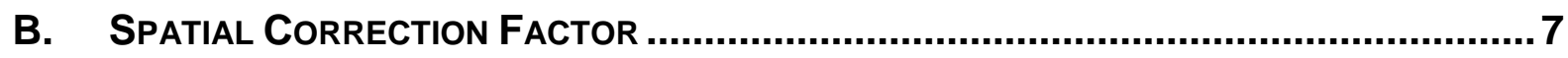

3. THE FLUX-TO-CURRENT RATIO METHOD ......................................... 8

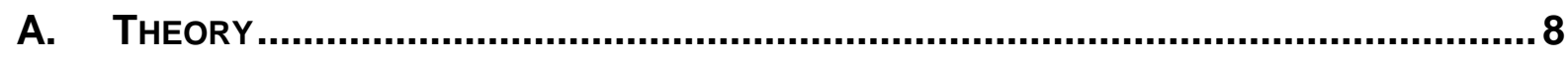

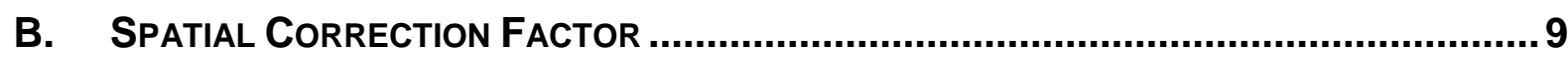

C. Kipt Spatial Corrections for the FluX-to-Current Ratio Method .............10

4. DETERMINATION OF NEUTRON DETECTOR POSITIONS IN KIPT SUBCRITICAL CORE ...................................................................... 13

A. Numerical Simulation Studies of the Neutron Detector Positions ............ 13

B. Neutron Detector Positions in the KIPT Subcritical Assembly .................. 20

5. DETERMINATION THE REACTIVITY OF THE KIPT SUBCRITICAL ASSEMBLY DURING THE FUEL LOADING PROCESS....................... 21

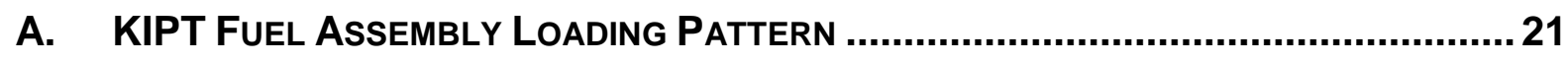

B. Pulsed-Neutron Experiments in the KIPT Neutron Source Facility ........... 23

C. KIPt Subcritical Assembly Reactivity Measurement at Each Fuel

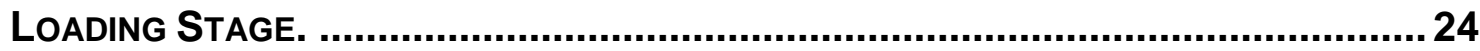

D. Flux-to-Current Ratio Method Measurement at the Kipt fuel

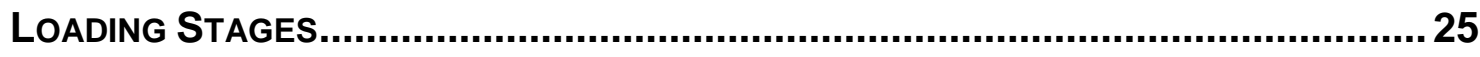

E. Spatial Correction factors for the Area-Ratio Method and the FLUX-TO-CURRENT RATIO METHOD............................................................ 28 
6. TRACKING THE REACTIVITY VARIATIONS OF THE KIPT SUBCRITICAL CORE AT FULL POWER OPERATION MODE .............. 38

A. Simulated Neutron Detector Responses during the Normal

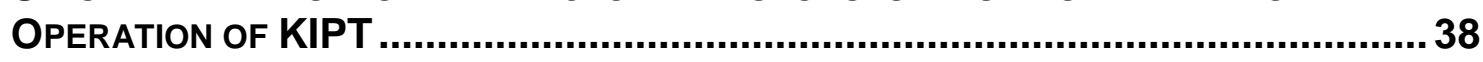

B. Flux-to-Current Ratio Method Utilization for monitoring the Reactivity Change of the KIPT NeUtron Source Facility duRING

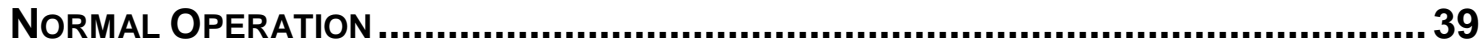

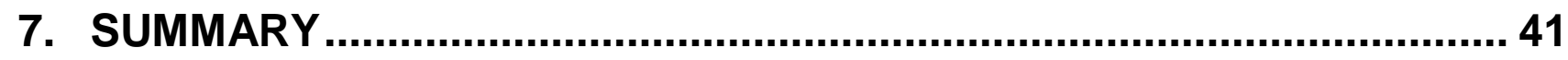

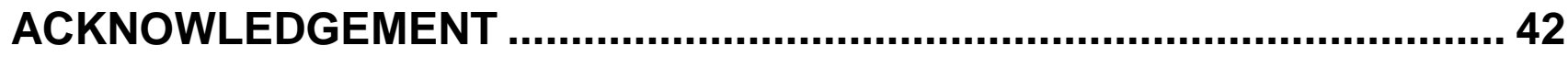

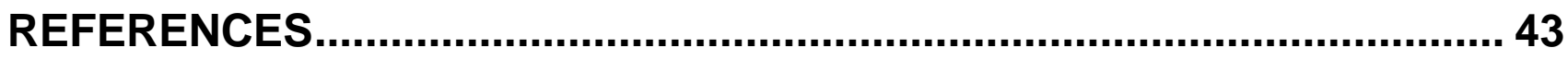

APPENDIX A: MONTE CARLO SIMULATIONS AND VALIDATIONS OF THE SOURCE-MODULATION METHOD ................................................ 45

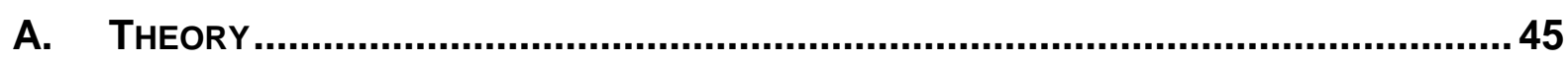

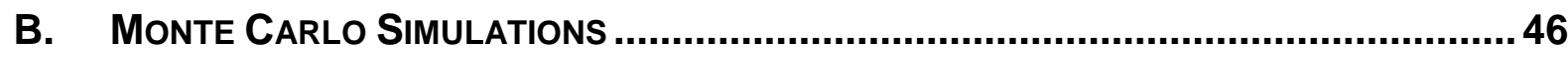

APPENDIX B: MONTE CARLO SAMPLING OF THE MODULATED EXTERNAL SOURCE ..................................................................... 50 


\title{
MEASURING AND MONITORING KIPT NEUTRON SOURCE FACILITY REACTIVITY
}

\author{
List of Figures
}

$\underline{\text { Page }}$

Figure 1. Monte CaRlo models of the KIPT NEUtRon SOURCE FACILITY (A) X-Y VIEW WITH THE TUNGSTEN TARGET AND 38 FUEL ASSEMBLIES, (B) X-Y VIEW WITH THE TUNGSTEN TARGET AND 42 FUEL ASSEMBLIES, (c) X-Y VIEW WITH THE NATURE URANIUM TARGET AND 37 FUEL ASSEMBLIES (D) X-Z VIEW OF THE FACILITY

FIGURE 2. A TYPICAL NEUTRON DETECTOR RESPONSE IN A PULSED-NEUTRON EXPERIMENT AND THE DIAGRAM OF CALCULATING NEUTRON AREAS FOR THE AREA-RATIO METHOD...

FIGURE 3. FUEL LOADING PATTERNS OF THE KIPT NEUTRON SOURCE FACILITY WITH TUNGSTEN USED IN THE MONTE CARLO SIMULATIONS

FiguRE 4. (A) TOP VIEW AND (B) SIDE VIEW OF THE CALCULATIONAL MODEL SHOWING THE NEUTRON FLUX TALLY POSITIONS IN THE NUMERICAL MODELS OF THE KIPT NEUTRON SOURCE FACILITY WITH THE TUNGSTEN TARGET AND 42 FUEL ASSEMBLIES.

FiguRE 5. SPATIAL CORRECTION FACTORS AT THE FUEL MIDDLE PLANE ( $Z=25 \mathrm{CM})$ FOR THE CONFIGURATIONS WITH THE TUNGSTEN TARGET AND 35 TO 42 FUEL ASSEMBLIES.

FIGURE 6. CORRECTION FACTORS AT THE Z $=60 \mathrm{cM}$ PLANE FOR THE CONFIGURATIONS WITH THE TUNGSTEN TARGET AND 35 TO 42 FUEL ASSEMBLIES.

FIGURE 7. FUEL LOADING PATTERNS OF THE KIPT NEUTRON SOURCE FACILITY FOR THE MONTE CARLO SIMULATIONS WITH THE URANIUM TARGET AND 20 TO 37 FUEL ASSEMBLIES.

FIGURE 8. FUEL LOADING PATTERNS OF THE KIPT NEUTRON SOURCE FACILITY FOR THE MONTE CARLO SIMULATIONS WITH THE TUNGSTEN TARGET AND 18 TO 38 FUEL ASSEMBLIES.

FiguRE 9. DETECTOR POSITIONS IN KIPT NEUTRON SOURCE FACILITY (A) HORIZONTAL VIEW AT Z $=65.0 \mathrm{CM}(\mathrm{B})$ VERTICAL VIEW AT THE CENTERLINE.

FIGURE 10. CORRECTION FACTORS OF THE KIPT NEUTRON SOURCE FACILITY CONFIGURATIONS WITH THE URANIUM TARGET AND 22 TO 37 FUEL ASSEMBLIES..... 18

FIGURE 11. CORRECTION FACTORS OF THE KIPT NEUTRON SOURCE FACILITY CONFIGURATIONS WITH THE TUNGSTEN TARGET AND 18 TO 38 FUEL ASSEMBLIES.

FIGURE 12. AVERAGE CORRECTION FACTORS OF THE KIPT NEUTRON SOURCE FACILITY CONFIGURATIONS WITH THE URANIUM TARGET AND 22 TO 37 FUEL ASSEMBLIES..... 19 
FIGURE 13. AVERAGE CORRECTION FACTORS OF THE KIPT NEUTRON SOURCE FACILITY CONFIGURATIONS WITH THE TUNGSTEN TARGET AND 18 TO 38 FUEL ASSEMBLIES.

Figure 14. (A) Neutron fluX tally zone and (B) NeUtron fluX leVel map above the GRAPHITE REFLECTOR FOR THE KIPT NEUTRON SOURCE FACILITY WITH THE URANIUM TARGET, 37 FUEL ASSEMBLIES, AND $100 \mathrm{KW}$ ELECTRON BEAM POWER.

Figure 15. Neutron detector locations at: (A) the SElected optimal detector LOCATIONS AND (B) THE BIOLOGICAL SHIELD SURFACE AT THE MIDDLE FUEL PLANE.

FIGURE 16. THE KIPT FUEL ASSEMBLY LOADING SEQUENCE FOR THE SUBCRITICAL ASSEMBLY WITH THE TUNGSTEN TARGET AND THE MAXIMUM FUEL LOADING OF 38 ASSEMBLIES

Figure. 17 Monte Carlo simulations of the neUtron fluXes from ONE NEUtron PULSE INJECTED IN THE KIPT SUBCRITICAL ASSEMBLY WITH THE TUNGSTEN TARGET FOR DIFFERENT FUEL LOADING STAGES.

Figure 18. Monte CARLO Simulations of the NeUtron fluXes from ONE NEUTRON PULSE INJECTED IN THE KIPT SUBCRITICAL ASSEMBLY WITH THE URANIUM TARGET FOR DIFFERENT FUEL LOADING STAGES.

Figure 19. Monte Carlo simulations of THE DETECTOR COUNTING RATES OF THE KIPT SUBCRITICAL ASSEMBLY WITH THE TUNGSTEN TARGET FOR DIFFERENT FUEL LOADING STAGES DRIVEN BY $10 \mathrm{~W}$ ELECTRON BEAM PULSES WITH $20 \mathrm{HZ}$ FREQUENCY.

Figure 20. Monte Carlo simulations of the Detector counting Rates of the KIPT SUBCRITICAL ASSEMBLY WITH THE URANIUM TARGET FOR DIFFERENT FUEL LOADING STAGES DRIVEN BY $10 \mathrm{~W}$ ELECTRON BEAM PULSES WITH $20 \mathrm{HZ}$ FREQUENCY.

Figure 21. Monte Carlo simulations of the aVeraged time-dependent neutron FLUX FROM EACH PULSE NORMALIZED TO THE STEADY STATE NEUTRON FLUX WITH THE SAME SOURCE STRENGTH FOR THE KIPT SUBCRITICAL ASSEMBLY WITH THE TUNGSTEN TARGET FOR DIFFERENT FUEL LOADING STAGES.

Figure 22. Monte Carlo Calculated SPATIAL CORRECTION FACtORS OF tHE AREA-RATIO METHOD FOR EACH NEUTRON DETECTOR LOCATION IN THE KIPT NEUTRON SOURCE FACILITY WITH THE TUNGSTEN TARGET FOR EACH FUEL LOADING STAGE.

Figure 23. Monte Carlo Calculated spatial correction factors of the fluX-toCURRENT RATIO METHOD FOR EACH NEUTRON DETECTOR LOCATION IN THE KIPT NEUTRON SOURCE FACILITY WITH THE TUNGSTEN TARGET FOR EACH FUEL LOADING STAGE. THE REFERENCE CONFIGURATION IS THE PREVIOUS FUEL LOADING STAGE.

Figure 24. GROUP AVERAGE CORRECTION FACTOR VALUES FOR THE AREA-RATIO METHOD AND THE FLUX-TO-CURRENT RATIO METHOD FOR THE KIPT NEUTRON SOURCE FACILITY WITH THE TUNGSTEN TARGET FOR EACH FUEL LOADING STAGE. 
Figure 25. Monte Carlo Calculation of the detector counting Rates after the KIPT SUBCRITICAL CORE REACHING THE DELAYED NEUTRON EQUILIBRIUM STATUS. THE SUBCRITICAL ASSEMBLY IS LOADED WITH 24 TO 38 FUEL ASSEMBLIES AND IT IS DRIVEN BY A $100 \mathrm{~kW}$ ELECTRON BEAM WITH $625 \mathrm{~Hz}$ FREQUENCY.

FIGURE 26. FUEL LOADING PATTERNS OF KIPT SUBCRITICAL ASSEMBLY AT DIFFERENT BURNUP STAGES FOR CONFIGURATION WITH NATURAL URANIUM TARGET. 39

FIGURE 27. MONTE CARLO MODEL OF THE YALINA-THERMAL SUBCRITICAL ASSEMBLY CONFIGURATION 18.

Figure 28. Monte Carlo simulation of the MC1 DETECTOR RESPONSE RT IN THE YALINA-THERMAL SUBCRITICAL ASSEMBLY USING THE EXTERNAL NEUTRON SOURCE $S T(t)$.

FIGURE 29. CALCULATED ASYMPTOTIC DETECTOR RESPONSES AT MC1 WITHIN ONE PERIOD WITH 1 TO 5000 PERIODS ACCUMULATED IN THE YALINA-THERMAL SUBCRITICAL ASSEMBLY.

FIGURE 30. THE SIMULATED ASYMPTOTIC DETECTOR RESPONSE RESPONSES AT MC1 POSITION AND ITS SINUSOIDAL FITTING IN YALINA-THERMAL SUBCRITICAL ASSEMBLY. 


\title{
MEASURING AND MONITORING KIPT NEUTRON SOURCE FACILITY REACTIVITY
}

\author{
List of Tables
}

$\underline{\text { Page }}$

TABle I: Monte CaRlo CRiticality CAlCulations of the KIPT SUBCRitical ASSEMBLy CONFIGURATION WITH THE TUNGSTEN TARGET AND 35 TO 42 FUEL ASSEMBLIES. ... 11

TABle II: MONTE CARlo CRIticality CALCULATIONS OF THE DIFFERENT KIPT NEUTRON SOURCE FACILITY CONFIGURATIONS WITH THE URANIUM TARGET AND 20 TO 37

FUEL ASSEMBLIES.

TABle III: MONTE CARLO CRITICALITY CALCULATIONS OF THE DIFFERENT KIPT NEUTRON SOURCE FACILITY CONFIGURATIONS WITH THE TUNGSTEN TARGET AND 18 TO 38 FUEL ASSEMBLIES.

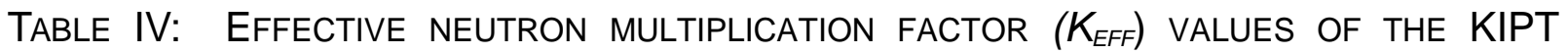
NEUTRON SOURCE FACILITY WITH THE TUNGSTEN TARGET AND DIFFERENT NUMBER OF THE FUEL ASSEMBLIES.

Table V: Monte Carlo calculated corRection factor Values of the area-Ratio METHOD FOR NEUTRON DETECTORS 1, 3 AND 5 (GROUP 1) OF THE KIPT NEUTRON SOURCE FACILITY WITH THE TUNGSTEN TARGET FOR EACH FUEL LOADING STAGE.

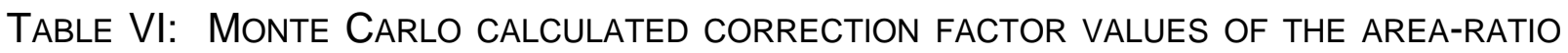
METHOD FOR NEUTRON DETECTORS 2, 4 AND 6 (GROUP 2) OF THE KIPT NEUTRON SOURCE FACILITY WITH THE TUNGSTEN TARGET FOR EACH FUEL LOADING STAGE.

TABle VII: MONTE CARLO CALCULATED CORRECTION FACTOR VALUES OF THE AREA-RATIO METHOD FOR NEUTRON DETECTORS 7, 8 AND 9 (GROUP 3) OF THE KIPT NEUTRON SOURCE FACILITY WITH THE TUNGSTEN TARGET FOR EACH FUEL LOADING STAGE.

Table Vill: Monte Carlo calculated correction factor values of the FluX-toCURRENT RATIO METHOD FOR NEUTRON DETECTORS 1, 3 AND 5 (GROUP 1) OF THE KIPT NEUTRON SOURCE FACILITY WITH THE TUNGSTEN TARGET FOR EACH FUEL LOADING STAGE. THE REFERENCE CONFIGURATION IS THE PREVIOUS FUEL LOADING STAGE.

Table IX: Monte Carlo calculated correction factor values of the FluX-toCURRENT RATIO METHOD FOR NEUTRON DETECTORS 2, 4 AND 6 (GROUP 2) OF THE KIPT NEUTRON SOURCE FACILITY WHICH WITH THE TUNGSTEN TARGET FOR EACH FUEL LOADING STAGE. THE REFERENCE CONFIGURATION IS THE PREVIOUS FUEL LOADING STAGE.

Table X: Monte Carlo calculated correction factor values of the fluX-toCURRENT RATIO METHOD FOR NEUTRON DETECTORS 7, 8 AND 9 (GROUP 3) OF 
THE KIPT NEUTRON SOURCE FACILITY WITH THE TUNGSTEN TARGET FOR EACH FUEL LOADING STAGE. THE REFERENCE CONFIGURATION IS THE PREVIOUS FUEL LOADING STAGE.

TABle XI. Calculated aVerage spatial corRection factors at optimal detector POSITIONS FOR KIPT SUBCRITICAL ASSEMBLY WITH NATURAL URANIUM TARGET.

TABLE XII: NUMERICAL SIMULATIONS OF THE SOURCE MODULATION METHOD FOR THE YALINA-THERMAL SUBCRITICAL ASSEMBLY (MONTE CARLO CALCULATED PARAMETERS $\beta$ eff $=0.0073$, kef $f=0.9654$, AND $\rho=-4.90 \$)$. 


\title{
MEASURING AND MONITORING KIPT NEUTRON SOURCE FACILITY REACTIVITY
}

\begin{abstract}
Argonne National Laboratory (ANL) of USA and Kharkov Institute of Physics and Technology (KIPT) of Ukraine have been collaborating on developing and constructing a neutron source facility at Kharkov, Ukraine. The facility consists of an accelerator-driven subcritical system. The accelerator has a $100 \mathrm{~kW}$ electron beam using $100 \mathrm{MeV}$ electrons. The subcritical assembly has $k_{\text {eff }}$ less than 0.98 . To ensure the safe operation of this neutron source facility, the reactivity of the subcritical core has to be accurately determined and continuously monitored. A technique which combines the area-ratio method and the flux-to-current ratio method is purposed to determine the reactivity of the KIPT subcritical assembly at various conditions. In particular, the arearatio method can determine the absolute reactivity of the subcritical assembly in units of dollars by performing pulsed-neutron experiments. It provides reference reactivities for the flux-to-current ratio method to track and monitor the reactivity deviations from the reference state while the facility is at other operation modes. Monte Carlo simulations are performed to simulate both methods using the numerical model of the KIPT subcritical assembly. It is found that the reactivities obtained from both the area-ratio method and the flux-to-current ratio method are spatially dependent on the neutron detector locations and types. Numerical simulations also suggest optimal neutron detector locations to minimize the spatial effects in the flux-to-current ratio method. The spatial correction factors are calculated using Monte Carlo methods for both measuring methods at the selected neutron detector locations. Monte Carlo simulations are also performed to verify the accuracy of the flux-to-current ratio method in monitoring the reactivity swing during a fuel burnup cycle.
\end{abstract}




\section{MEASURING AND MONITORING KIPT NEUTRON SOURCE FACILITY REACTIVITY}

\section{Introduction}

Argonne National Laboratory (ANL) of USA and Kharkov Institute of Physics and Technology (KIPT) of Ukraine have been collaborating on developing and constructing a neutron source facility at Kharkov, Ukraine [1]. The main function of this facility is to generate medical isotopes, to provide neutron source for material research and studies, and to serve as an educational facility for training young nuclear scientists. This neutron source facility utilizes a $100 \mathrm{~kW}$ electron beam accelerator to drive a subcritical assembly. Neutrons are produced from the interactions of $100 \mathrm{MeV}$ electrons with a natural uranium target or a tungsten target. The generated neutrons from the photo nuclear reactions leak out of the target zone and multiply in the fuel of the subcritical assembly. The subcritical assembly has a hexagonal shape fuel assemblies with low enriched uranium and aluminum clad. The active fuel length is $50 \mathrm{~cm}$. Beryllium assemblies are used as a reflector material around the fuel assemblies forming a hexagonal zone. The outside length of this hexagonal zone is $\sim 23.8 \mathrm{~cm}$. Graphite reflector is placed outside the hexagonal zone to improve the neutron economy. The whole subcritical assembly is submerged in a water tank and the tank dimensions are 2 $\mathrm{m}$ diameter and $3 \mathrm{~m}$ height. Figure 1 shows the calculational models of the facility with different fuel configurations. Depending on the target material, the neutron multiplication factor $k_{\text {eff }}$ of the subcritical is around 0.975 for the configuration with a natural uranium target and 37 fuel assemblies. It is 0.957 for the configuration with the tungsten target and 38 fuel assemblies.

To ensure the safe operation of the KIPT neutron source facility, the neutron multiplication factor $k_{\text {eff }}$ has to be less than 0.98 during any operating mode, i.e., the normal operation mode, the reactor refueling mode, or the maintenance mode etc. Therefore, the reactivity $\rho$ of the subcritical assembly which is inversely proportional to the $k_{\text {eff }}$ has to be continuously monitored.

For a conventional nuclear reactor close to a critical condition, a lot of techniques such as the slope method, the area-ratio method, or the rod-drop method can predict accurately the reactivity. In such reactors, the fundamental flux mode corresponding to the eigenvalue parameter $k_{\text {eff }}$ dominates over the high order harmonics and determines the spatial- and spectral- distributions of the neutron flux [2]. The KIPT subcritical system operates either at $\sim 0.975$ or $\sim 0.957 k_{\text {eff. }}$ As $k_{\text {eff }}$ of the subcritical system moves far away from 1.0, all the harmonic modes including the fundamental mode and the highorder harmonic modes become important in determining the spatial shape of the neutron flux. In the deep subcritical systems, it is a challenging tusk to separate the fundamental flux mode from the other high-order harmonic flux modes to determine the corresponding dominant eigenvalue $k_{\text {eff. }}$ 


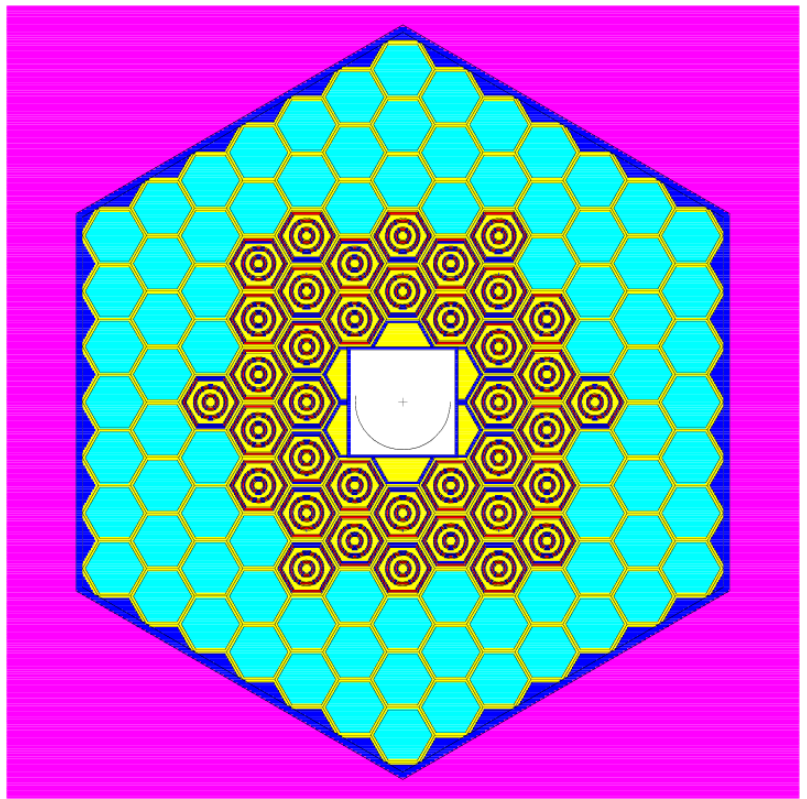

(a)

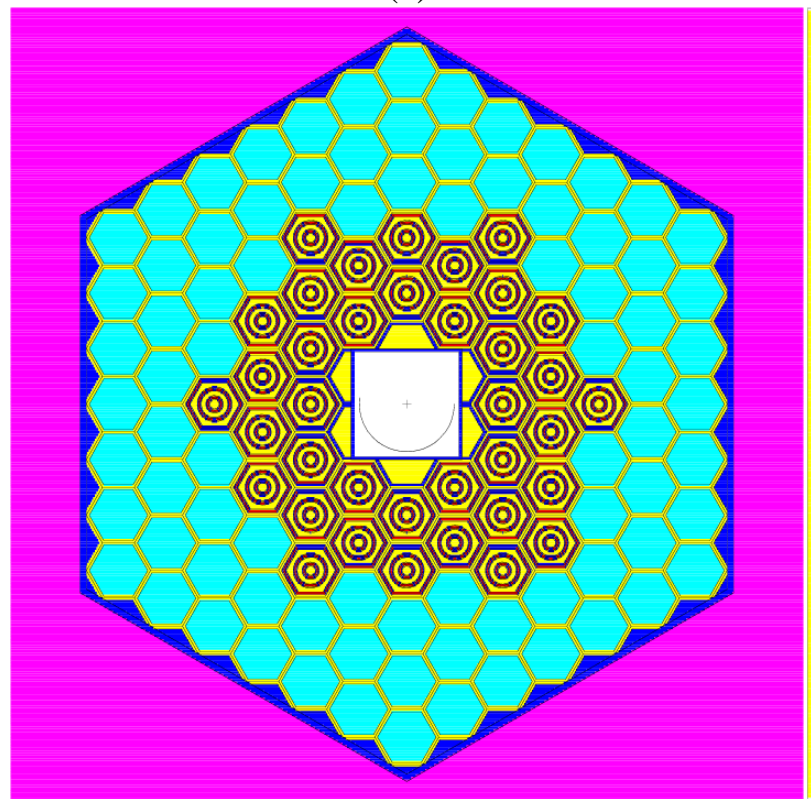

(c)

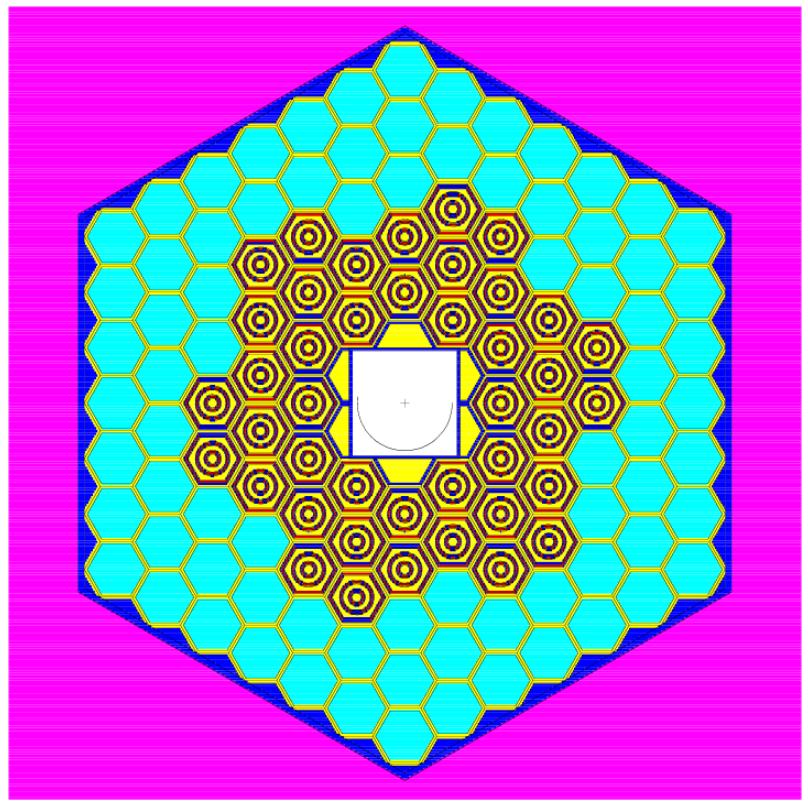

(b)

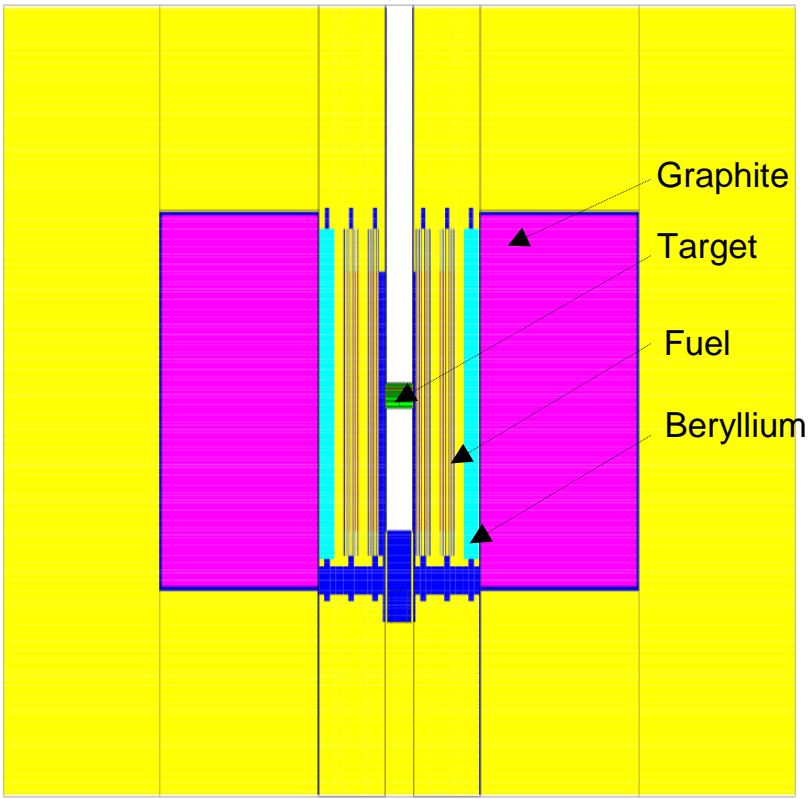

(d)

Figure 1. Monte Carlo models of the KIPT neutron source facility (a) X-Y view with the tungsten target and 38 fuel assemblies, (b) $X-Y$ view with the tungsten target and 42 fuel assemblies, (c) X-Y view with the nature uranium target and 37 fuel assemblies (d) X-Z view of the facility

Since the accelerator-driven subcritical systems are considered to transmute nuclear wastes [3], a lot of studies around the world have been devoted to understanding the reliability of the traditional methods for determining the reactivity of the subcritical systems [4-6]. The general approach usually involves numerous comparisons of the numerical simulation results with the actual experimental data. Till 
now, measuring and monitoring the reactivity of a subcritical core is still one of the main issues for operating ADS systems.

Specifically, the traditional techniques such as the rod-drop method, the source multiplication method, the pulsed-neutron experiments, and the noise analysis method etc. have been examined to determine the absolute reactivity of the subcritical core at deep subcritical states [4-7]. Those methods are accurate for systems close to critical condition. However, for deep subcritical systems, the point kinetics approximations are found to be not accurate. The obtained reactivities from these conventional methods are accurate for systems close to critical condition. The measured reactivities from these conventional methods are sensitive to the neutron detector position in the assembly and the neutron detector type in deep subcritical systems. Monte Carlo simulations have been extensively carried out carefully to calculate the spatial correction factors of the obtained $k_{\text {eff }}$ values with the traditional methods. Particularly, the area-ratio method from pulsed-neutron experiments are found to be a reliable method in determining the absolute reactivity of a subcritical system even at deep subcritical states after applying the spatial correction factors. These factors can be accurately calculated for each detector location using Monte Carlo simulations.

For subcritical assemblies operated at full power, the traditional methods cannot track the reactivity variations during operation. Few new techniques have been purposed to provide on-line reactivity measurements for subcritical systems, such as the flux-to-current ratio method and the source-modulation method [8-11]. These techniques have not completely tested in the experimental programs of the accelerator driven subcritical systems. Numerical validations of these techniques are also limited. In particular, the source-modulation technique performance was very poor as shown with simple analytical numerical models [12]. Talamo and Gohar [7] purposed a superposition technique to simulate the detector responses in a pulsed-neutron source experiment. Monte Carlo simulations using similar technique can be used to simulate the detector responses in a subcritical system driven by a modulated source. As shown in Appendix $A$ and $B$ this numerical simulation showed also the poor performance of the source-modulation method for determining the reactivity of the subcritical assembly for all the selected detector positions.

In this work, the pulsed-neutron experiments with the area-ratio method were first used to determine the absolute reactivity of the KIPT neutron source facility at different fuel loading stages. The dynamic neutron detector responses from the pulsed-neutron source were calculated using the Monte Carlo methods and the results were used to determine the proper parameters for the future pulsed-neutron source experiments performed in the KIPT facility. Also, Monte Carlo simulations were performed to calculate the spatial correction factors for the area-ratio method.

In addition, the flux-to-current ratio method was adopted to track the reactivity variations of the KIPT facility. Numerical simulations were performed to examine the performance of this method using several KIPT numerical models [13-14]. The spatial effects of the method were investigated and the spatial correction factors were 
calculated. These analyses helped determine the final position of the neutron detectors in the KIPT facility.

The actual fuel assembly loading sequence was selected for the KIPT facility with the tungsten target assembly. A procedure of measuring and monitoring the reactivity of the KIPT facility at various fuel loading stages was purposed. The spatial correction factors corresponding to each of these fuel loading stages at each detector locations were calculated.

Monte Carlo simulations were performed to simulate the responses of the neutron detectors of the KIPT facility during the fuel loading mode and at full power operation mode. In the fuel loading mode, the pulsed neutron source is at low power and low frequency while in the full power mode the neutron source is generated with $100 \mathrm{KW}$ electron beam with a high frequency. The flux-to-current ratio method was used to monitor the reactivity swing during the burnup fuel cycle, which has 18 fuel stages. Monte Carlo simulations were performed to calculate the spatial correction factors at each stage of the fuel burnup cycle.

\section{The Area-Ratio Method}

\section{A. Theory}

The area-ratio method is used in the pulsed-neutron experiment to determine the reactivity of a subcritical assembly. In a pulsed-neutron experiment, the reactivity $\rho$ in dollars of the subcritical assembly is given by the negative ratio of the prompt-neutron area $A_{p}$ and the delayed-neutron area $A_{d}$ :

$$
\rho(\$)=\frac{\rho}{\beta}=-\frac{A_{p}}{A_{d}}
$$

Where the delayed-neutron area $A_{d}$ is obtained by integrating the delayed neutron fluxes over the pulse period, and the prompt-neutron area $A_{p}$ is obtained by integrating the total neutron fluxes and subtracting the delayed-neutron area.

To perform a pulsed-neutron experiment, external pulsed source neutrons are injected into the subcritical core periodically. The neutron flux level in the subcritical core is monitored by the neutron detectors placed inside the subcritical assembly. During the experiment, the subcritical assembly is operated at a low power level. The pulsed source period has to be long enough such that the prompt neutron population generated due to the external pulsed-neutron source dies out completely. The pulsedneutron source period has also to be small compared with the half-live of the fastest decay group of the delayed neutrons, such that the delayed neutron population accumulated during all the previous source periods remains almost constant inside the source period. Figure 2 shows a typical detector response in a subcritical assembly simulated using the Monte Carlo method [15]. 


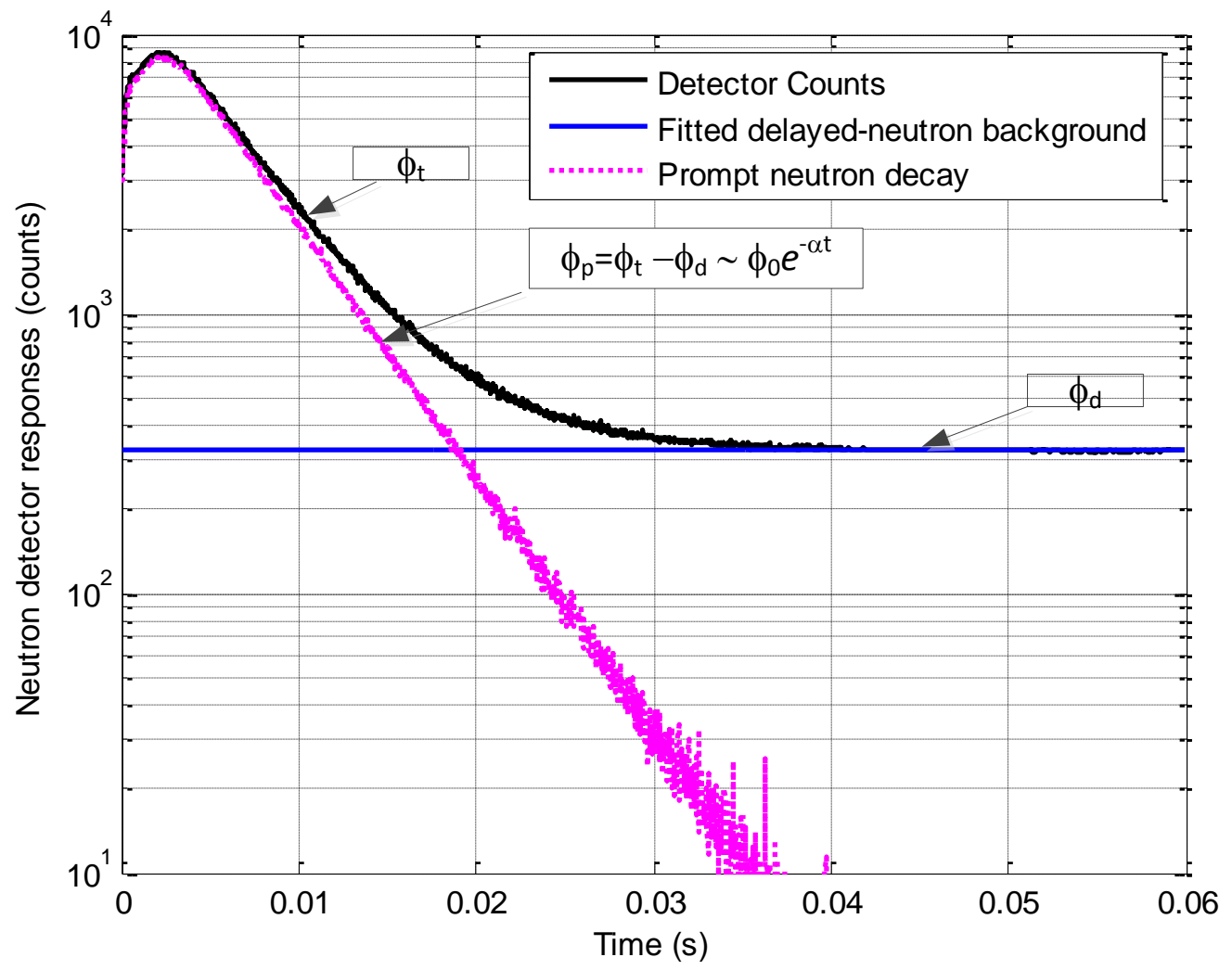

Figure 2. A typical neutron detector response in a pulsed-neutron experiment and the diagram of calculating neutron areas for the area-ratio method.

In actual experiments, $A_{p}$ and $A_{d}$ are neutron areas measured from the neutron detector responses after thousands of source periods are injected into the subcritical assembly. The neutron population in the subcritical assembly reaches a delayedneutron equilibrium status as shown in Figure 2. The delayed neutron background level $\phi_{d}$ is assumed to be a constant and is fitted from the detector responses at each detector location. The delayed neutron area is the integration of this constant background over the pulse period T:

$$
A_{d}=\phi_{d} T .
$$

The total neutron area is the integration of the total detector response over the pulse period, and the prompt neutron area $A_{p}$ is the total neutron area subtracting the delayed neutron area.

The area-ratio method in Equation (1) is derived based on the assumption that the subcritical reactor is a point assembly. In an actual experiment performed in the deep subcritical system, the reactivities obtained at different neutron detector locations are found to be different and are dependent on the type of neutron detectors being utilized at that position. 


\section{B. Spatial Correction Factor}

The spatial dependence of the area-ratio method has been explored thoroughly in the past research studies [4-6]. The neutron areas can be calculated with numerical simulations. If the prompt neutron flux $\phi_{p}$ is separated from the total neutron flux $\phi_{t}$ by ignoring the delayed neutrons, a transport equation solely for the prompt neutron flux can be obtained as:

$$
\begin{gathered}
\frac{1}{v} \frac{\partial \phi_{p}}{\partial t}+\boldsymbol{L} \phi_{p}=(1-\beta) \chi_{p} \boldsymbol{F} \phi_{p}+Q \\
\frac{1}{v} \frac{\partial \phi_{t}}{\partial t}+\boldsymbol{L} \phi_{t}=(1-\beta) \chi_{p} \boldsymbol{F} \phi_{t}+\sum_{i} \chi_{d i} \lambda_{i} C_{i}+Q \\
\frac{\partial C_{i}}{\partial t}+\lambda_{i} C_{i}=\beta_{i} \boldsymbol{F} \phi_{t}
\end{gathered}
$$

Where $\chi_{p}$ and $\chi_{d i}$ are the prompt neutron and the $\mathrm{i}_{\text {th }}$ group of delayed neutron fission spectra respectively, $\beta$ is the delayed neutron fraction, the operators $\mathbf{L}$ and $\mathbf{F}$ are the neutron destruction and the neutron fission operators respectively, and $Q$ is the external time-dependent neutron source. The prompt neutron area within a pulse period is then equal to the integration of the detector reaction rate contributed from the prompt neutrons: $A_{p}=\int_{0}^{T} \sigma_{d} \phi_{p}(t) d t$, where $\sigma_{d}$ is the corresponding cross section of the neutron sensitive materials for detecting neutrons. The delayed neutron area is the reaction rate contributed from the delayed neutrons: $A_{d}=\int_{0}^{T} \sigma_{d} \phi_{d} d t$, or it can be calculated through the total neutron area subtracting the prompt neutron area: $A_{d}=A_{t}-A_{p}=\int_{0}^{T} \sigma_{d}\left(\phi_{t}-\right.$ $\left.\phi_{p}\right) d t$.

For the Monte Carlo method, the neutron areas are obtained by tallying the reaction rates at the neutron detector location. One simulation is performed if the contributions of the prompt neutrons and delayed neutrons to the tallies can be separated. Or the neutron areas are calculated with two separate simulations for the prompt neutron flux $\int_{0}^{T} \phi_{p}(t) d t$ and for the total neutron flux $\int_{0}^{T} \phi_{t}(t) d t$ respectively:

$$
\begin{gathered}
\boldsymbol{L} \int_{0}^{T} \phi_{p}(t) d t=(1-\beta) \chi_{p} \boldsymbol{F} \int_{0}^{T} \phi_{p}(t) d t+\int_{0}^{T} Q(r, t) d t \\
\boldsymbol{L} \int_{0}^{T} \phi_{t}(t) d t=\chi \boldsymbol{F} \int_{0}^{T} \phi_{t}(t) d t+\int_{0}^{T} Q(r, t) d t
\end{gathered}
$$

The reactivity in dollars obtained at the detector location $r_{d}$ is calculated as:

$$
\rho^{\text {area-ratio }}\left(r_{d}\right)=-\left[\frac{A_{p}}{A_{d}}\right]^{M C}
$$


The actual reactivity in dollars $\rho(\$)^{M C}$ can be obtained from the Monte Carlo criticality calculations [17], the spatial correction factor at the detector location $r_{d}$ is calculated as:

$$
f^{M C}\left(r_{d}\right)=-\rho(\$)^{M C} \times\left[\frac{A_{d}}{A_{p}}\right]^{M C}
$$

The reactivity after the spatial correction at that detector position is then:

$$
\rho^{\text {correct }}\left(r_{d}\right)=\rho^{\exp }\left(r_{d}\right) \times f^{M C}\left(r_{d}\right)
$$

The use of spatial correction factor $f^{M C}$ eliminates the spatial effects in the area-ratio method in past experimental programs $[4,5]$. The area-ratio method is found to be a consistent and a reliable method in determining the absolute reactivity of a subcritical assembly.

\section{The Flux-to-Current Ratio Method}

\section{A. Theory}

The flux-to-current ratio method is purposed for on-line monitoring of the reactivity variation of the KIPT subcritical assembly. It is formulated from the point kinetics equations assuming that the subcritical core is driven by a steady state external source S:

$$
\begin{gathered}
0=\frac{d}{d t} P(t)=\frac{\rho-\beta}{\Lambda} P(t)+\sum_{i=1,6} \lambda_{i} C_{i}(t)+S \\
0=\frac{d}{d t} C_{i}(t)=\frac{\beta_{i}}{\Lambda} P(t)-\lambda_{i} C_{i}(t), i=1 \ldots 6
\end{gathered}
$$

Where, $P$ is the power of the subcritical assembly, $C_{i}$ is the $i_{\text {th }}$ group delayed neutron precursor density function, $\lambda_{i}$ is the $i_{\text {th }}$ group precursor decay constant, $\beta$ is the effective delayed neutron fraction, $\rho$ is the reactivity and $\Lambda$ is the mean generation time of the subcritical assembly. Then the reactivity $\rho$ of the subcritical core can be calculated as:

$$
\rho=\frac{S \Lambda}{-P}
$$

For the KIPT subcritical assembly, the external source intensity $S$ is directly proportional to the current of the accelerator beam, which is monitored continuously for the accelerator operation. The power of the system is replaced by the neutron detector response at certain locations since it can be measured and tracked. During operation, the reactivity $\rho$ of the subcritical core in equation (13) is formulated to be inversely proportional to the flux-to-current ratio [10]:

$$
\rho=C \frac{I}{<\epsilon, \sigma_{d} \phi>_{E}}
$$


Where $\mathrm{C}$ is a constant factor, $\left\langle\epsilon, \sigma_{d} \phi\right\rangle_{E}$ is the neutron detector response at the detector locations, $\epsilon$ is the neutron detector efficiency, and $I$ is the accelerator beam current. The absolute value of the constant factor $\mathrm{C}$ is complicated to be determined. To obtain the reactivity of the subcritical assembly, the reactivity at a reference state is often assumed to be known:

$$
\rho_{\text {ref }}=C \frac{I_{\text {ref }}}{<\epsilon, \sigma_{d} \phi_{\text {ref }}>_{E}}
$$

When the subcritical assembly deviates from the reference state, the reactivity at the new state is obtained by taking the relative flux-to-current ratios between these two states:

$$
\rho_{n}=\rho_{r e f}\left[\frac{<\epsilon, \sigma_{d} \phi_{r e f}(r)>_{E} / I_{r e f}}{<\epsilon, \sigma_{d} \phi_{n}(r)>_{E} / I_{n}}\right]
$$

where the subscript " $\mathrm{n}$ " represents the subcritical assembly at the new state.

The flux-to-current ratio method is simple and is easy to be implemented. It is fast responding to the reactivity variations in the subcritical assembly. However, the method can only provide reactivity of the subcritical assembly relative to a reference point. Other methods are required to provide the absolute reactivity of the subcritical assembly at the reference state.

\section{B. Spatial Correction Factor}

Similar to the area-ratio method, the reactivities obtained from the flux-to-current ratio method depend on the neutron detector locations and the neutron detector types. In addition, the obtained reactivities also depend on the differences between the configurations of the new state and the reference state. Equation (16) utilizes the point kinetics approximations and it is assumed the point kinetics parameters such as the neutron mean generation time $\Lambda$, the effective delayed neutron fraction $\beta$, the spatial effects due to a localized external source, etc. are the same for the reference and the new states. All these effects can be accounted for into a correction factor at each detector location. The correction factor $f$ is defined as:

$$
\rho^{\text {correct }}=\rho^{\exp }\left(r_{d}\right) \times f\left(r_{d}\right)
$$

Where $\rho^{\text {correct }}\left(r_{d}\right)$ is the correct reactivity of the subcritical assembly, and $\rho^{\exp }\left(r_{d}\right)$ is the reactivity obtained from the flux-to-current ratio method at detector location $r_{d}$.

The spatial correction factor can be calculated numerically. Monte Carlo simulations are utilized for calculating the correction factors. First, the detector responses $\left\langle\epsilon, \sigma_{d} \phi\left(r_{d}\right)\right\rangle_{E}$ at the selected neutron detector location corresponding to a fixed steady state source can be calculated at both the reference and the new states. Second, the reactivity $\rho_{r e f}^{M C}$ of the subcritical assembly at the reference state can be obtained using the k-eigenvalue calculations. Then, using the flux-to-current ratio method, the reactivity at the new state can be calculated as: 


$$
\rho_{n}^{\text {flux-to-current }}\left(r_{d}\right)=\rho_{\text {ref }}^{M C} \times \frac{<\epsilon, \sigma_{d} \phi\left(r_{d}\right)>_{r e f}^{M C}}{<\epsilon, \sigma_{d} \phi\left(r_{d}\right)>_{n}^{M C}}
$$

With the actual reactivity of the subcritical assembly at the new state calculated from the k-eigenvalue calculation $\rho_{n}^{M C}$, the correction factor $f$ can then be numerically obtained as:

$$
f^{M C}\left(r_{d}\right)=\frac{\rho_{n}^{M C}}{\rho_{\text {ref }}^{M C}} \times \frac{<\epsilon, \sigma_{d} \phi\left(r_{d}\right)>_{n}^{M C}}{<\epsilon, \sigma_{d} \phi\left(r_{d}\right)>_{r e f}^{M C}}
$$

\section{KIPT Spatial Corrections for the Flux-to-Current Ratio Method}

Monte Carlo numerical simulations were performed to study the spatial dependence of the measured reactivities using the flux-to-current ratio method for the KIPT neutron source facility with the tungsten target. To perform the numerical validations, the $k_{\text {eff }}$ of the KIPT neutron source facility was varied by loading different number of fuel assemblies into the subcritical assembly. The number of fuel assemblies was varied from 35 to 42 and the fuel loading pattern for each stage is shown in Figure 3 . The $k_{\text {eff }}$ value for each fuel loading configuration is listed in Table I. The $k_{\text {eff }}$ values are in the range of 0.908 to 0.978 .

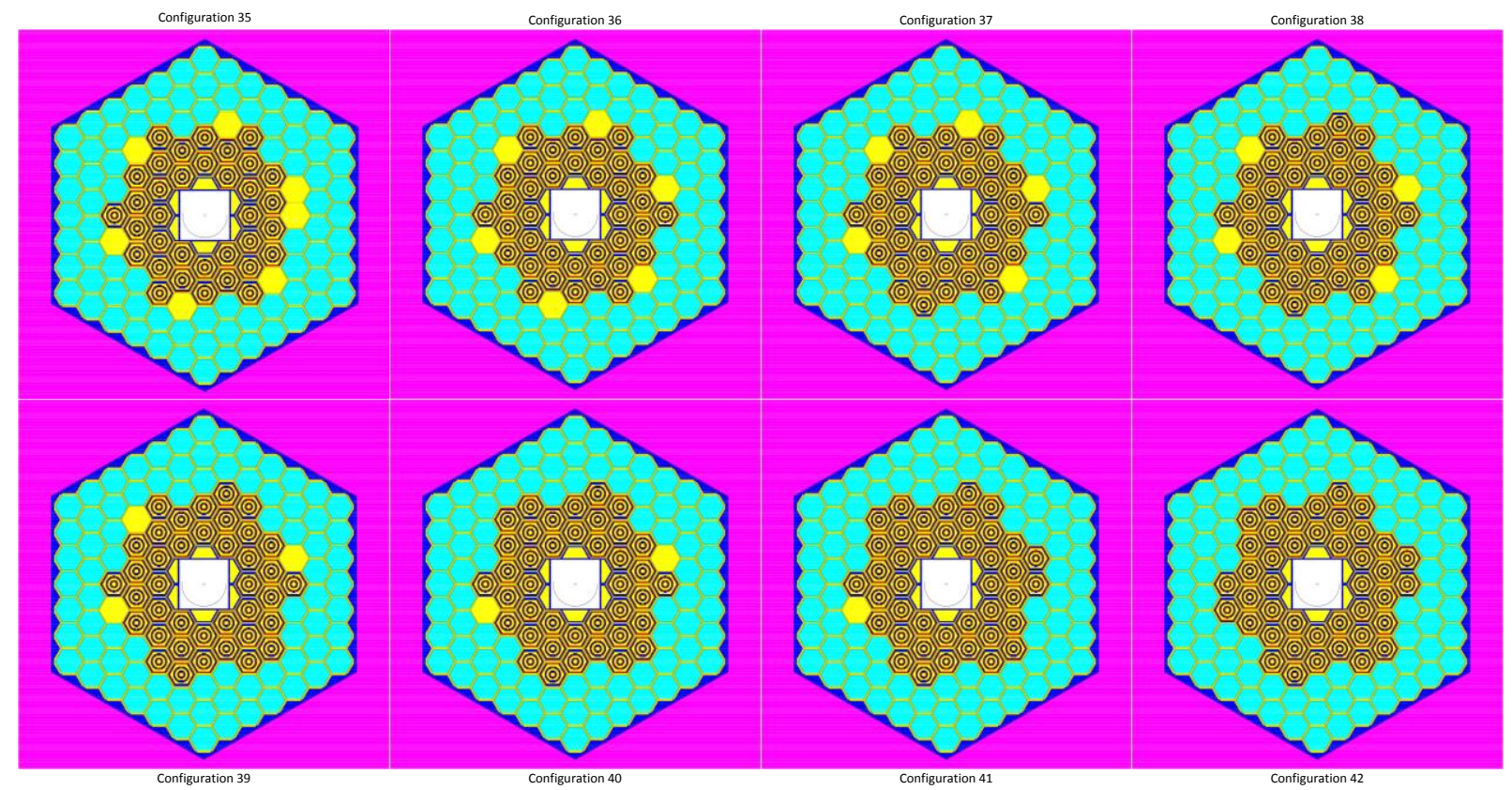

Figure 3. Fuel loading patterns of the KIPT neutron source facility with tungsten used in the Monte Carlo simulations

To apply the flux-to-current ratio method, the configuration with the 35 fuel assemblies was selected as the reference state. The accelerator beam power driving the subcritical assembly was the same for all the configurations. The neutron fluxes are tallied along the $y$-axis direction in the range of -30 to $30 \mathrm{~cm}$ at the middle plane $(z=25.0$ 
$\mathrm{cm})$ or at the upper end of the graphite radial reflector $(\mathrm{z}=60 \mathrm{~cm})$ as shown in Figure 4. The detector geometry was not explicitly modeled in these simulations. Figures 5 and 6 plot the calculated spatial correction factors at the two different elevations, respectively. The statistical errors of the Monte Carlo simulations are small with the maximum value of $\sim 2 \%$ and the statistical values are not plotted in these figures for clarity. The results show that the flux-to-current ratio method has a strong spatial dependence. The spatial corrections are larger when the detectors are closer to the external neutron source region located around $\mathrm{y}=0$. For detector positions away from the external neutron source, i.e., detectors at $z=60.0 \mathrm{~cm}$ as shown in Figure 5, the spatial corrections are much smaller even at the detector positions directly above the external source.

Table I: Monte Carlo criticality calculations of the KIPT subcritical assembly configuration with the tungsten target and 35 to 42 fuel assemblies.

\begin{tabular}{|c|c|c|c|c|c|}
\hline $\begin{array}{c}\text { \# of Fuel } \\
\text { Assemblies }\end{array}$ & $k_{\text {eff }}$ & $\rho$ & $\begin{array}{c}\text { \# of Fuel } \\
\text { Assemblies }\end{array}$ & $k_{\text {eff }}$ & $\rho$ \\
\hline 42 & $0.97855 \pm 0.00012$ & -0.0219 & 41 & $0.96924 \pm 0.00012$ & -0.0317 \\
\hline 40 & $0.95977 \pm 0.00012$ & -0.0419 & 39 & $0.95026 \pm 0.00012$ & -0.0523 \\
\hline 38 & $0.94052 \pm 0.00012$ & -0.0632 & 37 & $0.93099 \pm 0.00012$ & -0.0741 \\
\hline 36 & $0.92105 \pm 0.00012$ & -0.0857 & 35 & $0.90777 \pm 0.00012$ & -0.1016 \\
\hline
\end{tabular}

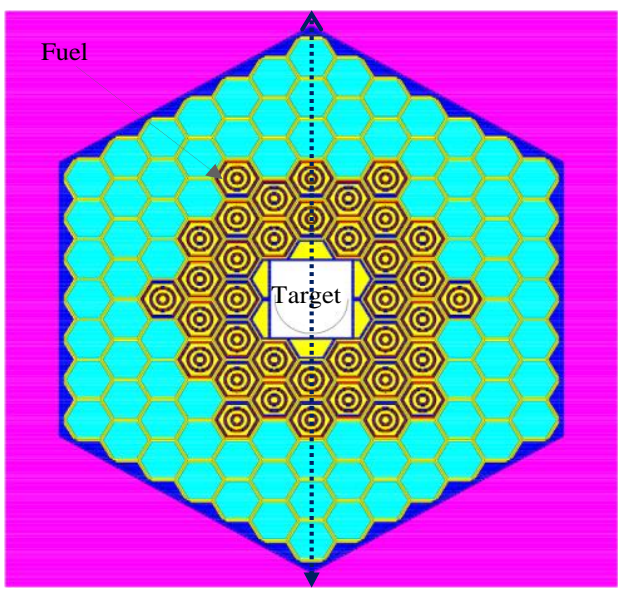

(a)

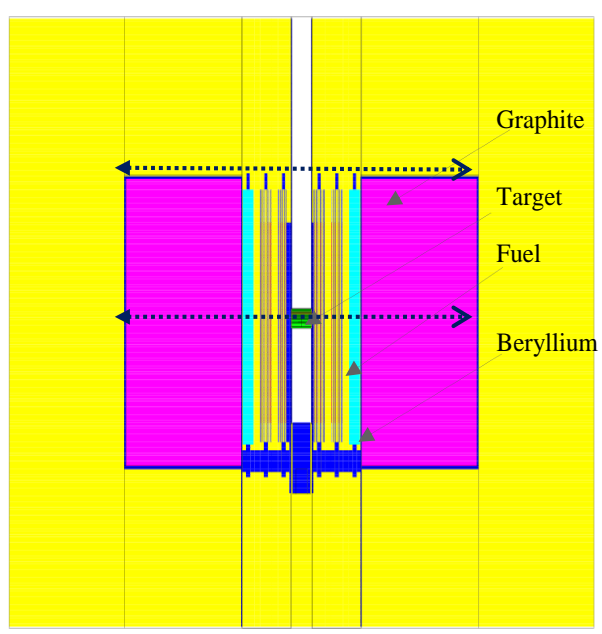

(b)

Figure 4. (a) Top view and (b) Side view of the calculational model showing the neutron flux tally positions in the numerical models of the KIPT neutron source facility with the tungsten target and 42 fuel assemblies. 


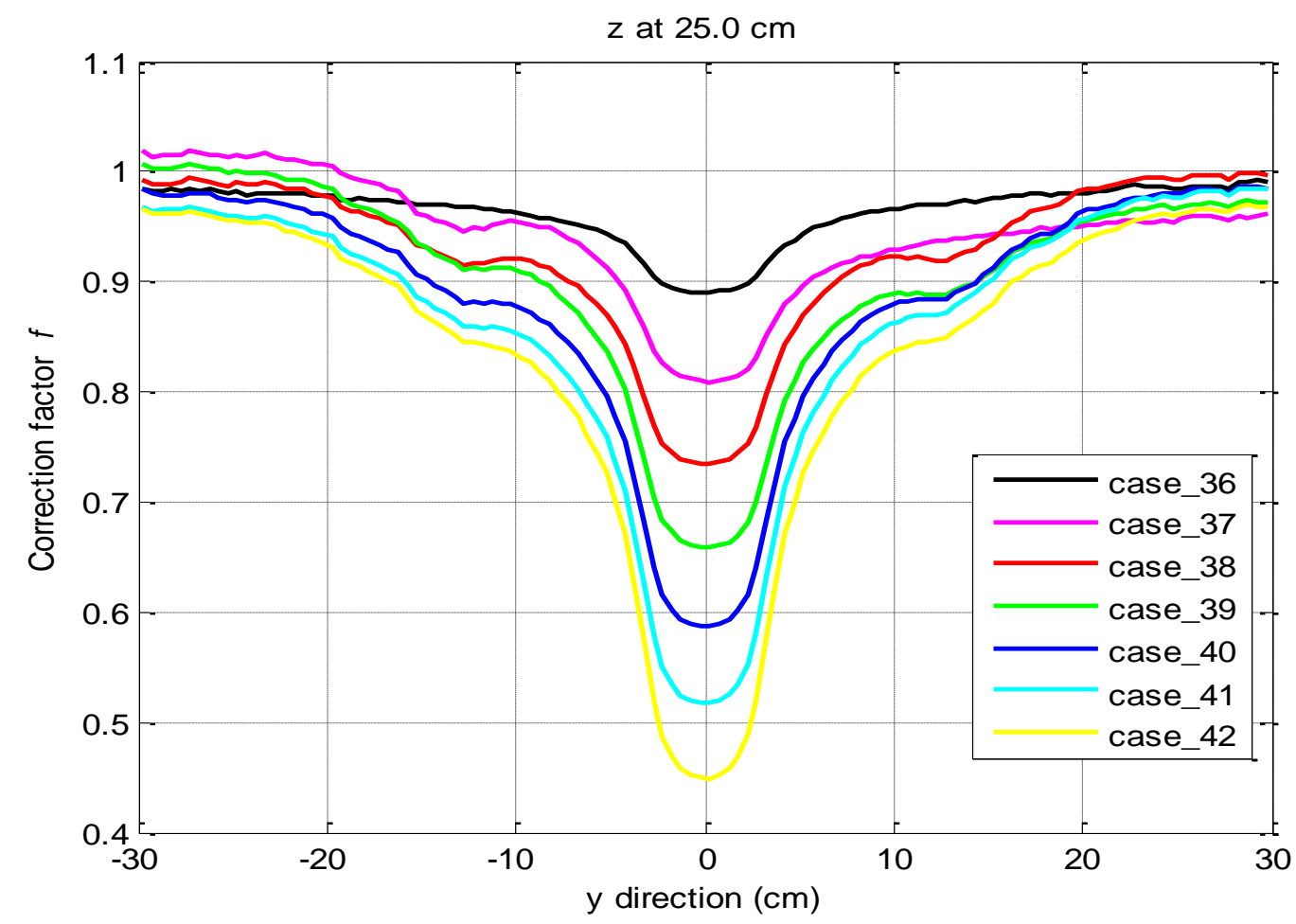

Figure 5. Spatial correction factors at the fuel middle plane $(z=25 \mathrm{~cm})$ for the configurations with the tungsten target and 35 to 42 fuel assemblies.

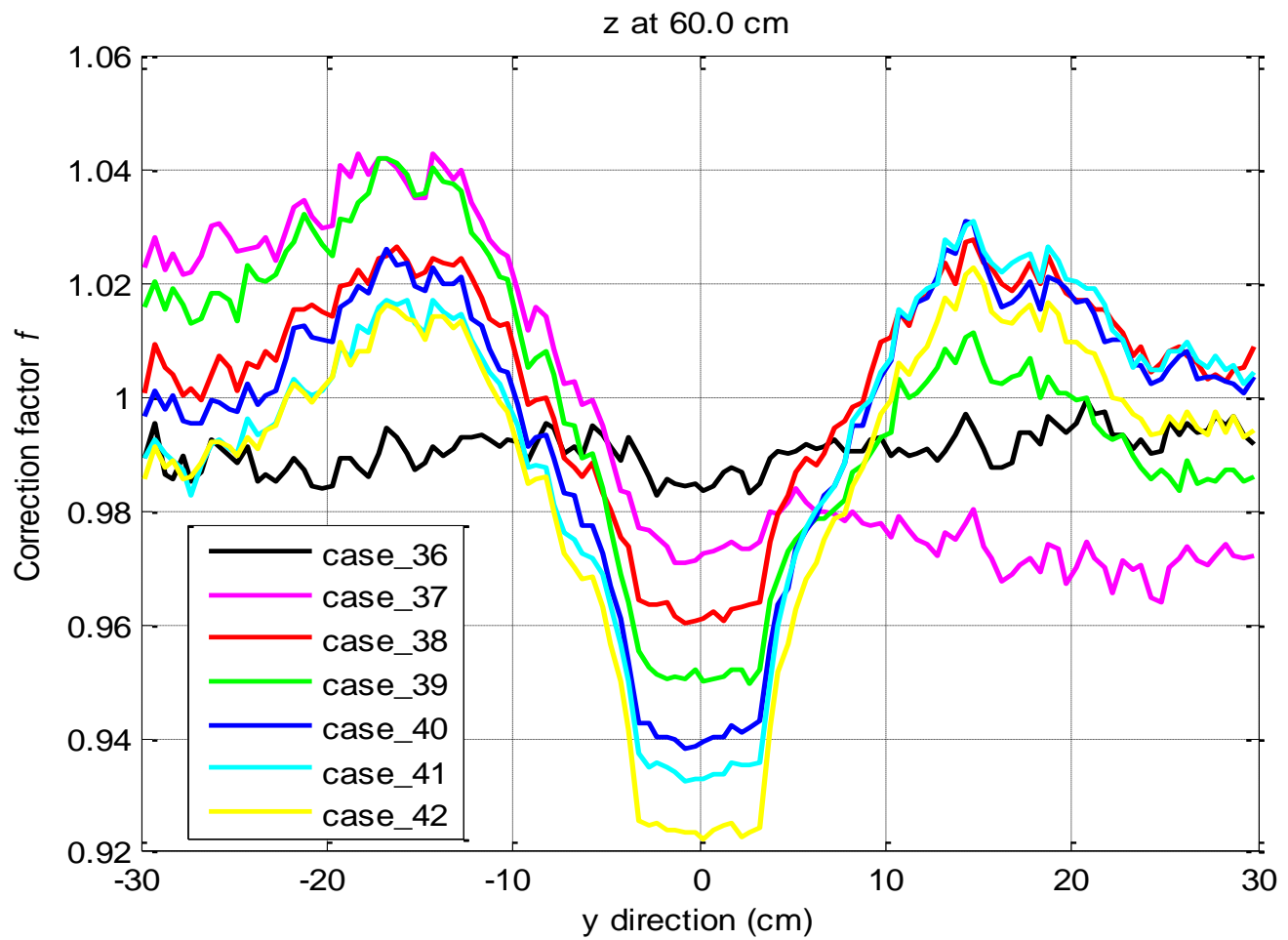

Figure 6. Correction factors at the $z=60 \mathrm{~cm}$ plane for the configurations with the tungsten target and 35 to 42 fuel assemblies. 


\section{Determination of Neutron Detector Positions in KIPT Subcritical Core}

\section{A. Numerical Simulation Studies of the Neutron Detector Positions}

The KIPT neutron source facility selected a configuration with 38 fuel assemblies for the tungsten target and a configuration with 37 fuel assemblies for the uranium target. Previous simulation results indicate that it is very important to select carefully the detector positions. The best positions suggested are the regions away from the external sources. To determine the accuracy of the reactivity measurements and define optimal positions for the neutron detectors, the correction factors calculated numerically for the flux-to-current ratio method act as guidance to determine the neutron detector positions in the KIPT neutron source facility. Again, the flux-to-current ratio method is considered to monitor the reactivity variations during the KIPT operating modes.

For the numerical simulations with the natural uranium target and the number of fuel assemblies from 20 to 37, the fuel loading patterns are shown in Figure 7, and their $k_{\text {eff }}$ values are listed in Table II. The $k_{\text {eff }}$ values vary in the range of 0.75 to 0.975 . The reference configuration has 20 fuel assemblies. Similarly for the numerical simulations with the tungsten target and the number of fuel assemblies from 18 to 38, the fuel loading patterns are shown in Figure 8 , and their $k_{\text {eff }}$ values are listed in Table III. The reference configuration has 18 fuel assemblies loaded.

Three radial rings for the detector positions in the water zone away from the external neutron source and outside the graphite reflector were examined. The axial positions of the radial rings are at the z-plane of $z=65 \mathrm{~cm}$, which is $5 \mathrm{~cm}$ above the graphite reflector. The ring radii are 26,40 , and $54 \mathrm{~cm}$, respectively. In each radial ring, twelve He-3 detectors are symmetrically arranged in the numerical simulations. Each detector is labeled by two numbers, the first number represents the radial ring number. The ring number are 1,3, and 5 . The second number represents the angular position in the ring starting from 1 to 12 as shown in the Figure 9 (a). For comparison, another 12 detector positions are also considered at the fuel middle plane with $\mathrm{z}=25 \mathrm{~cm}$ and radius $=65 \mathrm{~cm}$ in water tank outside the radial graphite reflector as shown in Figure 9 (b). The ring number for these detectors is 7.

At all these selected detector positions, the He-3 detector responses were tallied without explicit simulation of the detector geometries. The spatial correction factors calculated at all detector positions are plotted in Figures 10 and 11. The Monte Carlo statistical errors are also plotted in these figures. The spatial corrections for most of the detectors at the second ring position $(r, z)=(40,65) \mathrm{cm}$ are within $5 \%$. At the other detector radial positions, the spatial corrections are all less than or around $10 \%$. Figures 12 and 13 show the calculated mean spatial correction factors averaged over the 12 detector positions of each radial ring. For all the cases, the correction factors are greater than 1.0 at the first ring $(r, z)=(26,65) \mathrm{cm}$, and less than 1.0 at the third ring $(r, z)=(54,65) \mathrm{cm}$. Since the detector positions move gradually away from the target 
zone, the numerical results indicate that an optimal radial position for the flux-to-current ratio method exists around the second position, where the spatial corrections can be kept small while the $k_{\text {eff }}$ of the subcritical core varies within a large range.

Table II: Monte Carlo criticality calculations of the different KIPT neutron source facility configurations with the uranium target and 20 to 37 fuel assemblies.

\begin{tabular}{|c|c|c|c|c|c|}
\hline $\begin{array}{c}\# \text { of Fuel } \\
\text { Assemblies }\end{array}$ & $k_{\text {eff }}$ & $\rho$ & $\begin{array}{c}\text { \# of Fuel } \\
\text { Assemblies }\end{array}$ & $k_{\text {eff }}$ & $\rho$ \\
\hline 20 & $\begin{array}{r}0.75114 \\
\pm 0.00011 \\
\end{array}$ & -0.33131 & 32 & $\begin{array}{r}0.91645 \\
\pm 0.00011 \\
\end{array}$ & 0.09117 \\
\hline 22 & $\begin{array}{r}0.78212 \\
\pm 0.00011 \\
\end{array}$ & -0.27858 & 33 & $\begin{array}{r}0.92917 \\
\pm 0.00012 \\
\end{array}$ & $\begin{array}{c}- \\
0.07623 \\
\end{array}$ \\
\hline 24 & $\begin{array}{r}0.81309 \\
\pm 0.00012 \\
\end{array}$ & -0.22988 & 34 & $\begin{array}{r}0.94137 \\
\pm 0.00011 \\
\end{array}$ & 0.06228 \\
\hline 26 & $\begin{array}{r}0.83918 \\
\pm 0.00011 \\
\end{array}$ & -0.19164 & 35 & $\begin{array}{r}0.95413 \\
\pm 0.00012 \\
\end{array}$ & $\begin{array}{c}- \\
0.04808\end{array}$ \\
\hline 28 & $\begin{array}{r}0.86451 \\
\pm 0.00011\end{array}$ & -0.15672 & 36 & $\begin{array}{r}0.96589 \\
\pm 0.00013\end{array}$ & $\begin{array}{c}- \\
0.03531\end{array}$ \\
\hline 30 & $\begin{array}{r}0.88957 \\
\pm 0.00013 \\
\end{array}$ & -0.12414 & 37 & $\begin{array}{r}0.97547 \\
\pm 0.00011\end{array}$ & 0.02515 \\
\hline 31 & $\begin{array}{r}0.90293 \\
\pm 0.00013\end{array}$ & -0.10751 & & & \\
\hline
\end{tabular}

Table III: Monte Carlo criticality calculations of the different KIPT neutron source facility configurations with the tungsten target and 18 to 38 fuel assemblies.

\begin{tabular}{|c|c|c|c|c|c|}
\hline $\begin{array}{c}\text { \# of Fuel } \\
\text { Assemblies }\end{array}$ & $k_{\text {eff }}$ & $\rho$ & $\begin{array}{c}\text { \# of Fuel } \\
\text { Assemblie } \\
\mathrm{s}\end{array}$ & $k_{\text {eff }}$ & $\rho$ \\
\hline 18 & $\begin{array}{c}0.70864 \\
\pm 0.00016\end{array}$ & -0.41115 & 33 & $\begin{array}{c}0.90037 \\
\pm 0.00012\end{array}$ & -0.11065 \\
\hline 24 & $\begin{array}{c}0.80290 \\
\pm 0.00014\end{array}$ & -0.24549 & 34 & $\begin{array}{c}0.91237 \\
\pm 0.00012\end{array}$ & -0.09605 \\
\hline 26 & $\begin{array}{c}0.82133 \\
\pm 0.00013\end{array}$ & -0.21754 & 35 & $\begin{array}{c}0.92529 \\
\pm 0.00013\end{array}$ & -0.08074 \\
\hline 28 & $\begin{array}{c}0.83975 \\
\pm 0.00014\end{array}$ & -0.19083 & 36 & $\begin{array}{c}0.93800 \\
\pm 0.00013\end{array}$ & -0.0661 \\
\hline 30 & $\begin{array}{c}0.85838 \\
\pm 0.00014\end{array}$ & -0.16499 & 37 & $\begin{array}{c}0.94774 \\
\pm 0.00013\end{array}$ & -0.05514 \\
\hline 31 & $\begin{array}{c}0.87325 \\
\pm 0.00013\end{array}$ & -0.14515 & 38 & $\begin{array}{c}0.95724 \\
\pm 0.00013\end{array}$ & -0.04467 \\
\hline 32 & $\begin{array}{c}0.88709 \\
\pm 0.00014\end{array}$ & -0.12728 & --- & --- & -- \\
\hline
\end{tabular}




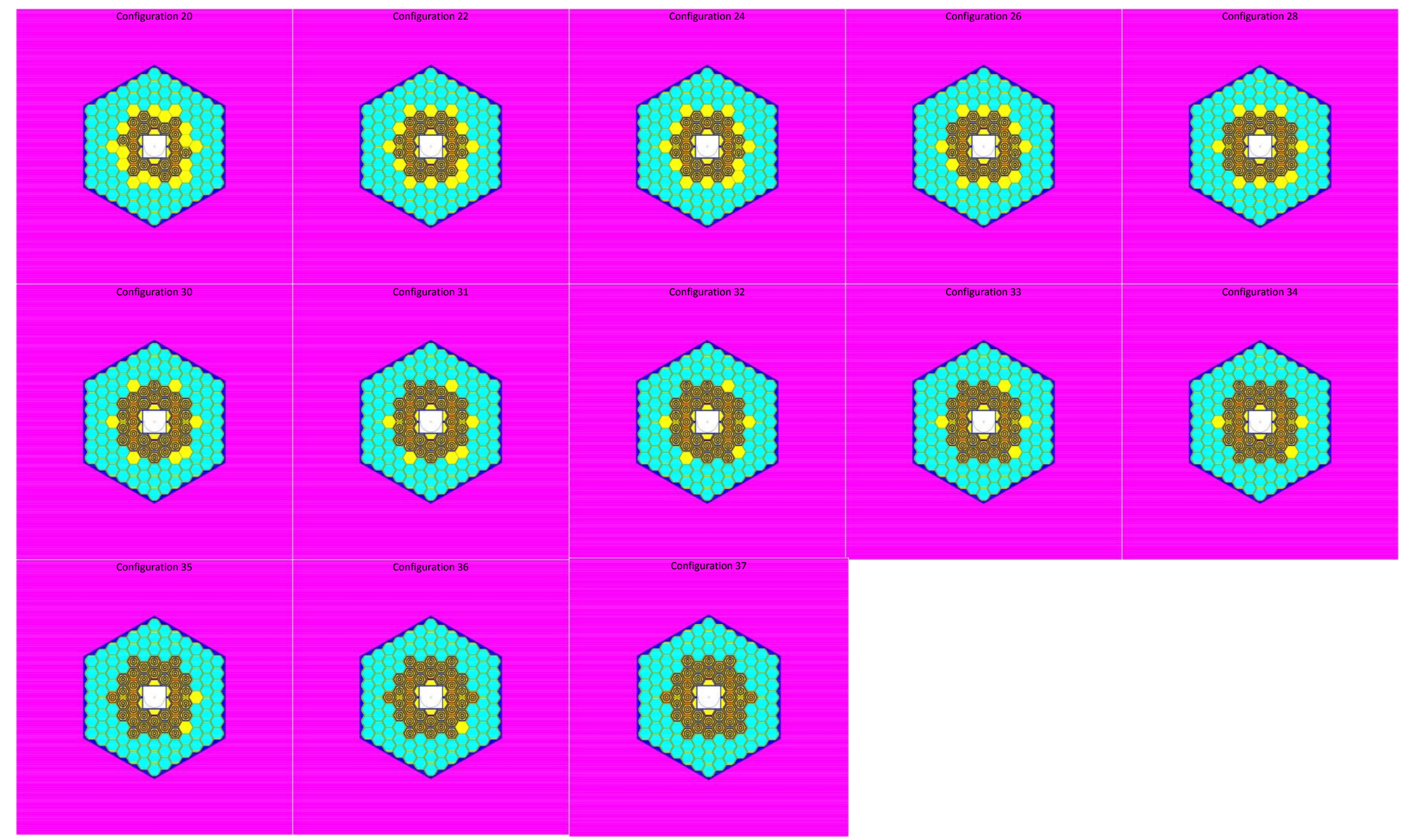

Figure 7. Fuel loading patterns of the KIPT neutron source facility for the Monte Carlo simulations with the uranium target and 20 to 37 fuel assemblies. 


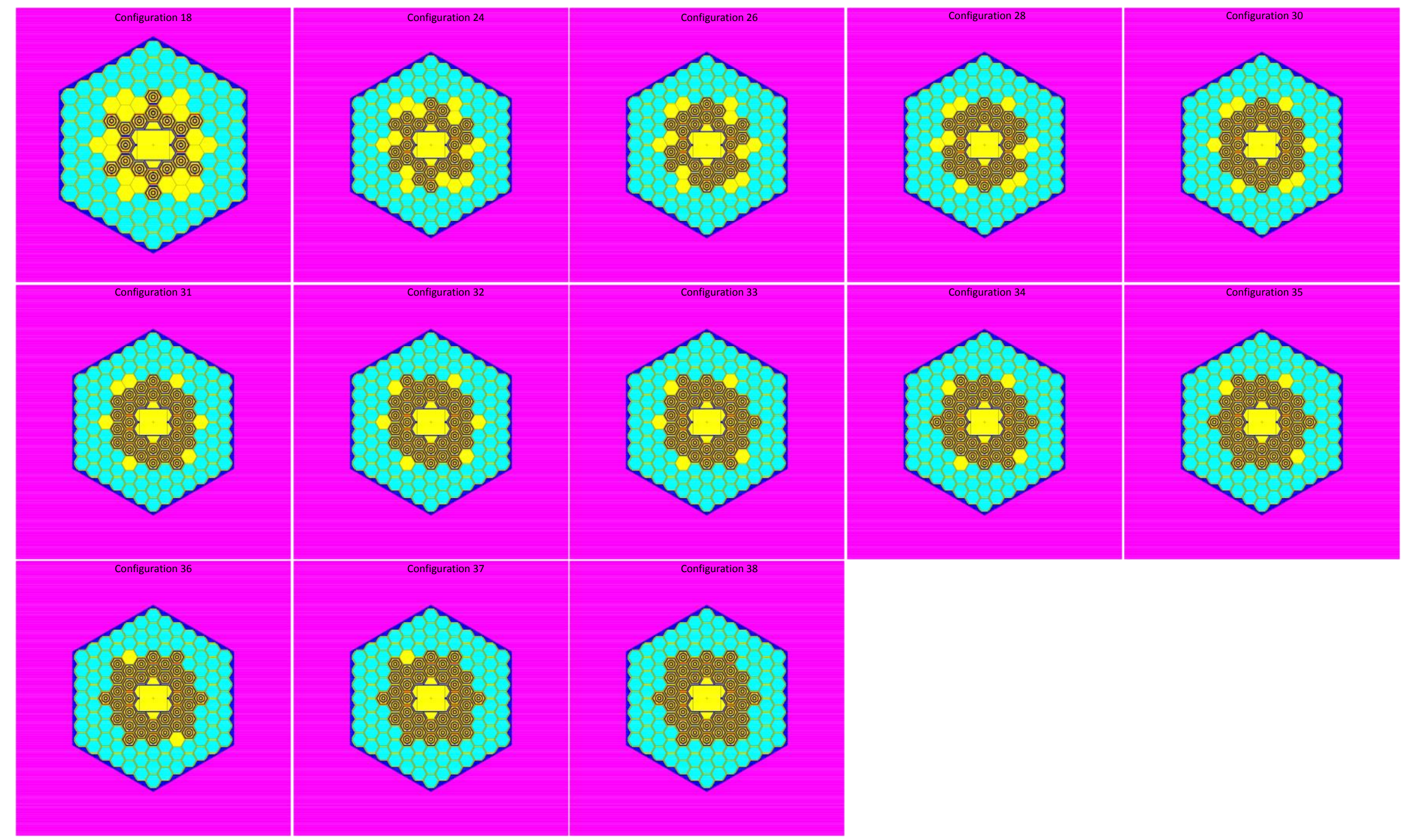

Figure 8. Fuel loading patterns of the KIPT neutron source facility for the Monte Carlo simulations with the tungsten target and 18 to 38 fuel assemblies. 


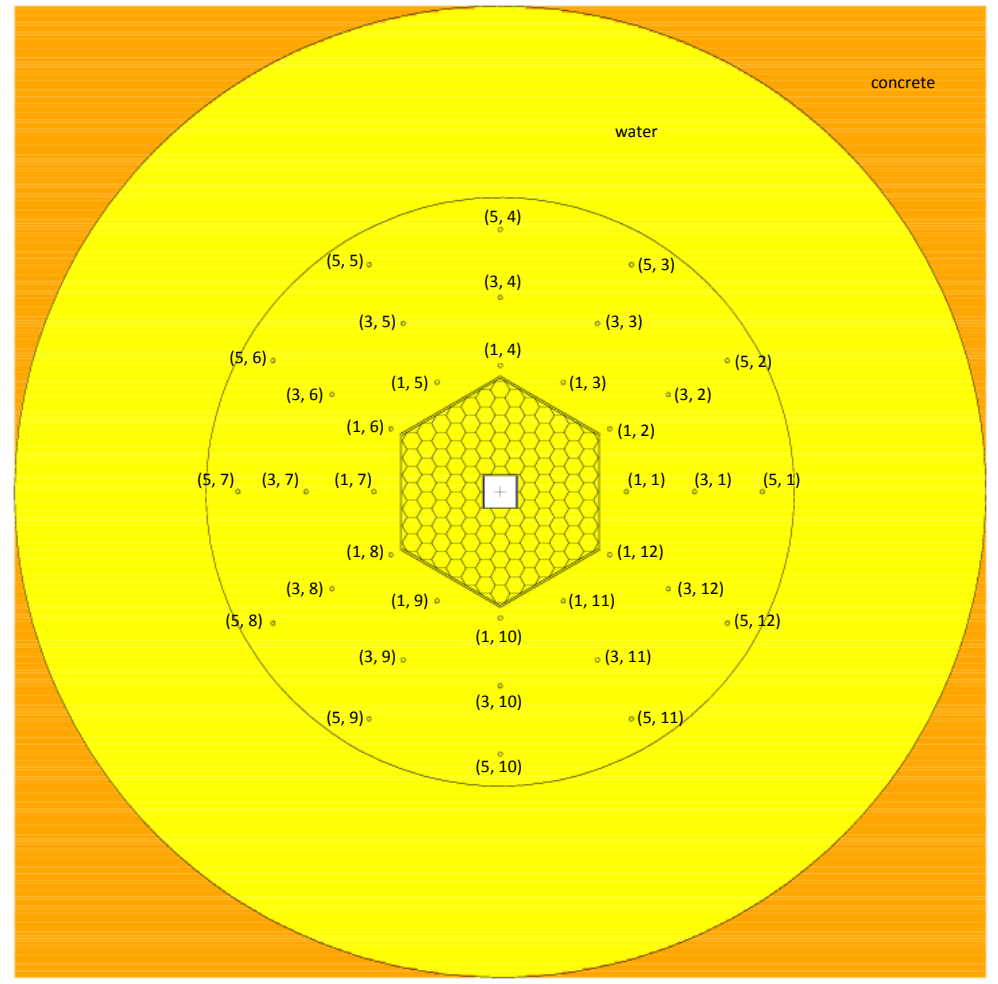

(a)

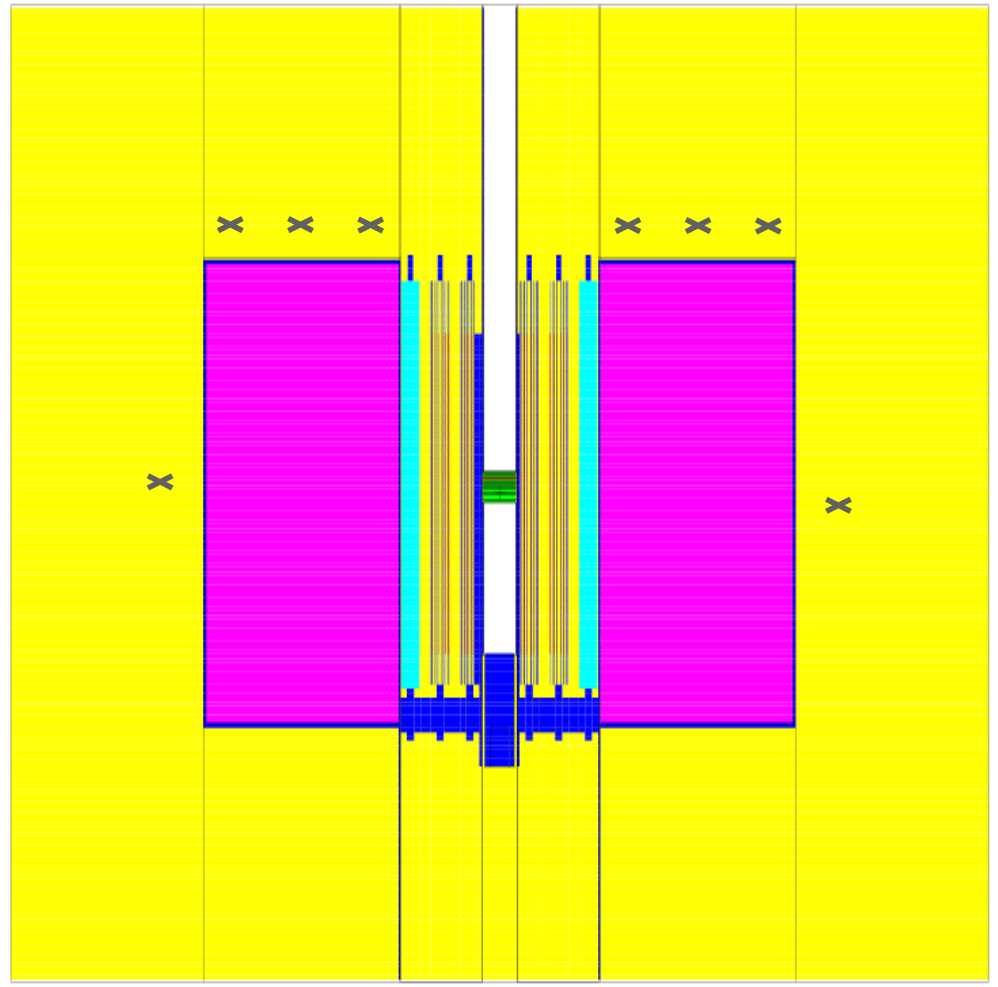

(b)

Figure 9. Detector positions in KIPT neutron source facility (a) horizontal view at $z=$ $65.0 \mathrm{~cm}(\mathrm{~b})$ vertical view at the centerline. 


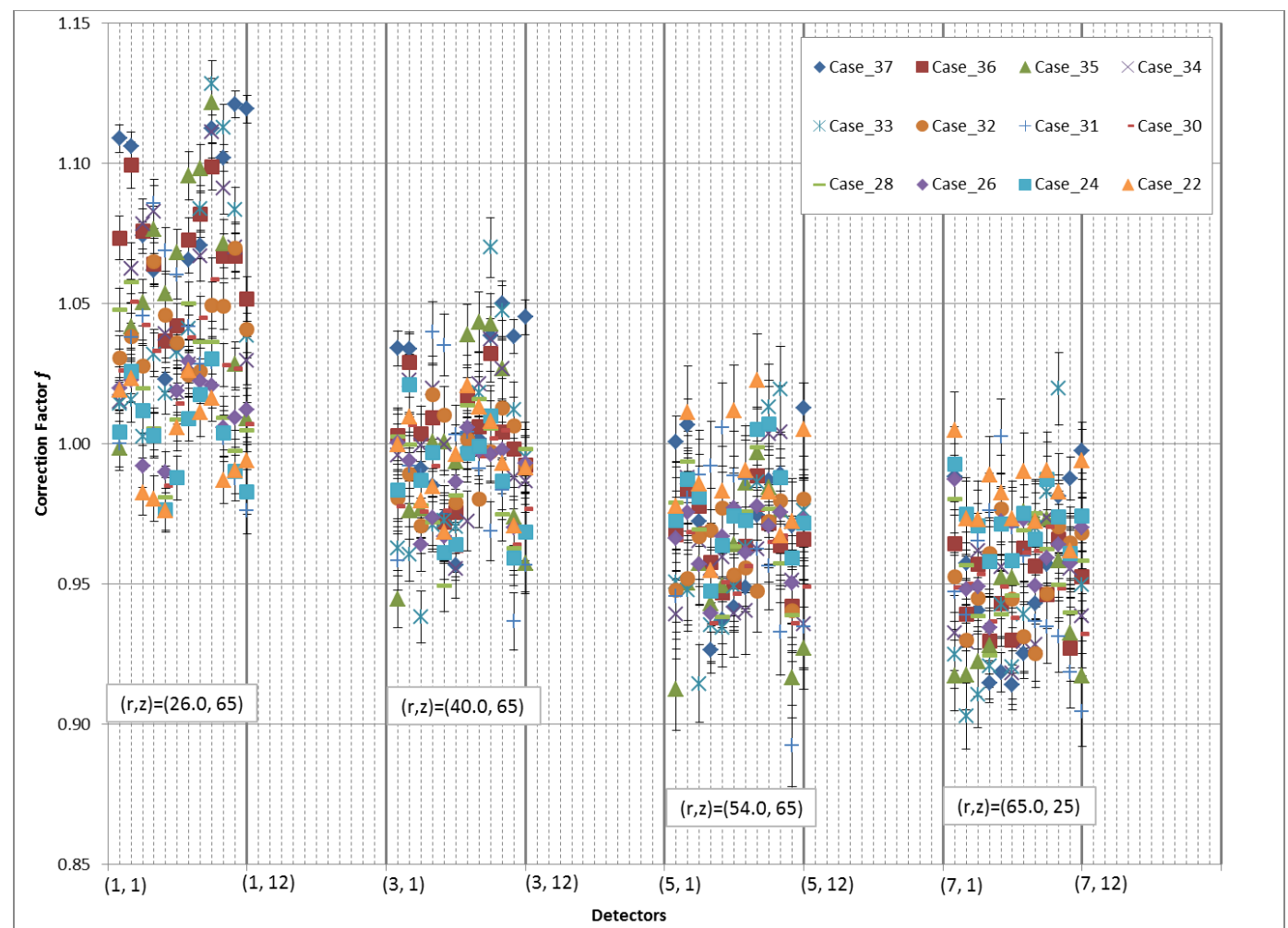

Figure 10. Correction factors of the KIPT neutron source facility configurations with the uranium target and 22 to 37 fuel assemblies.

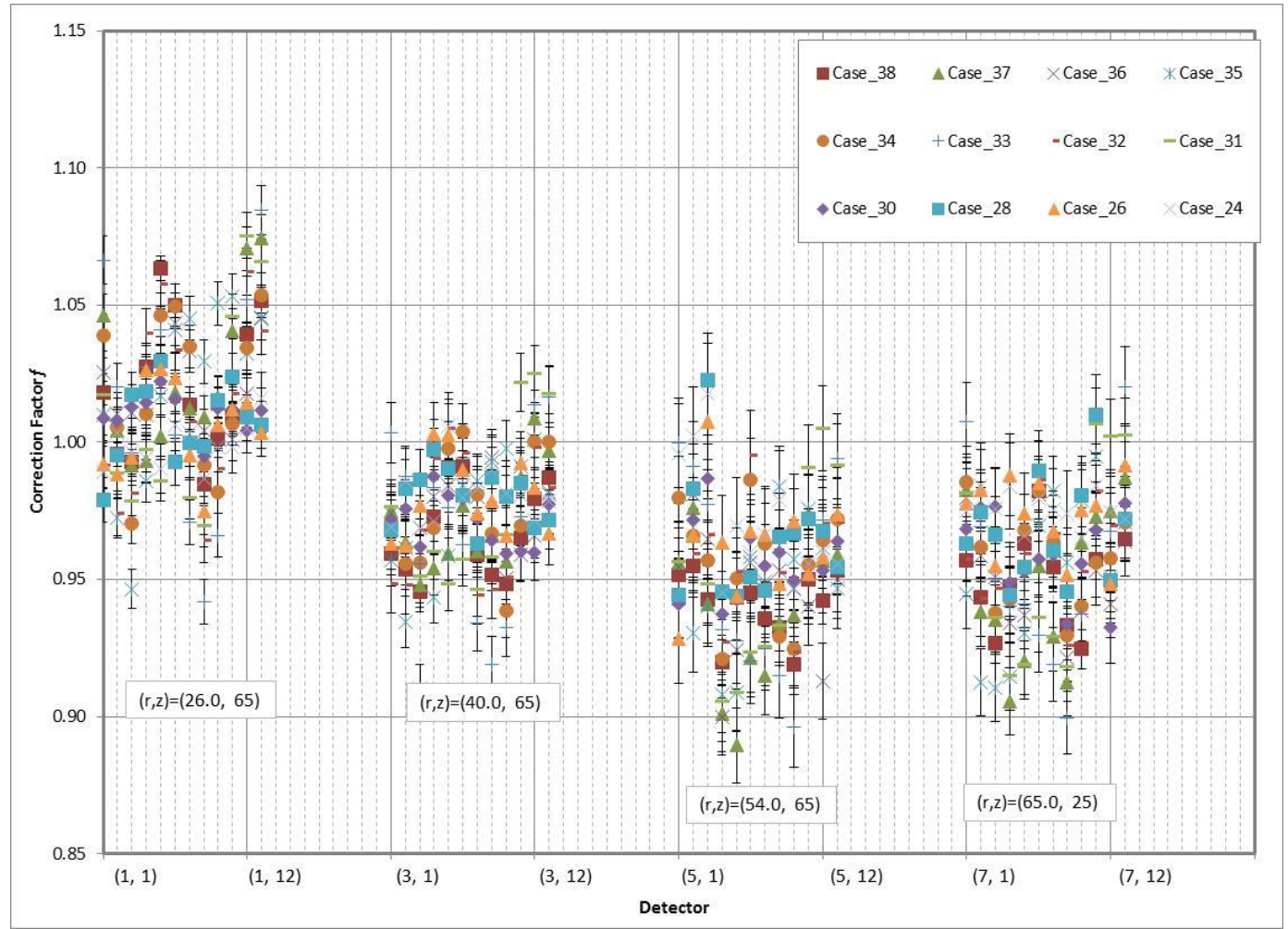

Figure 11. Correction factors of the KIPT neutron source facility configurations with the tungsten target and 18 to 38 fuel assemblies. 


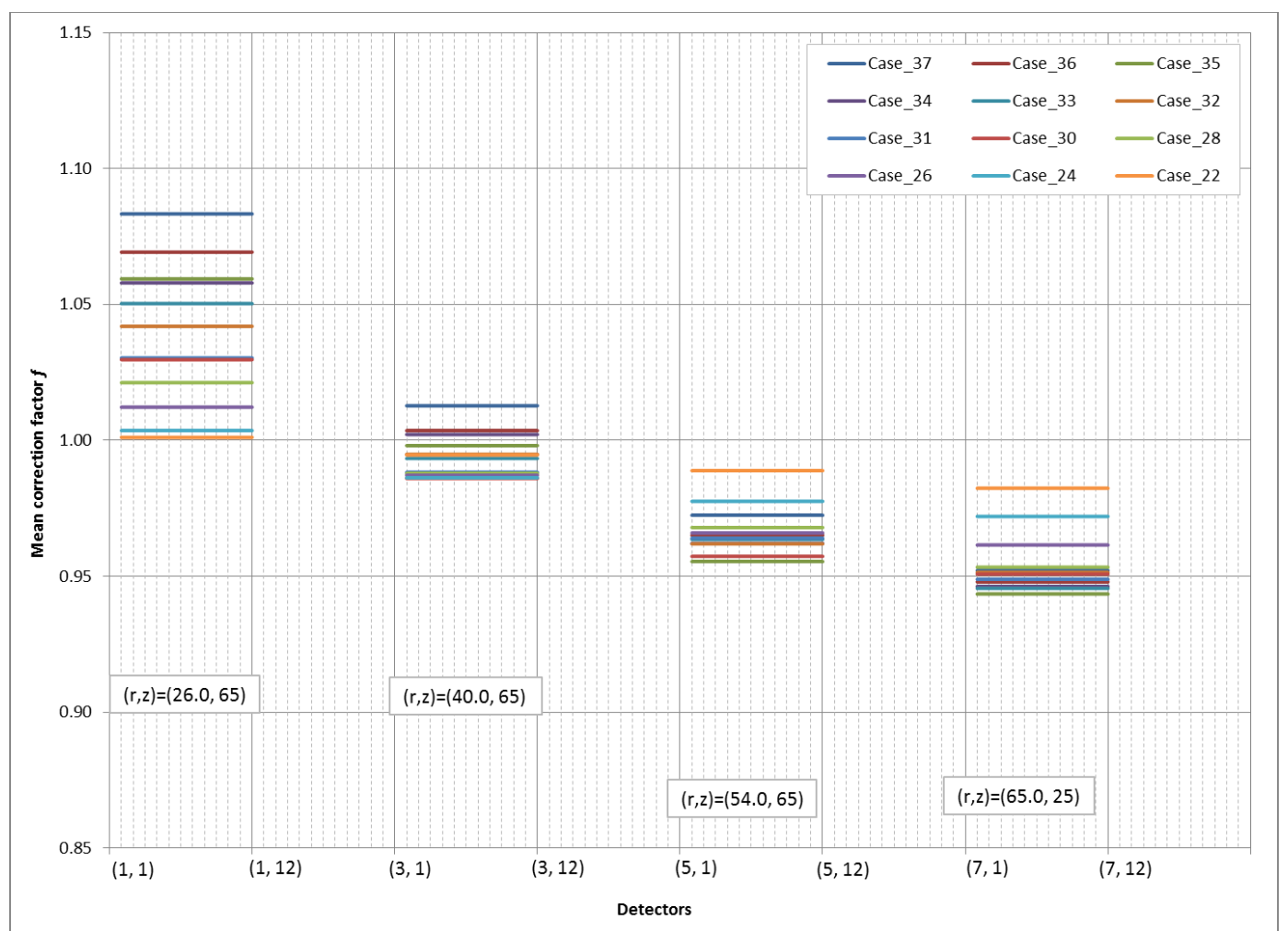

Figure 12. Average correction factors of the KIPT neutron source facility configurations with the uranium target and 22 to 37 fuel assemblies.

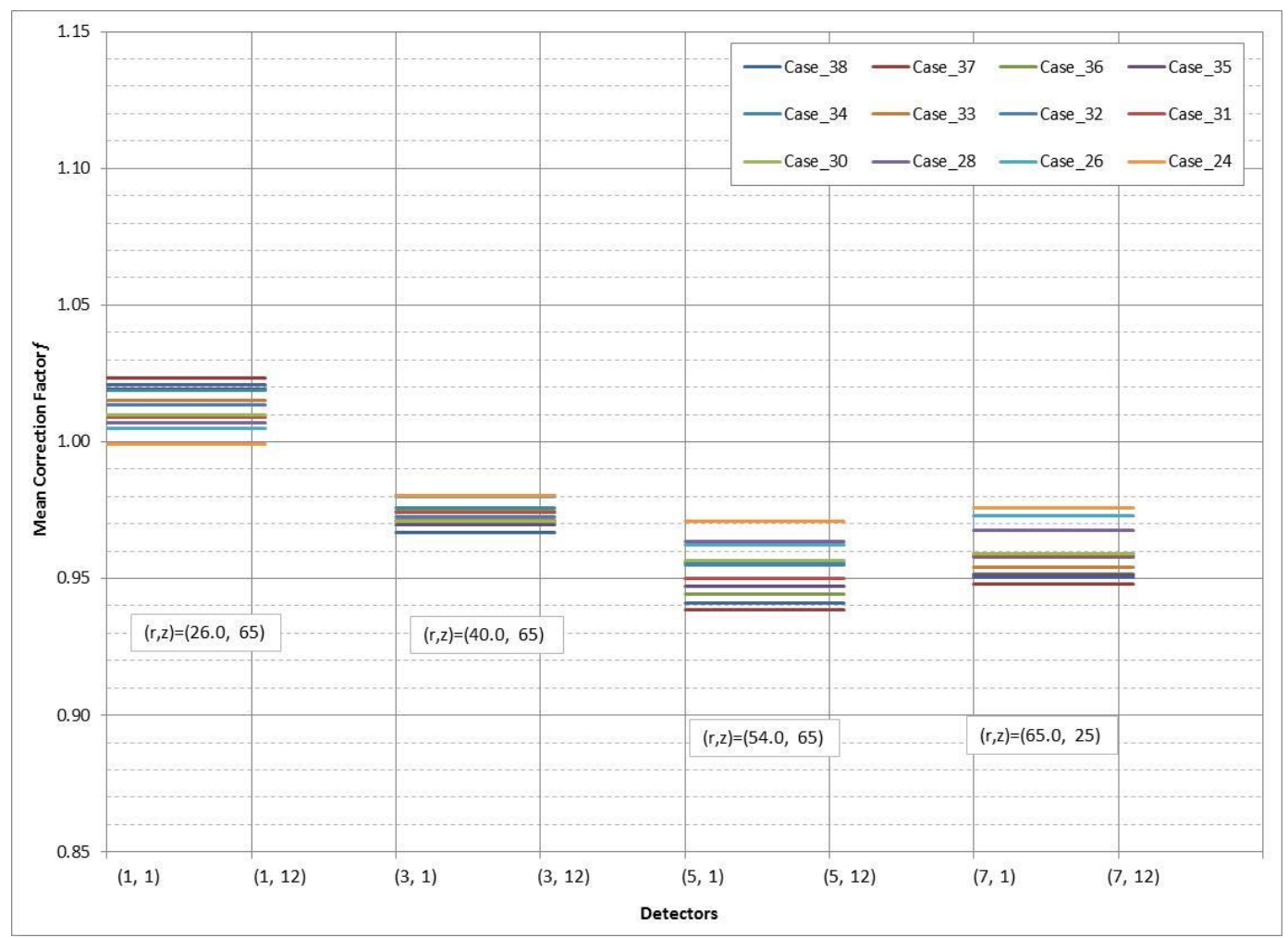

Figure 13. Average correction factors of the KIPT neutron source facility configurations with the tungsten target and 18 to 38 fuel assemblies. 


\section{B. Neutron Detector Positions in the KIPT Subcritical Assembly}

The neutron detector positions selected in the KIPT subcritical assembly are based on the physics consideration discussed above and the characteristics of the used neutron detectors. In the KIPT neutron source facility, U-235 fission chambers are utilized to measure the neutron flux level. The selected detectors operate with a neutron flux up to $5 \times 10^{10} \mathrm{n} / \mathrm{cm}^{2}$.s. Therefore, Monte Carlo simulations were performed to define the neutron flux map in the zone shown in Figure 14 (a). In this zone, the neutron detectors can be installed inside the water reflector above the radial graphite reflector. In addition, this zone was used in the previous physics simulations to locate the optimum neutron detector positions. For this simulation, the subcritical configuration uses the natural uranium target and the maximum fuel loading of 37 fuel assemblies. This configuration has the highest neutron multiplications among all the subcritical configurations for this facility. The linear accelerator is assumed to be operated at full power of $100 \mathrm{~kW}$. Based on the obtained neutron flux map shown in Figure 14(b), the selected detector position is $(r, z)=(54.0,72.5) \mathrm{cm}$, which is $12.5 \mathrm{~cm}$ above the graphite reflector. The neutron flux level at this position is calculated to be $1.6 \times 10^{10} \mathrm{n} / \mathrm{cm}^{2} . \mathrm{s}$, and the background photon flux level at this position is $2.9 \times 10^{11} \mathrm{p} / \mathrm{cm}^{2} . \mathrm{s}$.

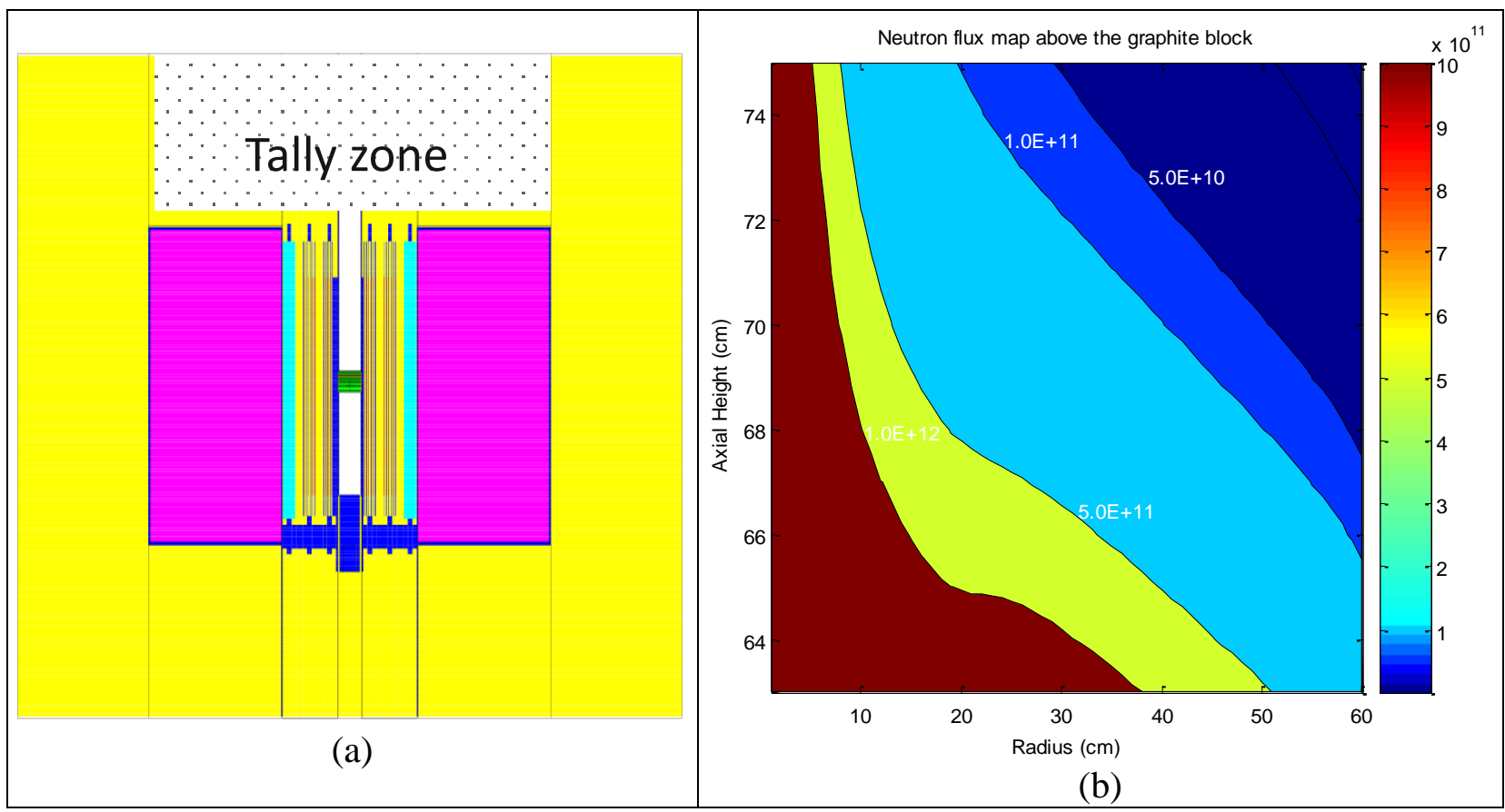

Figure 14. (a) Neutron flux tally zone and (b) Neutron flux level map above the graphite reflector for the KIPT neutron source facility with the uranium target, 37 fuel assemblies, and $100 \mathrm{KW}$ electron beam power.

At this select radial position, as shown in Figure 15 (a), six U-235 fission chambers are placed at the optimal position surrounding the hexagon subcritical assembly. Half of these neutron detectors have low neutron sensitivity of $10^{-6}$ counts/neutron and the other 
half have high neutron sensitivity of $10^{-3}$ counts/neutron. Another three U-235 fission chambers with high neutron sensitivity of $10^{-3}$ counts/neutron are placed at the innersurface of the biological shield at $(r, z)=(107.0,25.0)$ as shown in Figure 15 (b), which are further away from the neutron target zone. Monte Carlo simulations are performed to calculate the neutron flux level at these detector positions, and found that at detector 9 , the neutron flux level is about three orders of magnitude lower than at the selected optimal positions.

\section{Determination the Reactivity of the KIPT Subcritical Assembly during the Fuel Loading Process}

\section{A. KIPT Fuel Assembly Loading Pattern}

The KIPT neutron source facility will start its operation first with the core configuration which uses the tungsten as the target. In this core configuration, there will be maximum 38 fuel assemblies loaded at the fresh fuel core. Figure 16 indicates the designed sequence for loading all these fuel assemblies into the core. The corresponding $k_{\text {eff }}$ at each of these fuel loading stages is calculated by the Monte Carlo code and is listed in Table IV.

Table IV: Effective neutron multiplication factor $\left(K_{\text {eff }}\right)$ values of the KIPT neutron source facility with the tungsten target and different number of the fuel assemblies.

\begin{tabular}{|c|c|c|c|c|c|}
\hline $\begin{array}{c}\text { \# of Fuel } \\
\text { Assemblies }\end{array}$ & $k_{\text {eff }}$ & $\rho$ & $\begin{array}{c}\text { \# of Fuel } \\
\text { Assemblies }\end{array}$ & $k_{\text {eff }}$ & $\rho$ \\
\hline 4 & $0.27453 \pm 07 \mathrm{pcm}$ & -2.643 & 8 & $0.43518 \pm 08 \mathrm{pcm}$ & -1.298 \\
\hline 12 & $0.54366 \pm 10 \mathrm{pcm}$ & -0.839 & 14 & $0.59978 \pm 10 \mathrm{pcm}$ & -0.667 \\
\hline 16 & $0.65184 \pm 10 \mathrm{pcm}$ & -0.534 & 18 & $0.69984 \pm 10 \mathrm{pcm}$ & -0.429 \\
\hline 20 & $0.73317 \pm 11 \mathrm{pcm}$ & -0.364 & 22 & $0.76409 \pm 11 \mathrm{pcm}$ & -0.309 \\
\hline 24 & $0.79373 \pm 11 \mathrm{pcm}$ & -0.260 & 26 & $0.81757 \pm 11 \mathrm{pcm}$ & -0.223 \\
\hline 28 & $0.83993 \pm 12 \mathrm{pcm}$ & -0.191 & 30 & $0.86181 \pm 12 \mathrm{pcm}$ & -0.160 \\
\hline 31 & $0.87518 \pm 12 \mathrm{pcm}$ & -0.143 & 32 & $0.88789 \pm 12 \mathrm{pcm}$ & -0.126 \\
\hline 33 & $0.90087 \pm 12 \mathrm{pcm}$ & -0.110 & 34 & $0.91316 \pm 12 \mathrm{pcm}$ & -0.095 \\
\hline 35 & $0.92564 \pm 12 \mathrm{pcm}$ & -0.080 & 36 & $0.93751 \pm 12 \mathrm{pcm}$ & -0.067 \\
\hline 37 & $0.94738 \pm 12 \mathrm{pcm}$ & -0.056 & 38 & $0.95714 \pm 12 \mathrm{pcm}$ & -0.045 \\
\hline
\end{tabular}




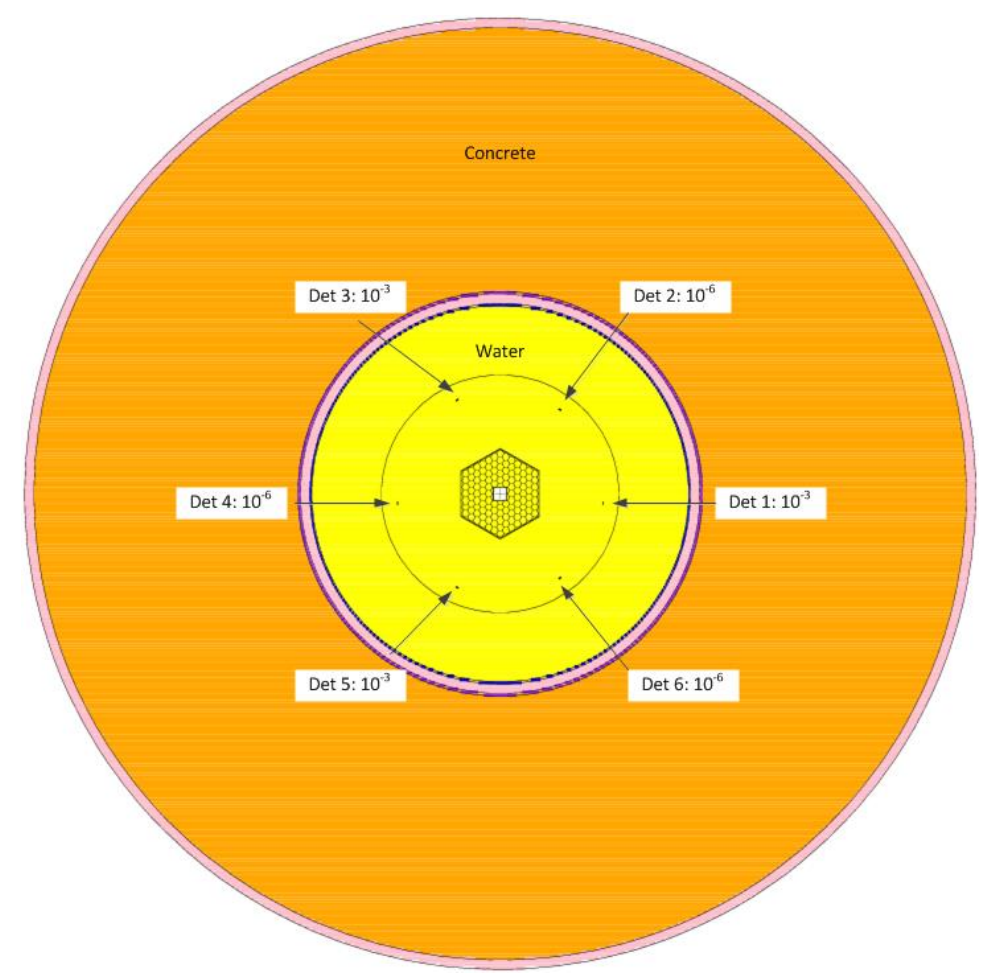

(a)

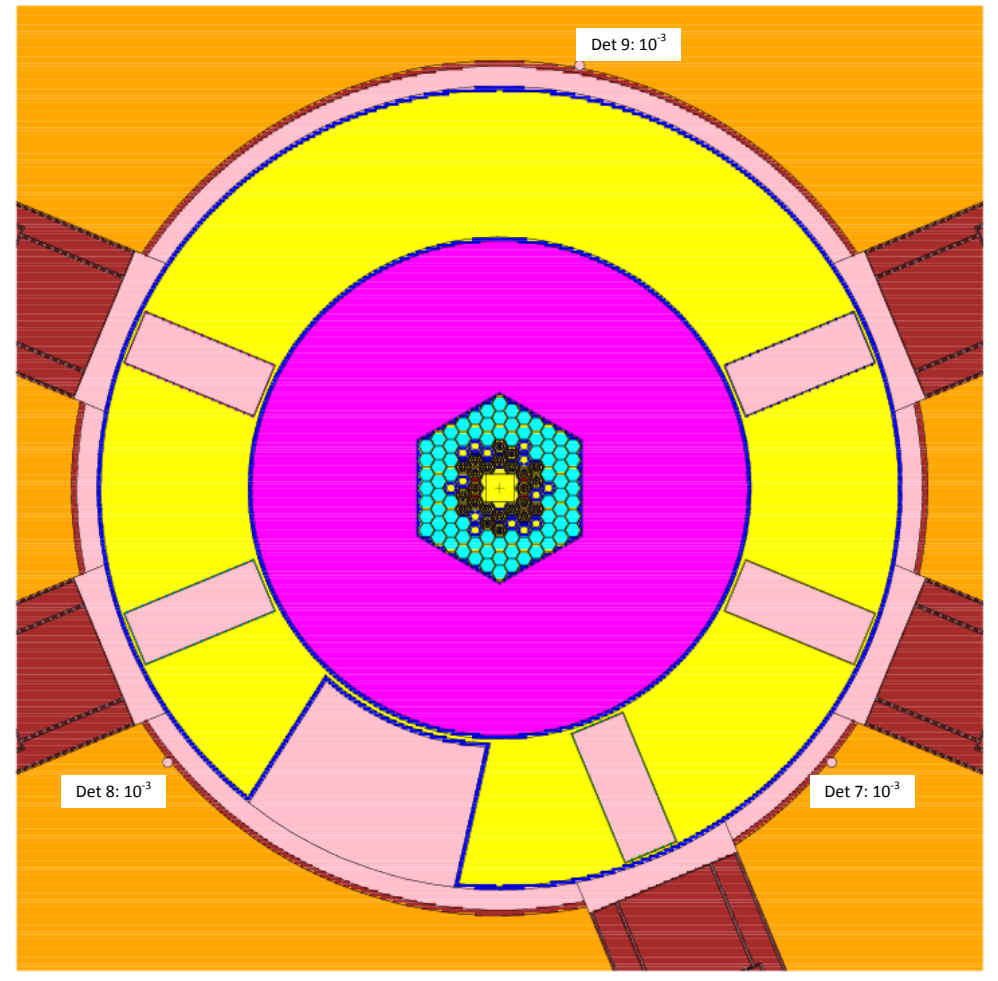

(b)

Figure 15. Neutron detector locations at: (a) the selected optimal detector locations and (b) the biological shield surface at the middle fuel plane. 


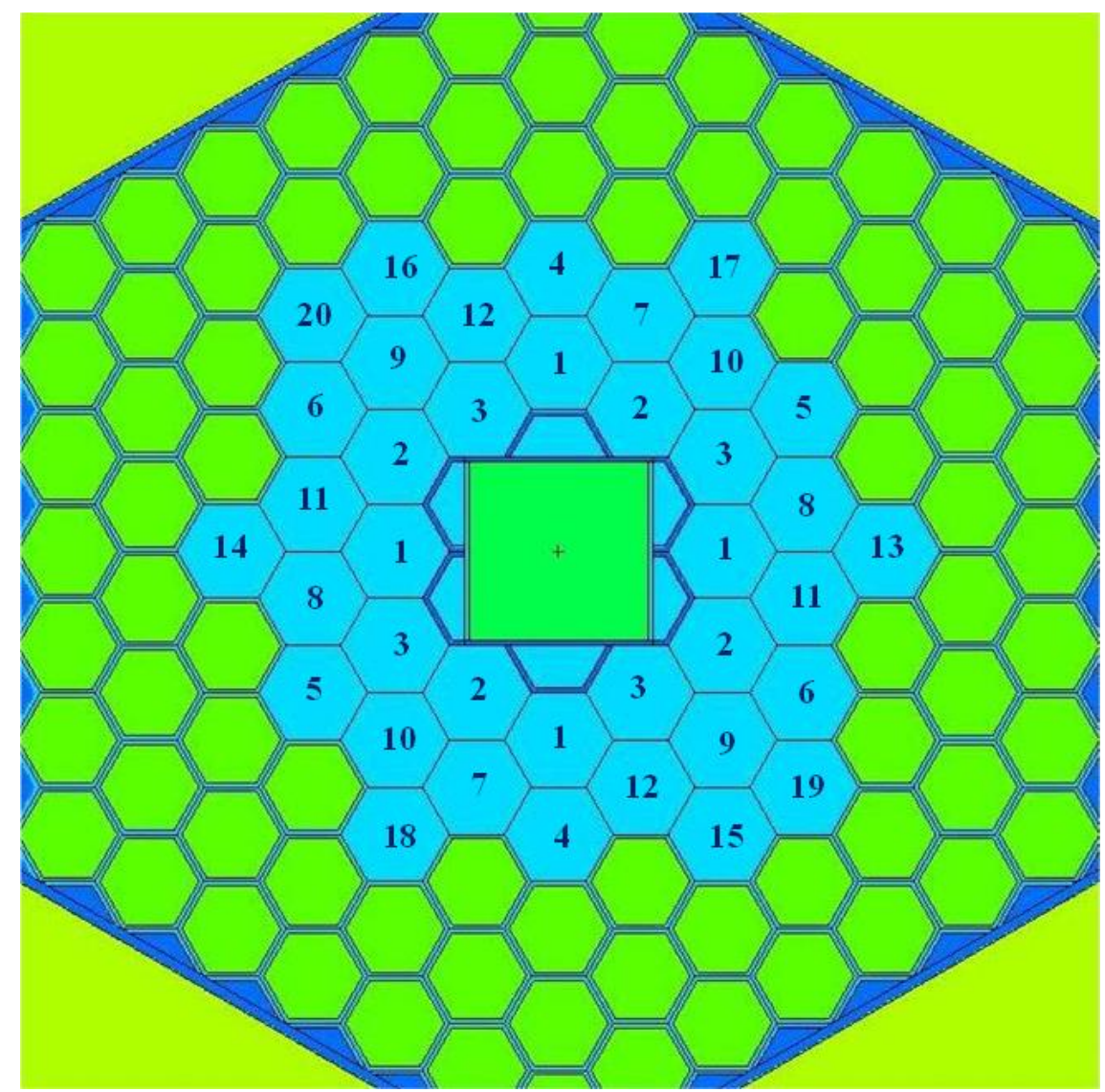

Figure 16. The KIPT fuel assembly loading sequence for the subcritical assembly with the tungsten target and the maximum fuel loading of 38 assemblies

During the fuel loading process, the subcritical assembly reactivity at each fuel loading stage will be measured by performing a pulsed-neutron experiment and will be also monitored with the Flux-to-Current Ratio Method. The electron accelerator will be operated at lower power and low frequency for the pulsed neutron experiments. The neutron fluxes in the subcritical core are measured by the three sets of U-235 fission chambers. The area-ratio method will be applied in the pulsed-neutron experiment to measure the reactivity. The spatial correction factors calculated at each detector locations at the corresponding fuel loading stage will be applied to correct the reactivity values. The final reactivity at the fuel loading stage is the mean value among all the corrected reactivities at all these locations.

\section{B. Pulsed-Neutron Experiments in the KIPT Neutron Source Facility}

To define the appropriate pulse parameters for performing the pulsed-neutron experiments in the KIPT subcritical assembly, Monte Carlo simulations were performed to calculate the average response from the six neutron detectors at the selected position $(r, z)=(54.0,72.5) \mathrm{cm}$ due to one neutron at time $\mathrm{t}=0$. Figure 17 shows the numerical simulation results for the subcritical assembly with the tungsten target and $24,30,34$, or 
38 fuel assemblies respectively. Similar results were obtained for the subcritical assembly with the natural uranium target as shown in Figure 18. The detector response from the prompt neutrons was also simulated for one configuration as shown in Figure 18. As expected, the neutron flux in the subcritical assembly decreases and vanishes faster as the number of the loaded fuel assemblies decreases. In the fully loaded subcritical assembly with the uranium target, the prompt neutron response in the neutron detector vanishes after about $\sim 40 \mathrm{~ms}$ relative to the contribution from the delayed neutrons. The half-life of the fastest-decayed delayed neutron precursor group is $\sim 80$ ms. Thus, in order to perform a pulsed neutron experiment, the pulse period is selected to be about $50 \mathrm{~ms}$. The external beam power of the linear accelerator is around $10 \mathrm{~W}$, which generates adequate counting rate.

The calculated average neutron detector counting rates for the subcritical configurations with the tungsten and the natural uranium targets are shown in Figures 19 and 20 , respectively. The subcritical core is driven by a linear accelerator with beam power of $10 \mathrm{~W}$ and pulse frequency of $20 \mathrm{HZ}$. The detector responses are calculated using the pulse superposition technique to obtain the delayed neutron equilibrium. The neutron detector sensitivity is assumed to be $10^{-3}$ counts/neutron. As shown in Figure 19 for the core configurations using the tungsten target, the counting rates for the delayed neutron background are $\sim 54$ counts/s for the core configuration with 38 fuel assemblies and $\sim 3$ counts/s for the configuration with 24 fuel assemblies. Figure 20 shows that the counting rates of the delayed neutron background are $\sim 323$ counts/s with 37 fuel assemblies, and $\sim 2.5$ counts/s with 20 fuel assemblies.

To achieve a statistics error less than $1 \%$ in the measured delayed neutron background, for the KIPT subcritical assembly with the uranium target or the tungsten and the maximum number of fuel assemblies fully, the required accumulation time of the pulsed-neutron source experiment was estimated to be $\sim 0.5$ and 3 minutes, respectively. This time was estimated to be $\sim 1$ hour for the subcritical assembly with the 20 or 24 fuel assemblies.

\section{KIPT Subcritical Assembly Reactivity Measurement at Each Fuel Loading Stage.}

To determine the reactivity of the KIPT subcritical assembly at each fuel loading stage, the subcritical core is driven by the external linear accelerator with lower power of $10 \mathrm{~W}$ and with low frequency of $20 \mathrm{HZ}$. The neutron fluxes in the subcritical core are measured by the nine U-235 fission chambers at the selected positions. The area-ratio method will be applied to measure the reactivity, which will require long counting time for the fuel stages with low number of fuel assemblies. The spatial correction factors calculated at each detector locations at the corresponding fuel loading stage will be applied to measure the reactivity. The final reactivity at the fuel loading stage is the mean value among all the corrected reactivities at all these locations. This measured reactivity at any fuel loading stage can be used as the reference reactivity for determining the reactivities at all the previous fuel loading stages using the flux-tocurrent ratio method. The spatial correction factors for the flux-to-current ratio method 
will be applied at each location and each fuel loading stage. The final reactivities at those stages are the mean value of the corrected reactivities among all the detectors.

\section{Flux-to-Current Ratio Method Measurement at the KIPT Fuel Loading Stages}

The flux-to-current ratio method assumes the subcritical core is driven by a steady state external neutron source at the reference state and at the new state. In the pulsedneutron source experiment, the external neutron source is a pulsed source and is always time-dependent. Correspondingly, the neutron fluxes and the neutron detector responses are solutions of the time-dependent Boltzmann equation, and have fine timedependent structures:

$$
\begin{gathered}
\frac{1}{v} \frac{\partial \phi(r, t)}{\partial t}+\boldsymbol{L} \phi(r, t)=(1-\beta) \chi_{p} \boldsymbol{F} \phi(r, t)+\sum_{i} \chi_{d i} \lambda_{i} C_{i}(r, t)+Q(r, t) \\
\frac{\partial C_{i}(r, t)}{\partial t}+\lambda_{i} C_{i}(r, t)=\beta_{i} \boldsymbol{F} \phi(r, t)
\end{gathered}
$$

To calculate the average neutron flux, the time-dependent Boltzmann Equation (20) is integrated over the pulse period T. At delayed neutron equilibrium status, the Boltzmann equations satisfy the periodic conditions: $\phi(r, 0)=\phi(r, T), C_{i}(r, 0)=C_{i}(r, T)$ and $Q(r, 0)=Q(r, T)$. Therefore it is possible to eliminate the delayed neutron term from the Boltzmann equation and Equation (7) of the total neutron area is obtained. Its solution is the average neutron flux of the subcritical assembly with the external source strength equal to the pulsed-neutron source integrated over the pulse period.

To apply the flux-to-current ratio method in the pulsed-neutron experiment, the total neutron flux area is integrated over the pulse periods and the neutron flux is averaged over the pulsed periods. Figure 21 shows the time-dependent averaged neutron flux over the pulse periods. It is normalized to the steady-state neutron flux which is calculated from a fixed source problem with the same source strength for the configuration with the tungsten target. The figure shows that the average neutron flux equals to the steady state neutron flux after the delayed neutrons reach an equilibrium. Therefore, the flux-to-current ratio method can use the pulsed-neutron experimental data to measure the reactivity of the subcritical assembly. 


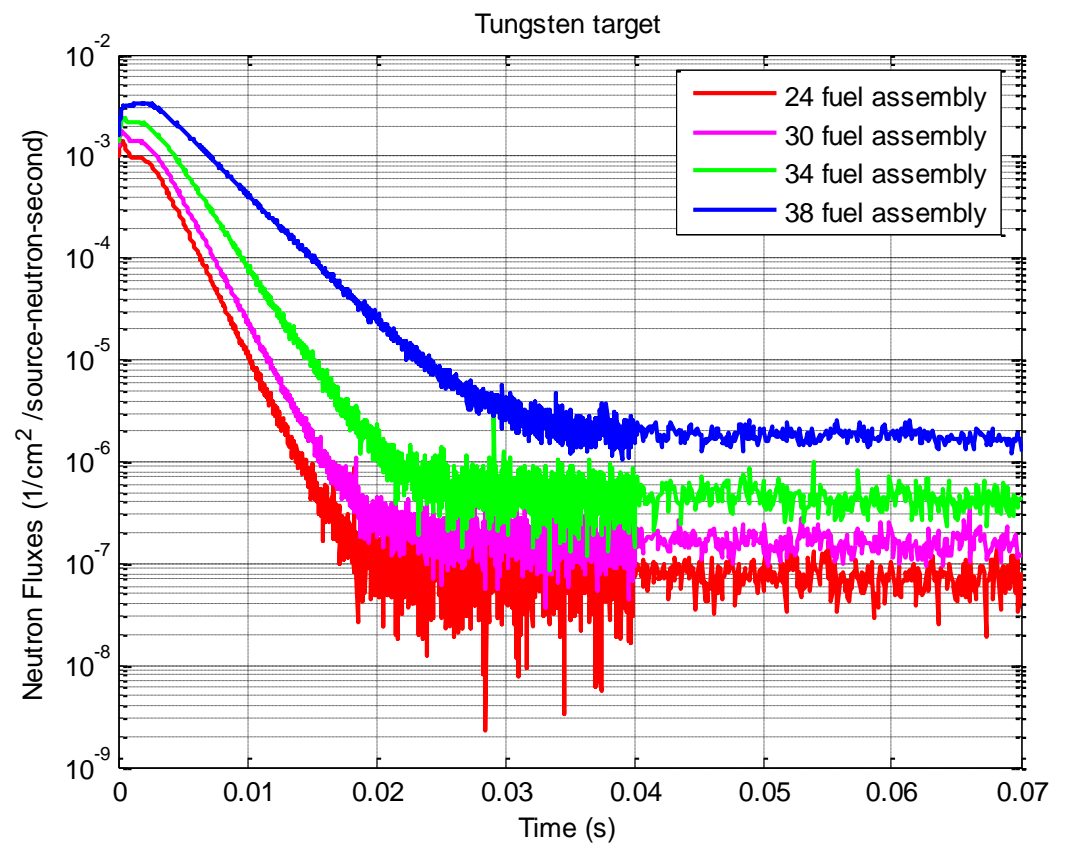

Figure. 17 Monte Carlo simulations of the neutron fluxes from one neutron pulse injected in the KIPT subcritical assembly with the tungsten target for different fuel loading stages.

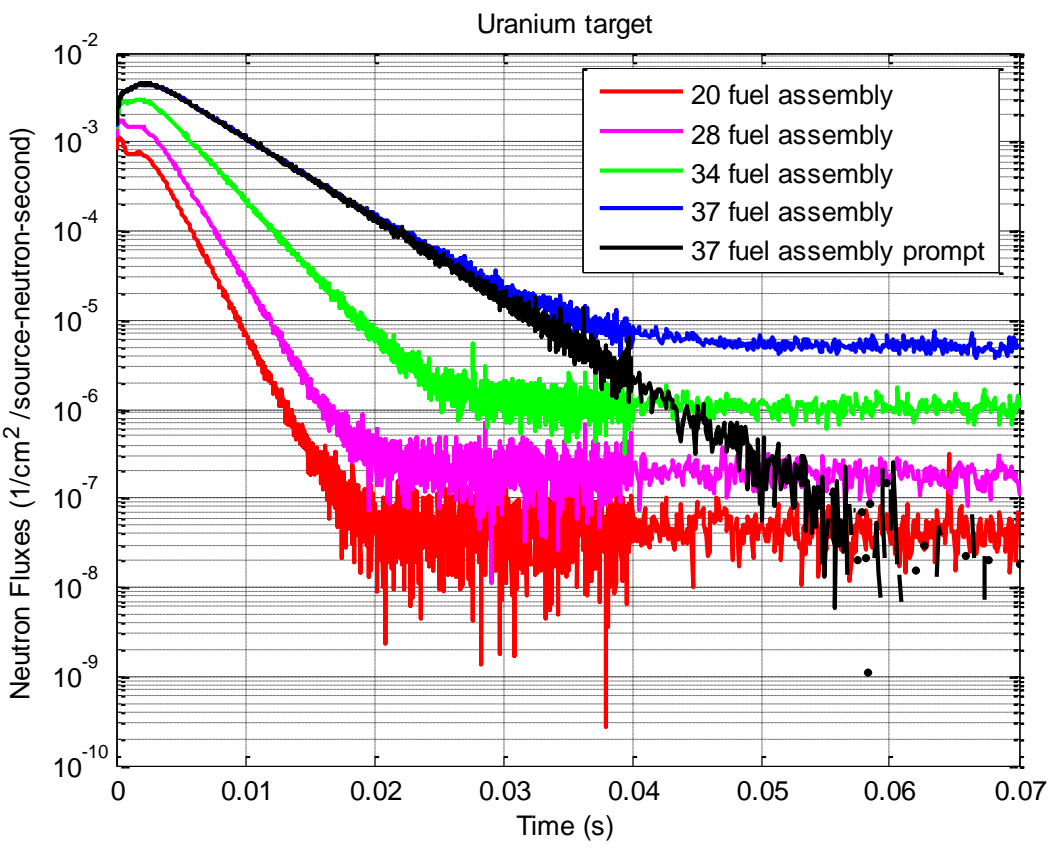

Figure 18. Monte Carlo simulations of the neutron fluxes from one neutron pulse injected in the KIPT subcritical assembly with the uranium target for different fuel loading stages. 


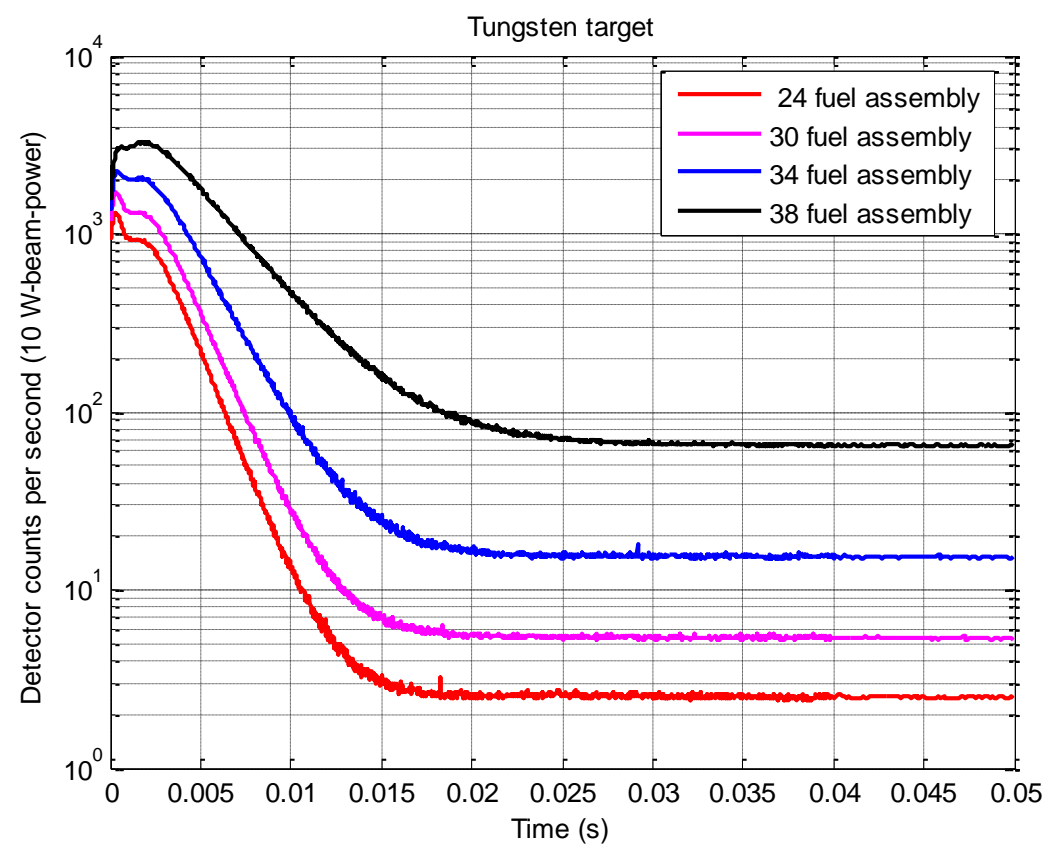

Figure 19. Monte Carlo simulations of the detector counting rates of the KIPT subcritical assembly with the tungsten target for different fuel loading stages driven by $10 \mathrm{~W}$ electron beam pulses with $20 \mathrm{HZ}$ frequency.

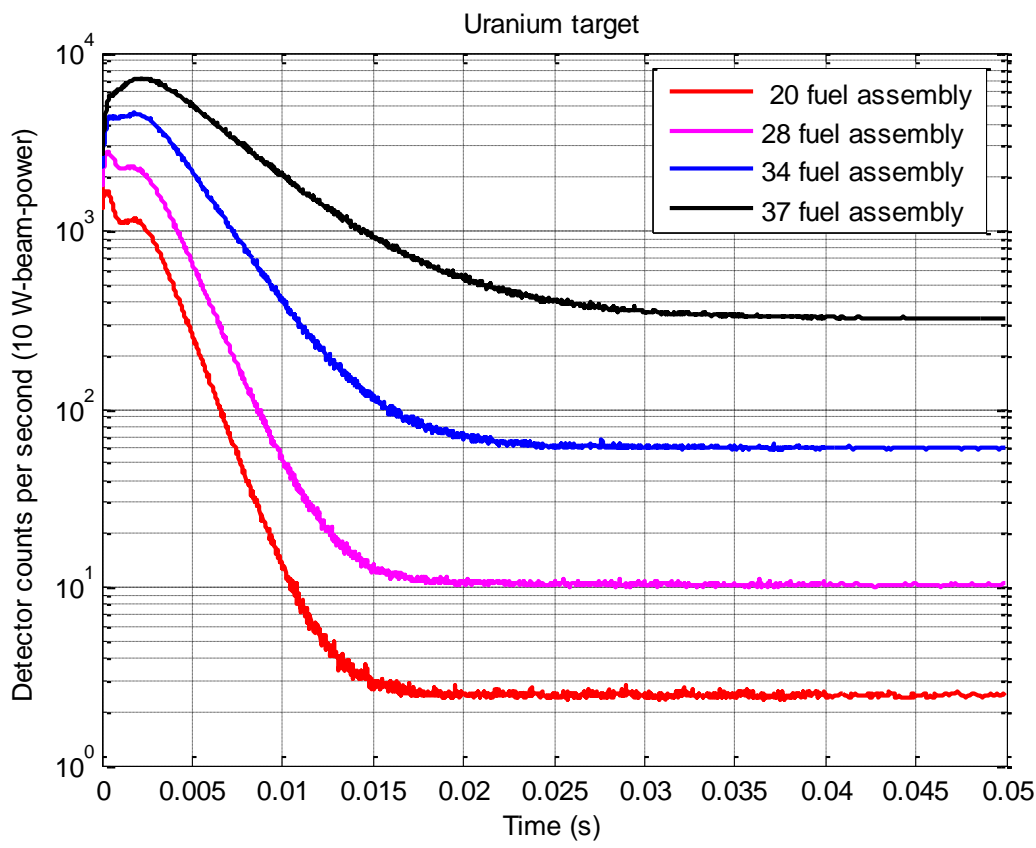

Figure 20. Monte Carlo simulations of the detector counting rates of the KIPT subcritical assembly with the uranium target for different fuel loading stages driven by $10 \mathrm{~W}$ electron beam pulses with $20 \mathrm{HZ}$ frequency. 


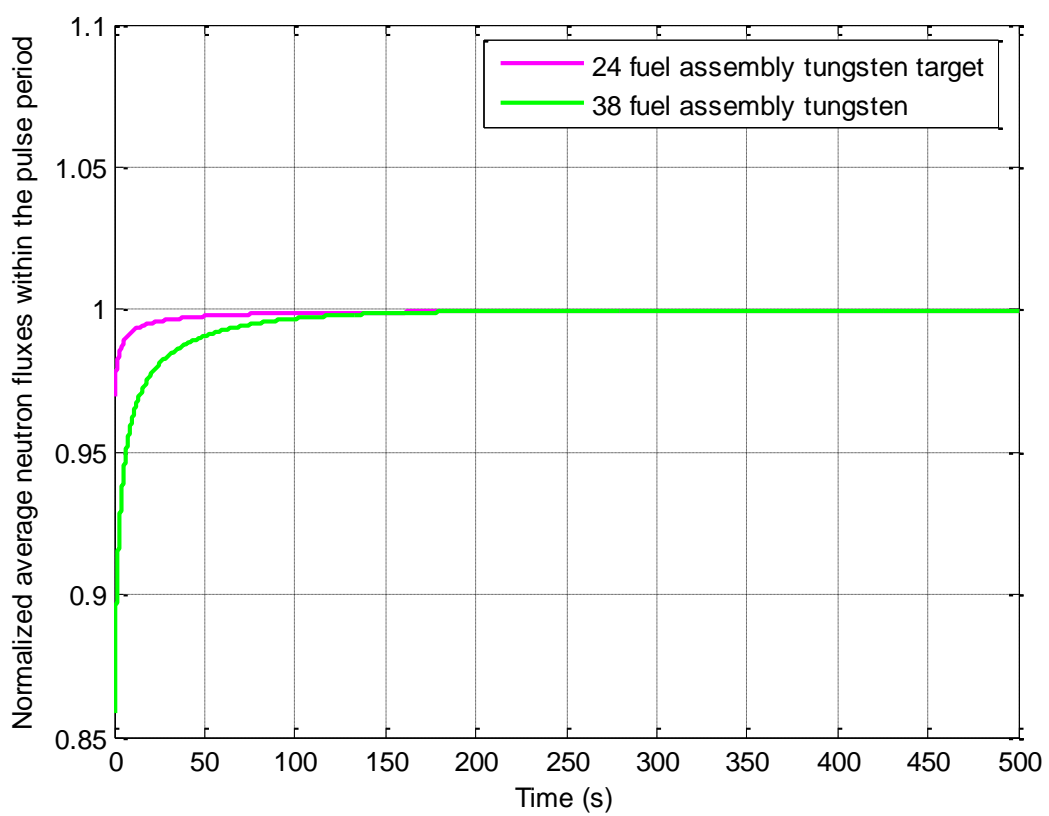

Figure 21. Monte Carlo simulations of the averaged time-dependent neutron flux from each pulse normalized to the steady state neutron flux with the same source strength for the KIPT subcritical assembly with the tungsten target for different fuel loading stages.

\section{E. Spatial Correction Factors for the Area-Ratio Method and the Flux-to-Current Ratio Method}

Monte Carlo simulations were performed to calculate the spatial correction factors for the area-ratio method and the flux-to-current ratio method for the 20 fuel assembly loading stages. For both methods, the neutron detector responses were simulated by tallying the U-235 fission reaction rates in the neutron detector active volume. The neutron detector sensitive material U-235 is not explicitly simulated, because its mass is in the order of milligrams and the self-shielding effects can be ignored in this case. The external neutron source is generated from a separate Monte Carlo electron photon neutron coupled simulation. In the coupled simulation, the energy, position, and direction of the neutron particles produced from the electron nuclear reactions in the target zone are recorded into a source file. This source file was used for the Monte Carlo neutron transport simulations to tally the reaction rates in the neutron detectors.

The spatial correction factors were calculated at the nine detector positions as listed in Tables $\mathrm{V}$ to $\mathrm{X}$, and the values are plotted as well in Figures 22 and 23 . The spatial correction for the area-ratio method are small and are $\leq 3 \%$ at the nine neutron detector positions when more than 35 fuel assemblies are loaded into the subcritical assembly. The spatial correction gradually decreases as the effective multiplication factor of the KIPT subcritical assembly increases. The spatial correction is slightly less than $10 \%$ with only 24 fuel assemblies loaded in the subcritical assembly. The corresponding statistical errors for the calculated correction factors are all around or less 
than $0.5 \%$. The correction factors for the configurations with less than 24 fuel assemblies loaded are also calculated. The maximum spatial corrections are around $10 \%-20 \%$ at the subcritical assembly configuration with 4 fuel assemblies. Its $k_{\text {eff }}$ calculated from Monte Carlo simulation is only $\sim 0.275$. The associated statistical errors for those correction factors are around 1-2\%.

For area-ratio method, as shown in Figure 22, the spatial correction factor values are always larger than 1.0, except at detector position 9 which are always less than 1.0. It is due to the difference in neutron spectrum at this position. For instance, Monte Carlo simulations show that $91 \%$ of neutrons at detector 7 and 8 have energy less than $1 \mathrm{eV}$. However, at detector position 9, only about $34 \%$ of neutrons have energy below $1 \mathrm{eV}$. In addition at detector position 9, half of the neutrons have energy larger than $1 \mathrm{keV}$, and $30 \%$ of the neutrons have energy larger than $1 \mathrm{MeV}$. The detector position 9 is far away from the neutron channels of the subcritical assembly. Unlike detector position 7 and 8, most of neutrons need to go through the water tank in order to reach detector position 9. Therefore, a large portion of thermal neutrons is absorbed in the water tank, and the neutron flux level is about one order of magnitude less than that at positions 7 and 8.

The spatial correction factors for the flux-to-current ratio methods are all less than $10 \%$ when more than 14 fuel assemblies are loaded into the core. The statistical errors of the numerical calculations are around or less than $0.1 \%$. As shown in Figure 23, the spatial corrections are significantly larger at the first few fuel loading stages, which indicates at such deep subcritical states, the flux-to-current ratio method is not accurate, and the reactivities derived based on the flux-to-current ratio method will have to be corrected with the correction factors.

The spatial correction factors of flux-to-current ratio method at all the neutron detector positions are consistent and their values are close to each other when the number of the loaded fuel assemblies in the subcritical assembly is less than 30 . After that, the spatial correction factors start to deviate from each other. These variations are due to the specific fuel loading pattern adopted in the KIPT subcritical assembly. According to Figure 16, at the earlier fuel loading stages, two or four assemblies are loaded into the subcritical assembly at the same time. Their positions are always on the opposite site of the hexagon geometry and these added assemblies are at similar distancing from the neutron detectors surrounding the hexagon. After loading more than 30 fuel assemblies, one fuel assembly is loaded in each fuel loading step. The new fuel assembly position is always closer to one of neutron detectors, and away from the others. This results in a larger perturbation in the neutron detector response, which is closer to the new fuel assembly. Consequently, the spatial correction of this neutron detector changes significantly.

The spatial correction factors at the nine neutron detectors are grouped together based on their radial positions and their sensitivities. Figure 24 shows that for the fluxto-current ratio method, the averaged spatial correction factor value for each group is $\sim 1.0$ when more than 30 fuel assemblies are loaded into the subcritical assembly. Thus, the numerical simulations suggest that using multiple neutron detectors surrounding the hexagon core can indeed reduce the spatial effects in the flux-to-current ratio method 
when the reactivity perturbation induced into the core is not symmetric with respect to the detector positions.

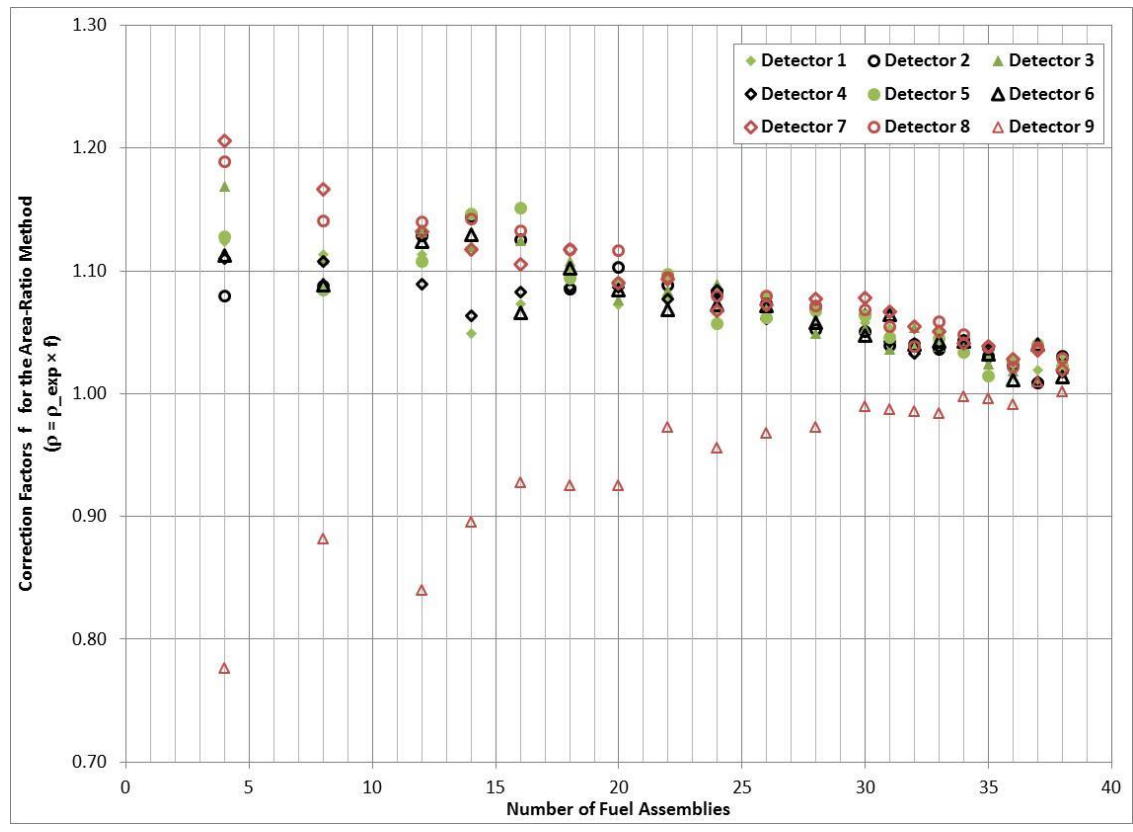

Figure 22. Monte Carlo calculated spatial correction factors of the area-ratio method for each neutron detector location in the KIPT neutron source facility with the tungsten target for each fuel loading stage.

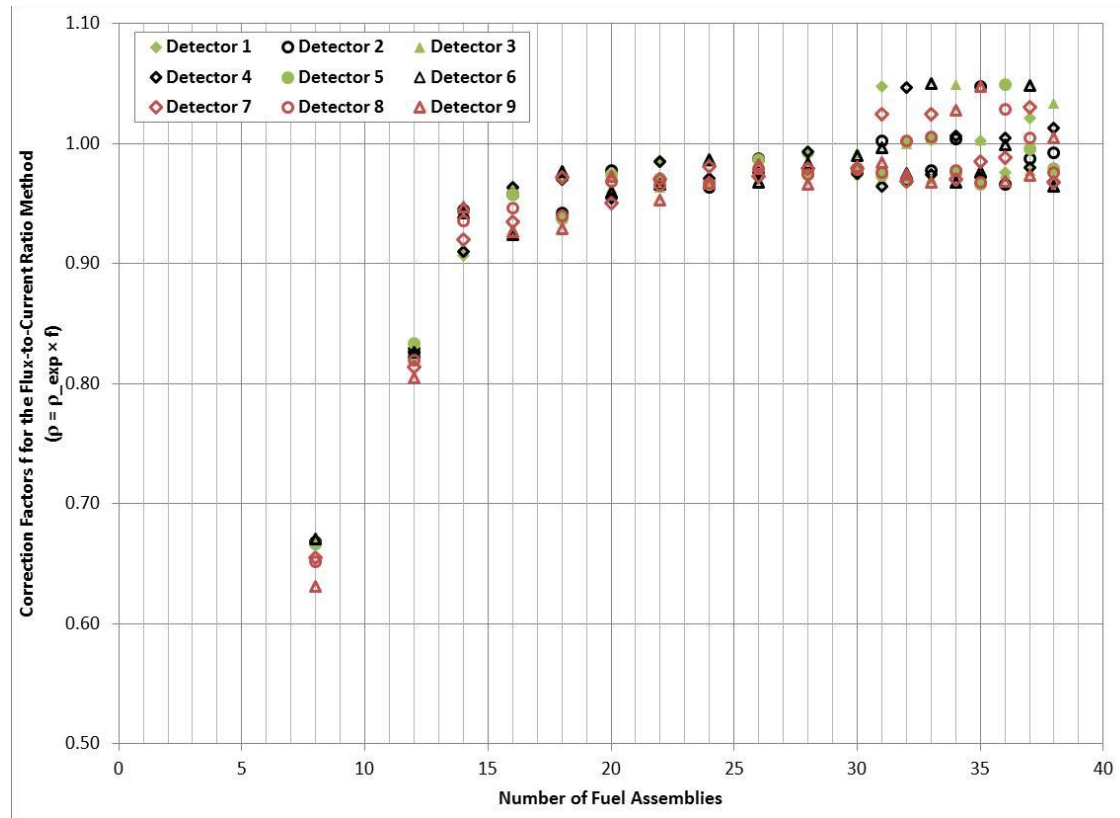

Figure 23. Monte Carlo calculated spatial correction factors of the flux-to-current ratio method for each neutron detector location in the KIPT neutron source facility with the tungsten target for each fuel loading stage. The reference configuration is the previous fuel loading stage. 


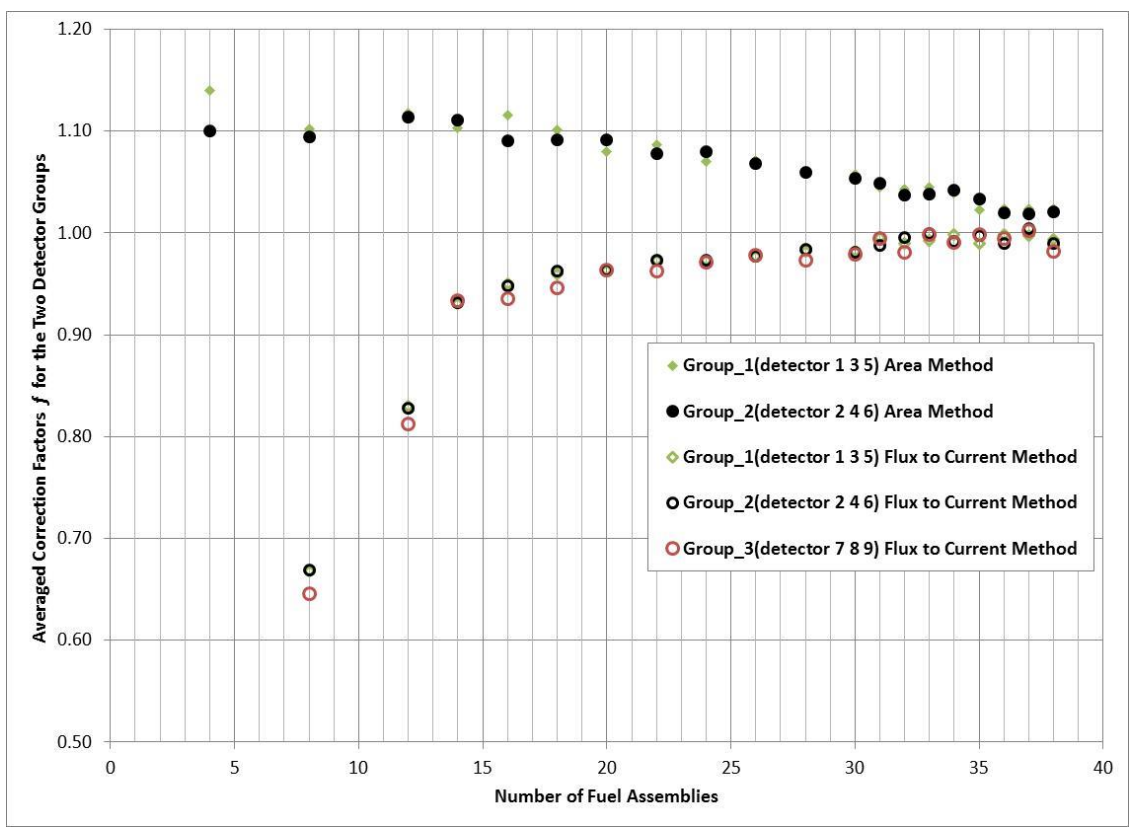

Figure 24. Group average correction factor values for the area-ratio method and the flux-to-current ratio method for the KIPT neutron source facility with the tungsten target for each fuel loading stage. 
Table V: Monte Carlo calculated correction factor values of the area-ratio method for neutron detectors 1, 3 and 5 (group 1) of the KIPT neutron source facility with the tungsten target for each fuel loading stage.

\begin{tabular}{|c|c|c|c|c|c|c|c|c|c|}
\hline \multirow{2}{*}{$\begin{array}{c}\# \\
\text { Fuel }\end{array}$} & \multirow{2}{*}{ keff } & \multicolumn{2}{|c|}{ Detector \# 1} & \multicolumn{2}{c|}{ Detector \# 3 } & \multicolumn{2}{c|}{ Detector \# } & \multicolumn{2}{|c|}{ Average } \\
\cline { 3 - 10 } & & $f$ & std & $f$ & std & $f$ & Std & $f$ & std \\
\hline 4 & 0.2745 & 1.1238 & 0.0242 & 1.1689 & 0.0234 & 1.1278 & 0.0237 & 1.1398 & 0.0249 \\
\hline 8 & 0.4352 & 1.1132 & 0.0144 & 1.1091 & 0.0144 & 1.0844 & 0.0145 & 1.1021 & 0.0156 \\
\hline 12 & 0.5437 & 1.1137 & 0.0216 & 1.1319 & 0.022 & 1.1075 & 0.0222 & 1.1176 & 0.0127 \\
\hline 14 & 0.6 & 1.0487 & 0.0178 & 1.1199 & 0.017 & 1.1464 & 0.0169 & 1.1034 & 0.0505 \\
\hline 16 & 0.6518 & 1.0728 & 0.0145 & 1.1249 & 0.0142 & 1.1515 & 0.0138 & 1.1154 & 0.04 \\
\hline 18 & 0.6998 & 1.1024 & 0.0117 & 1.1078 & 0.0117 & 1.0937 & 0.0116 & 1.1013 & 0.0071 \\
\hline 20 & 0.7332 & 1.0722 & 0.0103 & 1.0767 & 0.0101 & 1.0903 & 0.0101 & 1.0797 & 0.0094 \\
\hline 22 & 0.7641 & 1.0799 & 0.0094 & 1.0837 & 0.0094 & 1.0973 & 0.0093 & 1.0869 & 0.0091 \\
\hline 24 & 0.7937 & 1.0661 & 0.0076 & 1.089 & 0.0075 & 1.0567 & 0.0076 & 1.0704 & 0.0166 \\
\hline 26 & 0.8176 & 1.0796 & 0.0067 & 1.0714 & 0.0067 & 1.0621 & 0.0066 & 1.071 & 0.0088 \\
\hline 28 & 0.8399 & 1.0651 & 0.0071 & 1.0491 & 0.007 & 1.0671 & 0.007 & 1.0604 & 0.0099 \\
\hline 30 & 0.8618 & 1.0574 & 0.0089 & 1.0532 & 0.009 & 1.0633 & 0.0089 & 1.0579 & 0.0051 \\
\hline 31 & 0.8752 & 1.0531 & 0.0058 & 1.0362 & 0.0061 & 1.0455 & 0.0061 & 1.0449 & 0.0085 \\
\hline 32 & 0.8879 & 1.0379 & 0.0069 & 1.0539 & 0.007 & 1.0384 & 0.007 & 1.0434 & 0.0091 \\
\hline 33 & 0.9009 & 1.0504 & 0.0061 & 1.0384 & 0.0064 & 1.0447 & 0.0063 & 1.0445 & 0.006 \\
\hline 34 & 0.9132 & 1.0453 & 0.0054 & 1.0372 & 0.0054 & 1.0336 & 0.0055 & 1.0387 & 0.006 \\
\hline 35 & 0.9256 & 1.0305 & 0.0048 & 1.0239 & 0.0047 & 1.0143 & 0.005 & 1.0229 & 0.0081 \\
\hline 36 & 0.9375 & 1.0257 & 0.0041 & 1.0187 & 0.0041 & 1.0262 & 0.0041 & 1.0235 & 0.0042 \\
\hline 37 & 0.9474 & 1.019 & 0.011 & 1.0112 & 0.0113 & 1.0403 & 0.0112 & 1.0233 & 0.015 \\
\hline 38 & 0.9571 & 1.0281 & 0.0093 & 1.0219 & 0.0093 & 1.0223 & 0.0093 & 1.0241 & 0.0034 \\
\hline
\end{tabular}


Table VI: Monte Carlo calculated correction factor values of the area-ratio method for neutron detectors 2, 4 and 6 (group 2) of the KIPT neutron source facility with the tungsten target for each fuel loading stage.

\begin{tabular}{|c|c|c|c|c|c|c|c|c|c|}
\hline \multirow{2}{*}{$\begin{array}{c}\# \\
\text { Fuel }\end{array}$} & \multirow{2}{*}{ keff } & \multicolumn{2}{|c|}{ Detector \# 2} & \multicolumn{2}{c|}{ Detector \# 4} & \multicolumn{2}{c|}{ Detector \# 6} & \multicolumn{2}{|c|}{ Average } \\
\cline { 3 - 9 } & & $f$ & std & $f$ & std & $f$ & std & $f$ & std \\
\hline 4 & 0.2745 & 1.0798 & 0.0241 & 1.1100 & 0.0237 & 1.1126 & 0.0236 & 1.1006 & 0.0182 \\
\hline 8 & 0.4352 & 1.0874 & 0.0145 & 1.1079 & 0.0143 & 1.0880 & 0.0143 & 1.0943 & 0.0116 \\
\hline 12 & 0.5437 & 1.1289 & 0.0217 & 1.0891 & 0.0222 & 1.1235 & 0.0219 & 1.1136 & 0.0216 \\
\hline 14 & 0.6 & 1.1447 & 0.0171 & 1.0631 & 0.0174 & 1.1295 & 0.0168 & 1.1113 & 0.0434 \\
\hline 16 & 0.6518 & 1.1253 & 0.0138 & 1.0824 & 0.0143 & 1.0655 & 0.0144 & 1.0905 & 0.0308 \\
\hline 18 & 0.6998 & 1.0855 & 0.0116 & 1.0869 & 0.0117 & 1.1022 & 0.0116 & 1.0915 & 0.0093 \\
\hline 20 & 0.7332 & 1.1032 & 0.01 & 1.0866 & 0.0102 & 1.0841 & 0.0102 & 1.0912 & 0.0104 \\
\hline 22 & 0.7641 & 1.0883 & 0.0093 & 1.0775 & 0.0093 & 1.0685 & 0.0094 & 1.078 & 0.0099 \\
\hline 24 & 0.7937 & 1.0824 & 0.0076 & 1.0844 & 0.0075 & 1.072 & 0.0076 & 1.0796 & 0.0067 \\
\hline 26 & 0.8176 & 1.0732 & 0.0066 & 1.0611 & 0.0066 & 1.0713 & 0.0066 & 1.0685 & 0.0065 \\
\hline 28 & 0.8399 & 1.0521 & 0.007 & 1.069 & 0.007 & 1.0575 & 0.0071 & 1.0595 & 0.0086 \\
\hline 30 & 0.8618 & 1.0503 & 0.0089 & 1.0643 & 0.0089 & 1.0471 & 0.009 & 1.0538 & 0.0091 \\
\hline 31 & 0.8752 & 1.0396 & 0.006 & 1.0428 & 0.0061 & 1.0639 & 0.006 & 1.0487 & 0.0132 \\
\hline 32 & 0.8879 & 1.0397 & 0.007 & 1.0332 & 0.0069 & 1.04 & 0.007 & 1.0376 & 0.0038 \\
\hline 33 & 0.9009 & 1.0358 & 0.0064 & 1.0373 & 0.0063 & 1.0428 & 0.0061 & 1.0386 & 0.0037 \\
\hline 34 & 0.9132 & 1.0436 & 0.0054 & 1.0389 & 0.0053 & 1.0424 & 0.0053 & 1.0416 & 0.0025 \\
\hline 35 & 0.9256 & 1.0305 & 0.0048 & 1.036 & 0.0048 & 1.0322 & 0.0048 & 1.0329 & 0.0028 \\
\hline 36 & 0.9375 & 1.0231 & 0.0041 & 1.0263 & 0.0041 & 1.0112 & 0.0041 & 1.0201 & 0.0079 \\
\hline 37 & 0.9474 & 1.0084 & 0.0112 & 1.0094 & 0.0113 & 1.0399 & 0.011 & 1.019 & 0.0179 \\
\hline 38 & 0.9571 & 1.0304 & 0.0094 & 1.0175 & 0.0094 & 1.0139 & 0.0093 & 1.0206 & 0.0087 \\
\hline
\end{tabular}


Table VII: Monte Carlo calculated correction factor values of the area-ratio method for neutron detectors 7, 8 and 9 (group 3) of the KIPT neutron source facility with the tungsten target for each fuel loading stage.

\begin{tabular}{|c|c|c|c|c|c|c|c|c|c|}
\hline \multirow{2}{*}{$\begin{array}{c}\# \\
\text { Fuel }\end{array}$} & \multirow{2}{*}{ keff } & \multicolumn{2}{|c|}{ Detector \# } & \multicolumn{2}{c|}{ Detector \# 8} & \multicolumn{2}{c|}{ Detector \# 9 } & \multicolumn{2}{c|}{ Average } \\
\cline { 3 - 10 } & & $f$ & std & $f$ & std & $f$ & std & $f$ & std \\
\hline 4 & 0.2745 & 1.2058 & 0.0115 & 1.1888 & 0.0187 & 0.7764 & 0.0378 & --- & --- \\
\hline 8 & 0.4352 & 1.1668 & 0.0074 & 1.1407 & 0.0115 & 0.8815 & 0.0255 & --- & --- \\
\hline 12 & 0.5437 & 1.1320 & 0.0082 & 1.1396 & 0.0095 & 0.8398 & 0.0181 & --- & --- \\
\hline 14 & 0.6 & 1.1177 & 0.0071 & 1.1425 & 0.0080 & 0.8954 & 0.0136 & --- & --- \\
\hline 16 & 0.6518 & 1.1049 & 0.0072 & 1.1328 & 0.0058 & 0.9276 & 0.0304 & --- & --- \\
\hline 18 & 0.6998 & 1.1177 & 0.0145 & 1.1175 & 0.0064 & 0.9254 & 0.0125 & --- & --- \\
\hline 20 & 0.7332 & 1.0902 & 0.0064 & 1.1162 & 0.0047 & 0.9254 & 0.0076 & --- & --- \\
\hline 22 & 0.7641 & 1.0929 & 0.0064 & 1.0950 & 0.0053 & 0.9725 & 0.0200 & --- & --- \\
\hline 24 & 0.7937 & 1.0674 & 0.0071 & 1.0792 & 0.0062 & 0.9553 & 0.0079 & --- & --- \\
\hline 26 & 0.8176 & 1.0721 & 0.0065 & 1.0795 & 0.0062 & 0.9673 & 0.0134 & --- & --- \\
\hline 28 & 0.8399 & 1.0775 & 0.0066 & 1.0713 & 0.0078 & 0.9722 & 0.0072 & --- & --- \\
\hline 30 & 0.8618 & 1.0776 & 0.0068 & 1.0684 & 0.0065 & 0.9893 & 0.0098 & --- & --- \\
\hline 31 & 0.8752 & 1.0669 & 0.0064 & 1.0548 & 0.0050 & 0.9866 & 0.0089 & --- & --- \\
\hline 32 & 0.8879 & 1.0544 & 0.0054 & 1.0386 & 0.0054 & 0.9853 & 0.0068 & --- & --- \\
\hline 33 & 0.9009 & 1.0508 & 0.0047 & 1.0582 & 0.0070 & 0.9838 & 0.0063 & --- & --- \\
\hline 34 & 0.9132 & 1.0413 & 0.0043 & 1.0478 & 0.0044 & 0.9972 & 0.0071 & --- & --- \\
\hline 35 & 0.9256 & 1.0382 & 0.0041 & 1.0377 & 0.0070 & 0.9956 & 0.0047 & --- & --- \\
\hline 36 & 0.9375 & 1.0284 & 0.0039 & 1.0219 & 0.0059 & 0.9913 & 0.0049 & --- & --- \\
\hline 37 & 0.9474 & 1.0355 & 0.0077 & 1.0373 & 0.0059 & 1.0093 & 0.0065 & --- & --- \\
\hline 38 & 0.9571 & 1.0188 & 0.0038 & 1.0291 & 0.0067 & 1.0017 & 0.0051 & --- & --- \\
\hline
\end{tabular}


Table VIII: Monte Carlo calculated correction factor values of the flux-to-current ratio method for neutron detectors 1,3 and 5 (group 1) of the KIPT neutron source facility with the tungsten target for each fuel loading stage. The reference configuration is the previous fuel loading stage.

\begin{tabular}{|c|c|c|c|c|c|c|c|c|c|}
\hline \multirow{2}{*}{$\begin{array}{c}\# \\
\text { Fuel }\end{array}$} & \multirow{2}{*}{ keff } & \multicolumn{2}{|c|}{ Detector \# 1} & \multicolumn{2}{c|}{ Detector \# 3 } & \multicolumn{2}{c|}{ Detector \# } & \multicolumn{2}{|c|}{ Average } \\
\cline { 3 - 9 } & & $f$ & std & $f$ & std & $f$ & std & $f$ & std \\
\hline 4 & 0.2745 & --- & --- & --- & --- & --- & --- & --- & --- \\
\hline 8 & 0.4352 & 0.6673 & 0.0017 & 0.6712 & 0.0017 & 0.6663 & 0.0017 & 0.6683 & 0.0026 \\
\hline 12 & 0.5437 & 0.8326 & 0.0025 & 0.8226 & 0.0025 & 0.8331 & 0.0025 & 0.8294 & 0.0060 \\
\hline 14 & 0.6 & 0.9066 & 0.0029 & 0.9421 & 0.0029 & 0.9426 & 0.0029 & 0.9302 & 0.0206 \\
\hline 16 & 0.6518 & 0.9627 & 0.0025 & 0.9288 & 0.0025 & 0.958 & 0.0025 & 0.9496 & 0.0184 \\
\hline 18 & 0.6998 & 0.9714 & 0.0023 & 0.9722 & 0.0023 & 0.9371 & 0.0023 & 0.9599 & 0.02 \\
\hline 20 & 0.7332 & 0.9549 & 0.0022 & 0.9627 & 0.0022 & 0.9738 & 0.0022 & 0.9637 & 0.0095 \\
\hline 22 & 0.7641 & 0.986 & 0.0021 & 0.9635 & 0.0021 & 0.9712 & 0.0021 & 0.9735 & 0.0114 \\
\hline 24 & 0.7937 & 0.9693 & 0.002 & 0.9849 & 0.002 & 0.9657 & 0.002 & 0.9732 & 0.0102 \\
\hline 26 & 0.8176 & 0.9761 & 0.0018 & 0.97 & 0.0018 & 0.9865 & 0.0018 & 0.9775 & 0.0083 \\
\hline 28 & 0.8399 & 0.9909 & 0.0018 & 0.98 & 0.0018 & 0.9752 & 0.0018 & 0.982 & 0.0081 \\
\hline 30 & 0.8618 & 0.9736 & 0.0024 & 0.9924 & 0.0024 & 0.9793 & 0.0024 & 0.9817 & 0.0097 \\
\hline 31 & 0.8752 & 1.0472 & 0.0023 & 0.9703 & 0.0023 & 0.973 & 0.0024 & 0.9956 & 0.0436 \\
\hline 32 & 0.8879 & 0.9692 & 0.0021 & 0.9993 & 0.0021 & 1.0013 & 0.0021 & 0.9897 & 0.018 \\
\hline 33 & 0.9009 & 1.0039 & 0.0022 & 0.9707 & 0.0023 & 1.0035 & 0.0023 & 0.9924 & 0.0191 \\
\hline 34 & 0.9132 & 0.9731 & 0.0021 & 1.0488 & 0.0021 & 0.9759 & 0.0021 & 0.9981 & 0.0429 \\
\hline 35 & 0.9256 & 1.0018 & 0.002 & 1.0028 & 0.0019 & 0.9661 & 0.002 & 0.9899 & 0.0209 \\
\hline 36 & 0.9375 & 0.9757 & 0.0019 & 0.9746 & 0.0018 & 1.0491 & 0.0019 & 0.9986 & 0.0427 \\
\hline 37 & 0.9474 & 1.0212 & 0.0038 & 0.9777 & 0.0039 & 0.9959 & 0.0038 & 0.9979 & 0.0219 \\
\hline 38 & 0.9571 & 0.9689 & 0.0049 & 1.0336 & 0.005 & 0.9793 & 0.0049 & 0.9931 & 0.0347 \\
\hline
\end{tabular}


Table IX: Monte Carlo calculated correction factor values of the flux-to-current ratio method for neutron detectors 2, 4 and 6 (group 2) of the KIPT neutron source facility which with the tungsten target for each fuel loading stage. The reference configuration is the previous fuel loading stage.

\begin{tabular}{|c|c|c|c|c|c|c|c|c|c|}
\hline \multirow{2}{*}{$\begin{array}{c}\# \\
\text { Fuel }\end{array}$} & \multirow{2}{*}{ keff } & \multicolumn{2}{|c|}{ Detector \# 2} & \multicolumn{2}{c|}{ Detector \# 4 } & \multicolumn{2}{c|}{ Detector \# 6} & \multicolumn{2}{|c|}{ Average } \\
\cline { 3 - 9 } & & $f$ & std & $f$ & std & $f$ & std & $f$ & std \\
\hline 4 & 0.2745 & --- & --- & --- & --- & --- & --- & --- & --- \\
\hline 8 & 0.4352 & 0.6679 & 0.0017 & 0.6688 & 0.0017 & 0.6705 & 0.0017 & 0.6690 & 0.0013 \\
\hline 12 & 0.5437 & 0.8262 & 0.0025 & 0.8296 & 0.0025 & 0.8264 & 0.0025 & 0.8274 & 0.0019 \\
\hline 14 & 0.6 & 0.9449 & 0.0029 & 0.9096 & 0.0029 & 0.9417 & 0.0029 & 0.9318 & 0.0195 \\
\hline 16 & 0.6518 & 0.9573 & 0.0025 & 0.9638 & 0.0025 & 0.9238 & 0.0025 & 0.948 & 0.0215 \\
\hline 18 & 0.6998 & 0.942 & 0.0023 & 0.9702 & 0.0023 & 0.9762 & 0.0023 & 0.9626 & 0.0182 \\
\hline 20 & 0.7332 & 0.9777 & 0.0022 & 0.9541 & 0.0022 & 0.9595 & 0.0022 & 0.9637 & 0.0124 \\
\hline 22 & 0.7641 & 0.9699 & 0.0021 & 0.9846 & 0.0021 & 0.9657 & 0.0021 & 0.9733 & 0.0099 \\
\hline 24 & 0.7937 & 0.9635 & 0.002 & 0.9706 & 0.002 & 0.9868 & 0.002 & 0.9735 & 0.0119 \\
\hline 26 & 0.8176 & 0.9871 & 0.0018 & 0.9756 & 0.0018 & 0.9678 & 0.0018 & 0.9768 & 0.0097 \\
\hline 28 & 0.8399 & 0.976 & 0.0018 & 0.993 & 0.0018 & 0.983 & 0.0018 & 0.984 & 0.0086 \\
\hline 30 & 0.8618 & 0.9791 & 0.0024 & 0.9752 & 0.0024 & 0.9894 & 0.0024 & 0.9812 & 0.0074 \\
\hline 31 & 0.8752 & 1.002 & 0.0023 & 0.9644 & 0.0024 & 0.9967 & 0.0023 & 0.9874 & 0.0204 \\
\hline 32 & 0.8879 & 0.9693 & 0.0021 & 1.0464 & 0.0021 & 0.9753 & 0.0021 & 0.9958 & 0.0429 \\
\hline 33 & 0.9009 & 0.9776 & 0.0023 & 0.9743 & 0.0023 & 1.0496 & 0.0022 & 0.9993 & 0.0426 \\
\hline 34 & 0.9132 & 1.004 & 0.0021 & 1.0061 & 0.0021 & 0.9673 & 0.0021 & 0.9921 & 0.0218 \\
\hline 35 & 0.9256 & 1.0475 & 0.0019 & 0.9714 & 0.002 & 0.9765 & 0.002 & 0.9973 & 0.0425 \\
\hline 36 & 0.9375 & 0.966 & 0.0018 & 1.0048 & 0.0018 & 0.9985 & 0.0018 & 0.9895 & 0.0208 \\
\hline 37 & 0.9474 & 0.9869 & 0.0038 & 0.9801 & 0.0039 & 1.0479 & 0.0038 & 1.0041 & 0.0373 \\
\hline 38 & 0.9571 & 0.9921 & 0.0049 & 1.0125 & 0.005 & 0.9646 & 0.0049 & 0.9894 & 0.024 \\
\hline
\end{tabular}


Table X: Monte Carlo calculated correction factor values of the flux-to-current ratio method for neutron detectors 7, 8 and 9 (group 3) of the KIPT neutron source facility with the tungsten target for each fuel loading stage. The reference configuration is the previous fuel loading stage.

\begin{tabular}{|c|c|c|c|c|c|c|c|c|c|}
\hline \multirow{2}{*}{$\begin{array}{c}\# \\
\text { Fuel }\end{array}$} & \multirow{2}{*}{ keff } & \multicolumn{2}{|c|}{ Detector \# 7} & \multicolumn{2}{c|}{ Detector \# 8} & \multicolumn{2}{c|}{ Detector \# 9 } & \multicolumn{2}{|c|}{ Average } \\
\cline { 3 - 9 } & & $f$ & std & $f$ & std & $f$ & std & $f$ & std \\
\hline 4 & 0.2745 & ---- & ---- & --- & --- & ---- & --- & --- & ---- \\
\hline 8 & 0.4352 & 0.6546 & 0.0013 & 0.6512 & 0.0015 & 0.631 & 0.0036 & 0.6454 & 0.0090 \\
\hline 12 & 0.5437 & 0.8136 & 0.0013 & 0.8194 & 0.0014 & 0.8045 & 0.0033 & 0.8125 & 0.0053 \\
\hline 14 & 0.6 & 0.9197 & 0.0013 & 0.9354 & 0.0013 & 0.947 & 0.0033 & 0.9339 & 0.0097 \\
\hline 16 & 0.6518 & 0.9344 & 0.0016 & 0.9462 & 0.0011 & 0.9261 & 0.0030 & 0.9355 & 0.0071 \\
\hline 18 & 0.6998 & 0.9718 & 0.0018 & 0.9397 & 0.0011 & 0.9290 & 0.0025 & 0.9465 & 0.0158 \\
\hline 20 & 0.7332 & 0.9505 & 0.0018 & 0.9686 & 0.0011 & 0.9723 & 0.0023 & 0.9637 & 0.0082 \\
\hline 22 & 0.7641 & 0.9700 & 0.0018 & 0.9650 & 0.0011 & 0.9525 & 0.0022 & 0.9624 & 0.0064 \\
\hline 24 & 0.7937 & 0.9803 & 0.0025 & 0.9666 & 0.0014 & 0.9667 & 0.0022 & 0.9712 & 0.0056 \\
\hline 26 & 0.8176 & 0.9722 & 0.0036 & 0.9787 & 0.0016 & 0.9824 & 0.0023 & 0.9777 & 0.0037 \\
\hline 28 & 0.8399 & 0.9788 & 0.0030 & 0.9741 & 0.0019 & 0.9655 & 0.0025 & 0.9728 & 0.0048 \\
\hline 30 & 0.8618 & 0.9794 & 0.0018 & 0.9780 & 0.0021 & 0.9807 & 0.0023 & 0.9794 & 0.0010 \\
\hline 31 & 0.8752 & 1.0246 & 0.0018 & 0.9755 & 0.0018 & 0.9841 & 0.0022 & 0.9943 & 0.0185 \\
\hline 32 & 0.8879 & 0.9683 & 0.0018 & 1.0019 & 0.0017 & 0.9743 & 0.0028 & 0.9813 & 0.0127 \\
\hline 33 & 0.9009 & 1.0244 & 0.0019 & 1.0054 & 0.0021 & 0.9677 & 0.0028 & 0.9986 & 0.0204 \\
\hline 34 & 0.9132 & 0.9700 & 0.0022 & 0.9771 & 0.0020 & 1.0277 & 0.0028 & 0.9909 & 0.0223 \\
\hline 35 & 0.9256 & 0.9849 & 0.0020 & 0.9673 & 0.0023 & 1.0472 & 0.0027 & 0.9986 & 0.0297 \\
\hline 36 & 0.9375 & 0.9882 & 0.0022 & 1.0285 & 0.0027 & 0.9680 & 0.0024 & 0.9943 & 0.0218 \\
\hline 37 & 0.9474 & 1.0304 & 0.0028 & 1.0044 & 0.0026 & 0.9737 & 0.0025 & 1.0023 & 0.0201 \\
\hline 38 & 0.9571 & 0.9679 & 0.0026 & 0.9754 & 0.0030 & 1.0046 & 0.0026 & 0.9824 & 0.0137 \\
\hline
\end{tabular}




\section{Tracking the Reactivity Variations of the KIPT Subcritical Core at Full Power Operation Mode}

\section{A. Simulated Neutron Detector Responses during the Normal Operation of KIPT}

At normal operation mode, the KIPT neutron source facility is driven by the $100 \mathrm{~kW}$ electron beam. The electron beam frequency is $625 \mathrm{~Hz}$, which generates a pulse every $1.6 \mathrm{~ms}$. Within such a short pulse, the prompt neutron population is contributed from several successive pulses. Monte Carlo simulations were performed to simulate the average detector responses at the selected neutron detector position $(r, z)=(54.0,72.5$ $\mathrm{cm}$ ) of the KIPT neutron source facility with the tungsten target. The selected neutron detector sensitivity is $10^{-6}$ counts/neutron. Figure 25 plots the simulated detector responses within one pulse when the KIPT subcritical assembly has different number of fuel assemblies. The numerical simulations are obtained by the superposition technique using the $625 \mathrm{~Hz}$ frequency to include the delayed neutron equilibrium status. As shown in the Figure 25, the neutron detector responses have fine time-dependent structures within the pulse period. However, this structure is much smoother compared with the responses obtained from the pulsed-neutron experiment with low frequency. Similarly, the averaged neutron fluxes over the pulse period are also compared with the steady state neutron fluxes with same source strength. It is found that the averaged neutron fluxes over the pulse period are identical to the steady state neutron fluxes after the delayed neutrons reach an equilibrium status. Thus, the averaged neutron fluxes over the pulse period can be used in the flux-to-current ratio method to monitor the reactivity variations in the KIPT subcritical assembly.

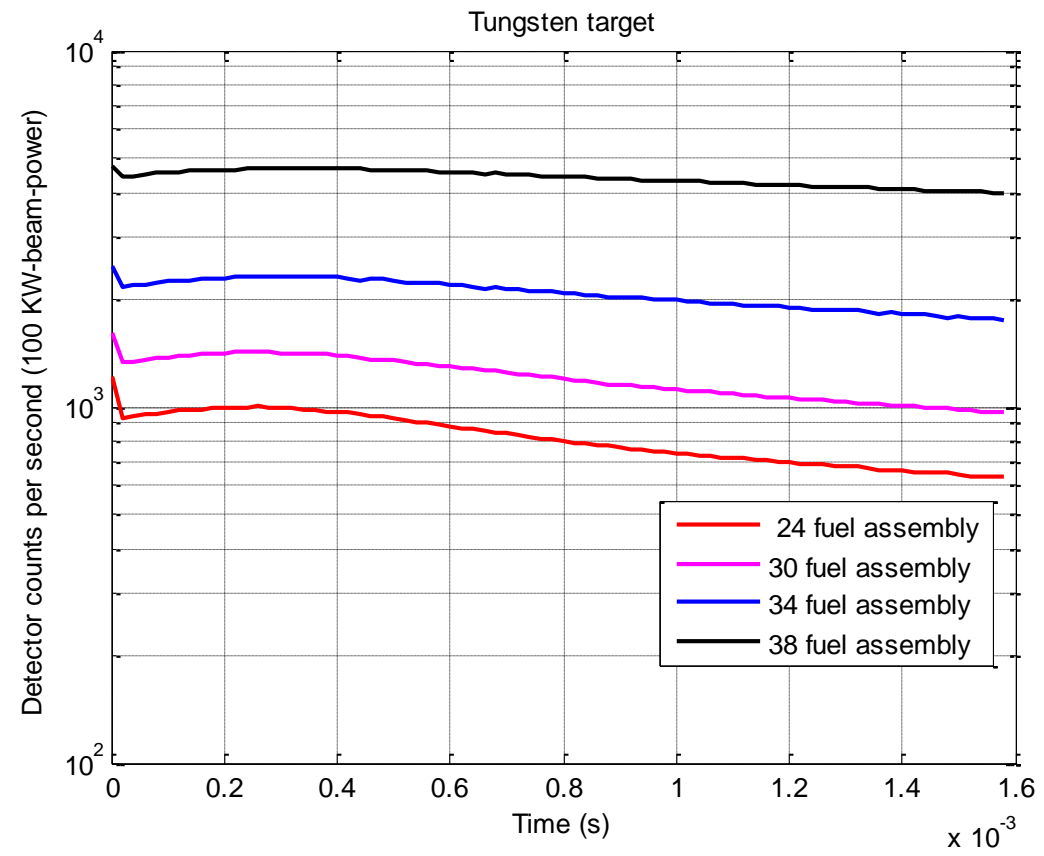

Figure 25. Monte Carlo calculation of the detector counting rates after the KIPT subcritical core reaching the delayed neutron equilibrium status. The subcritical assembly is loaded with 24 to 38 fuel assemblies and it is driven by a $100 \mathrm{~kW}$ electron beam with $625 \mathrm{~Hz}$ frequency. 


\section{B. Flux-to-Current Ratio Method Utilization for Monitoring the Reactivity Change of the KIPT neutron Source Facility during Normal Operation}

As soon as the subcritical assembly starts, its $k_{\text {eff }}$ value will significantly decreases during the first two-day of operation due to the build-up of xenon fission gas. For example, for the subcritical assembly with the uranium target, its $\mathrm{K}_{\text {eff }}$ value will decrease from 0.975 to 0.966 . Then the $k_{\text {eff }}$ value will slowly decrease during normal operation due to the burnup of the fuel fissile material. The KIPT subcritical assembly does not have control rods or burnable poison material to compensate for the lost reactivity. To compensate for the lost reactivity, the fuel assemblies will be moved gradually away from each other to enhance the slowing down of the neutron population. Such effect will increase the Keff value because of the increase of the fission reaction rate of U-235 fissile fuel isotope. Therefore during operation, the subcritical assembly fuel configuration will change from a compact fuel configuration to a larger configuration with fuel assemblies distributed over all the rings of the hexagon at the end of the fuel burnup stage.

The applicability of the flux-to-current ratio method to monitor the reactivity swing at the normal operation mode was explored using one of the KIPT fuel burnup model ${ }^{15}$. As shown in Figure 26, a fuel burnup cycle with 18 fuel burnup stages is designed for the KIPT subcritical assembly with the natural uranium target. As shown in Figure 26, to compensate for the lost reactivity of a fuel burnup stage, a few fuel assemblies are moved away from their neighbors at the beginning of the next fuel burnup stage.

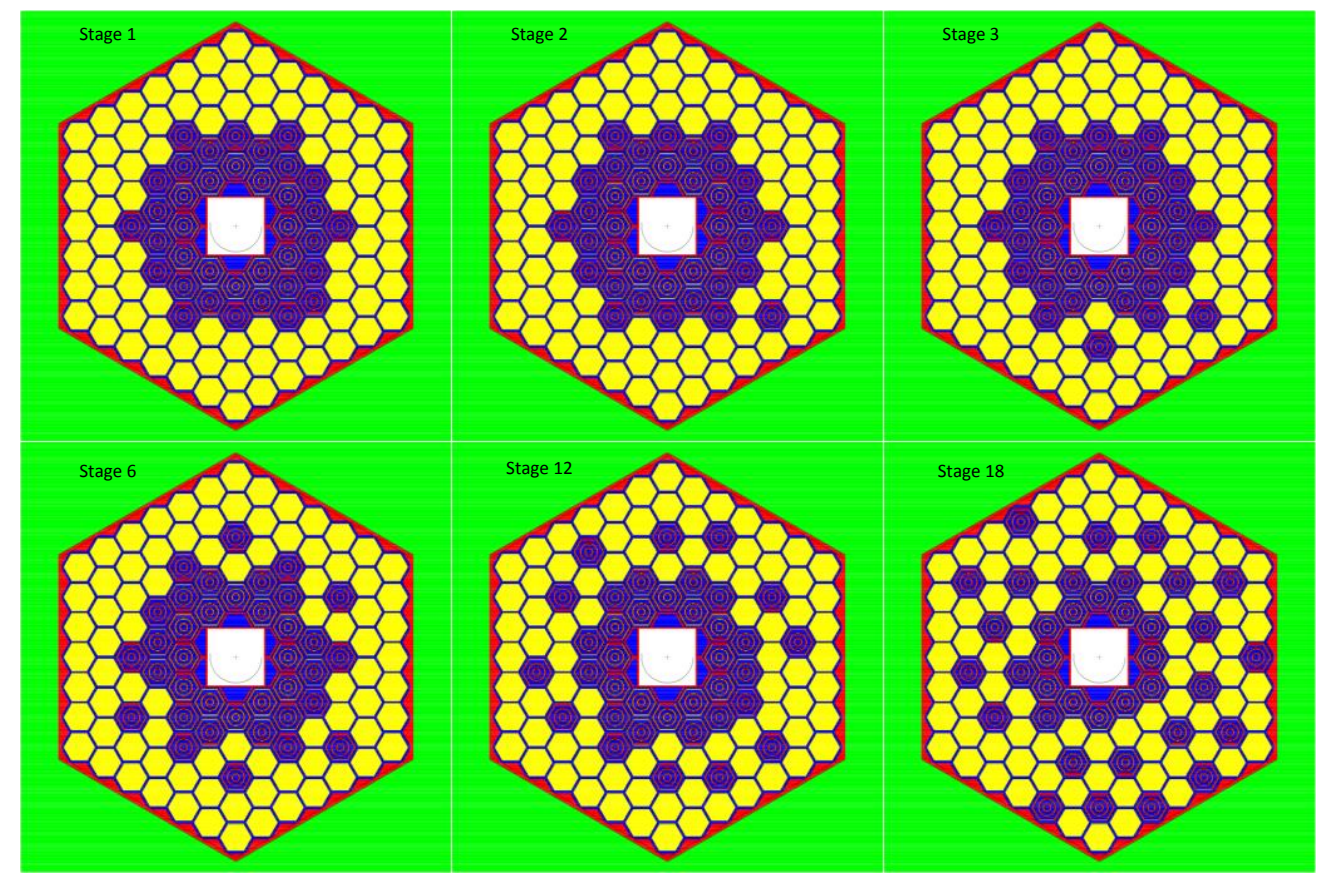

Figure 26. Fuel loading patterns of KIPT subcritical assembly at different burnup stages for configuration with natural uranium target. 
The spatial correction factors for the flux-to-current ratio method were calculated using the fresh fuel assemblies at the beginning of fuel burnup stage 1 as the reference subcritical assembly configuration. Then, the spatial correction factors were calculated at the beginning and at the end of each burnup stage. Only the detectors at the selected optimal positions were considered. As shown in Table XI, the spatial correction factors increases as the fuel burnup stage gradually deviate from the first fuel burnup stage. By the beginning of the fuel burnup stage 18, the spatial correction factors can be as large as $\sim 30 \%$, even though the $k_{\text {eff }}$ of the subcritical core does not change significantly from the reference core.

To improve the reactivity monitoring accuracy of the flux-to-current ratio method, the reference state needs frequent update. For instance, as more fuel assemblies moved intermediate reference points such as the assembly configurations at the beginning of stage 3, 6 and 16 can be added. At these "intermediate" reference points, the selected reference state is close to the monitored configuration, and the absolute reactivities are determined by the area-ratio method. The spatial correction factors based on these intermediate reference core configurations were also calculated as shown in Table XI, which are much smaller and can be kept within a few percent.

The spatial correction factors at the end of each fuel burnup stage were calculated if the assembly configuration at the beginning of each particular burnup stage is selected as the reference point. As listed in the last column of Table XI, these spatial corrections are all extremely small which indicates that during each fuel burnup stage, if the reactivity at the beginning of the fuel burnup stage can be determined, the flux-to-current ratio method can be utilized to track the reactivity swing very accurately over that fuel burnup stage. Usually, the fuel burnup stages can last long from around 30 days to 80 days.

Table XI. Calculated average spatial correction factors at optimal detector positions for KIPT subcritical assembly with natural uranium target.

\begin{tabular}{|c|c|c|c|c|c|c|}
\hline \multirow{2}{*}{$\begin{array}{c}\text { Burnup } \\
\text { Stage }\end{array}$} & \multicolumn{3}{|c|}{ Keff } & \multicolumn{2}{c|}{$\begin{array}{c}\text { Averaged F (with Fixed } \\
\text { Reference Point) }\end{array}$} & \multicolumn{2}{c|}{$\begin{array}{c}\text { Averaged F (with Updated } \\
\text { Reference Points) }\end{array}$} \\
\cline { 2 - 7 } & $\begin{array}{c}\text { Beginning } \\
\text { of Stage }\end{array}$ & $\begin{array}{c}\text { End } \\
\text { of Stage }\end{array}$ & $\begin{array}{c}\text { Beginning } \\
\text { of Stage }\end{array}$ & $\begin{array}{c}\text { End } \\
\text { of Stage }\end{array}$ & $\begin{array}{c}\text { Beginning } \\
\text { of Stage }\end{array}$ & $\begin{array}{c}\text { End } \\
\text { of Stage }\end{array}$ \\
\hline 1 & 0.9756 & 0.9665 & --- & $1.010 \pm 0.006$ & --- & $1.010 \pm 0.006$ \\
\hline 2 & 0.9698 & 0.9661 & $1.020 \pm 0.031$ & $1.028 \pm 0.025$ & $1.020 \pm 0.031$ & $1.007 \pm 0.008$ \\
\hline 3 & 0.9698 & 0.9661 & $1.033 \pm 0.040$ & $1.032 \pm 0.043$ & $1.033 \pm 0.040$ & $0.998 \pm 0.005$ \\
\hline 6 & 0.9706 & 0.9673 & $1.054 \pm 0.021$ & $1.063 \pm 0.025$ & $1.021 \pm 0.023$ & $1.009 \pm 0.005$ \\
\hline 12 & 0.9690 & 0.9665 & $1.128 \pm 0.018$ & $1.132 \pm 0.015$ & $1.057 \pm 0.033$ & $1.004 \pm 0.004$ \\
\hline 18 & 0.9690 & ---- & $1.289 \pm 0.082$ & -- & $1.066 \pm 0.056$ & -- \\
\hline
\end{tabular}


The spatial correction factor at the end of first burnup stage is also small as shown in Table XI. Thus, these numerical simulations demonstrate that the flux-to-current ratio method can be utilized not only to monitor the reactivity variations in the KIPT subcritical assembly due to the buildup of the poison fission gases, but also to monitor the reactivity variations within each fuel burnup stage with reference core configurations updated at the beginning of the fuel burnup stage.

\section{Summary}

A technique is proposed in this report, which combines the area-ratio method with the flux-to-current ratio method to measure and to monitor the reactivity of the KIPT subcritical assembly during the operation of the KIPT neutron source facility. Specifically, when the KIPT neutron source facility is in the fuel loading mode, the area-ratio method with the pulsed-neutron experiment is utilized to measure the absolute reactivity at each fuel loading stage. The area-ratio method is also utilized to provide reference reactivities for other operation modes. When the neutron source facility is operated at full power, the flux-to-current ratio method is utilized to monitor the reactivity changes due to fuel burnup and to track the reactivity variations due to other conditions.

Extensive number of simulations were performed to study the capability of the purposed technique for the KIPT neutron source facility. Specifically, Monte Carlo simulations are performed to study the spatial effects of both the area-ratio method and the flux-to-current ratio method by placing neutron detectors at different locations in the subcritical assembly. The spatial correction factors for both methods were calculated at all the selected detector positions. The simulation results show that both the area-ratio method and the flux-to-current ratio method are sensitive to the neutron detector positions. Numerical simulations show that with multiple neutron detectors placed inside the subcritical assembly, there are optimal neutron detector positions inside the water tank for minimizing the spatial corrections for the flux-to-current ratio method.

Based on the results from these numerical simulations, six U-235 fission chambers are placed at an optimal position, which is $12.5 \mathrm{~cm}$ above the graphite reflector and 54 $\mathrm{cm}$ radially from the subcritical core center line with the detectors facing the middle of the flat surface of the hexagon boundary. Another three U-235 fission chambers are placed at inner-surface of the biological shield. For the KIPT subcritical assembly configuration with the tungsten target and 38 fuel assemblies, Monte Carlo simulations were performed to calculate the spatial correction factors for both methods at all the nine detector positions for the 20 fuel loading stages.

At the selected neutron detector optimal positions, Monte Carlo simulations were performed to simulate the detector responses obtained from the pulsed-neutron experiments with different number of fuel assemblies. The numerical simulations determined that the required accelerator beam power is $10 \mathrm{~W}$ and the pulse frequency is $20 \mathrm{~Hz}$. The detector counting rates at the selected optimal positions are calculated, which defined the required counting time for the pulsed neutron experiments in order to 
obtain good measurement accuracy. Based on the results from these numerical analyses, a procedure was established for using both the area-ratio method and the fluxto-current ratio method to determine and monitor the reactivity of the KIPT subcritical assembly during the fuel loading stages.

Monte Carlo simulations were performed to study the accuracy of the flux-tocurrent ratio method for monitoring the reactivity of the KIPT subcritical assembly during the fuel burnup cycle. The spatial correction factors for the measured values using this method were calculated based on KIPT fuel burnup cycle which is divided into 18 fuel burnup stages. The results indicate that the measurements using the flux-to-current ratio method is not very accurate when the subcritical assembly fuel loading pattern is significantly different from that of the reference state fuel loading pattern. In this case, the area-ratio method shall be used to update the reference reactivity to maintain the accuracy of the flux-to-current ratio method for monitoring the reactivity changes during the fuel burnup cycle. The flux-to-current ratio method is found to be very accurate on monitoring the reactivity swing within each fuel burnup stage, if the reference reactivity at the beginning of the fuel burnup stage is measured by the area-ratio method.

In this report, numerical simulations have demonstrated that the technique of combining the flux-to-current ratio method and the area-ratio method is capable of measuring and monitoring the reactivity of the KIPT neutron source facility during the different operating modes.

\section{Acknowledgement}

This work is supported by the U.S. Department of Energy, National Nuclear Security Administration, Office of Material Management and Minimization (M3), under Contract No. DE-AC02-06CH11357. 


\section{References}

[1] Z. Zhao, Y. Gohar, D. G. Naberezhnev and J. Duo, "Shielding Analysis and Design of the KIPT Experimental Neutron Source Facility of Ukraine," ANL-08/23 (2008).

[2] G. I. Bell and S. Glasstone, Nuclear Reactor Theory, Van Nostrand Reinhold Co. (1970).

[3] Y. Cao and Y. Gohar, "Conceputal Configurations of an Accelerator-Driven Subcritical System utilizing minor actinides," PHYSOR2012-Advances in Reactor Physics Linking Research, Industry, and Education, Knoxville, Tennessee, USA, April 15-20 (2012).

[4] J. F. Lebrat, G. Aliberti, A. D’Angelo, C. Billebaud, R. Brissot, H. Brockmann, M. Carta, C. Destouches, F. Gabrielli, E. Gonzalez, A. Hogenbrik, R. KleinMeulenkamp, C. Le Brun, E. Liatard, F. Mellier, N. Messaoudi, V. Peluso, M. Plaschy, M. Thomas, D. Villamarin, and J. Vollaire, "Global Results from Deterministic and Stochastic Analysis of the MUSE-4 Experiments on the Neutronics of Accelerator-Driven Systems," Nucl. Sci. Eng., 158, 49-67 (2008).

[5] Y. Cao and Y. Gohar, "YALINA-Booster Subcritical Assembly Pulsed-Neutron Experiments: Data Processing and Spatial Corrections," ANL-10/22 (2010).

[6] Y. Cao and J. C. Lee, "Spatial Corrections for Pulsed-Neutron Reactivity Measurements," Nucl. Sci. Eng., 270-282 (2010).

[7] Talamo, Y. Gohar, C. Rabiti, G. Aliberti, F. Kondev, D. Smith, Z. Zhong, H. Kiyavitskaya, V. Bournos, Y. Fokov, C. Routkovskaya, and I. Serafimovich, "Pulse Superimposition Calculational Methodology for Estimating the Subcriticality Level of Nuclear Fuel Assemblies," NIM, 661-668 (2009).

[8] M. Carta and A. D'Angelo, "Subcriticality-Level Evaluation in Accelerator-Driven Systems by Harmonic Modulation of the External Source," Nucl. Sci. Eng., 133, 282-292 (1999).

[9] W. Uyttenhove, P. Baeten, G. Van den Eynde, A. Kochetkov, D. Lathouwers, M. Carta, "The Neutronic Design of a Critical Lead Reflected Zero-Power Reference Core for On-Line Subcriticality Measurements in Accelerator Driven Systems," Ann. Nucl. Eng., 38, 1519-1526 (2011).

[10] J. Lecouey, G. Ban, P. Bergonzo, A. Billebaud, R. Brissot, S. Chabod, P. Dessagne, J. M. Fontbone, M. Kerveno, C. Le Brun, F. R. Lecolley, J. F. Lecolley, E. Liatard, N. Marie, C. Mer, A. Nuttin, M. Pomorski, J. C. Steckmeyer, H. E. Thyebault and D. Tromson, "Monitoring Fast Neutron Sources for Accelerator Driven Subcritical Reactor Experiments," Advancements in Nuclear Instrmentation Measurement Methods and their Applications (ANIMMA), 2009 First International Conference, June (2009).

[11] P. Baeten, H. Ait Abderrajo, "Reactivity Monitoring in ADS, Application to the MYRRHA ADS Project," Prg. Nuc. Eng., 43, 413-419 (2003).

[12] J. Wright and I. Pazsit, "Neutron Kinetics in Subcritical Cores with Application to the Source Modulation Method," Ann. Nucl. Eng., 33, 149-158 (2006).

[13] Y. Cao, Y. Gohar and Z. Zhong, "Numerical Studies of the Flux-to-Current Ratio Method in the KIPT Neutron Source Facility," International Conference on Mathematics and Computational Methods Applied to Nuclear Science \& Engineering (M\&C 2013), Sun Valley, Idaho, USA, May 5-9 (2013). 
[14] Y. Cao, Y. Gohar and Z. Zhong, "Reactivity Monitoring Methods For the KIPT Neutron Source Facility," AccApp 2013, Eleventh International Topical Meeting on Nuclear Applications of Accelerators, Bruges, Belgium, August 5-8 (2013).

[15] B. Pelowitz, "MCNPX User's Manual, Version 2.6.0," LA-CP-07-1473 (2008).

[16] B. PELOWITZ, "MCNP6TM USER'S MANUAL," LA-CP-11-01708 (2011). 45 


\section{Appendix A: Monte Carlo Simulations and Validations of the Source-Modulation Method}

\section{A. Theory}

The source-modulation method has been purposed to determine the absolute reactivity of a subcritical system while the system is operated at full power [6]. It is one of the dynamic methods which utilize a time-dependent external source to measure the reactivity $\rho$ [8]. It is directly derived by assuming the subcritical fission assembly satisfies the point kinetics equations:

$$
\begin{gathered}
\frac{d}{d t} P(t)=\frac{\rho-\beta}{\Lambda} P(t)+\sum_{i=1,6} \lambda_{i} C_{i}(t)+S(t) \\
\frac{d}{d t} C_{i}(t)+\lambda_{i} C_{i}(r, t)=\frac{\beta_{i}}{\Lambda} P(t) i=1, \ldots, 6 .
\end{gathered}
$$

It assumes that the external neutron source has a fixed component but fluctuates periodically with a modulated component:

$$
S(t)=S_{0}+\Delta S \cos (\omega t)
$$

where $\Delta S$ is the amplitude of the neutron source modulation part, and $\omega$ is the frequency of the modulated part of the neutron source. To solve the point kinetics equations, assuming that the system has been in the asymptotic states using the periodic external neutron source. Laplace transform is applied to obtain the simple relationship between the amplitude of the power variation $\Delta \mathrm{P}$ and the external neutron source variation $\Delta \mathrm{S}$ as follows:

$$
\frac{\Delta P}{P}=\frac{\rho(\$)}{\rho(\$)-1} \frac{\Delta S}{S}
$$

Where $\rho(\$)$ is the reactivity of the subcritical assembly in dollars. $\Delta \mathrm{P}$ is measured as the variation of the detector responses at the detector locations, and $\Delta S$ is replaced by the fluctuations of the current of the accelerator beam.

Equation (25) shows that the source-modulation method can provide the absolute reactivity of the system. It does not require reference value and only requires a small modulation term during the normal continuous operation. This method is derived from the point kinetics assumption. However, the total power is replaced by the neutron detector response which is a localized quantity.

Wright and Pazsit investigated the source-modulation method using a onedimensional numerical model [12], and found that the source-modulation method has very poor performance in their analyses. They conclude that the poor performance originates from of the replacement of the total power with the local detector responses. 
To extend their studies, the applicability of the source-modulation method is studied through the numerical simulations of a modulated source varying periodically in a numerical model using YALINA thermal facility [7].

\section{B. Monte Carlo Simulations}

The numerical model of the YALINA thermal is chosen for this study, with 4 detectors MC1 to MC4 arranged at the four corners of the subcritical assembly, and two detectors EC5 and EC6 in the reflector zone as shown in Figure 27. The external source is assumed to be a modulated source:

$$
S(r, t)=S_{0}(r)\left[1+0.1 \times \sin \left(\frac{2 \pi}{T} t\right)\right]
$$

To simulate the detector response corresponding to the sinusoidal external source, its response to the first source period $S_{T}$ is calculated using the Monte Carlo method as shown in Figure 28:

$$
S_{T}(r, t)=\left\{\begin{array}{cc}
S_{0}(r)[1+f \sin (\omega t)] & t \in[0, T] \\
0 & t \geq T
\end{array}\right.
$$

Therefore, the superposition technique [7] was used to obtain the asymptotic detector response as shown in Figure 29.

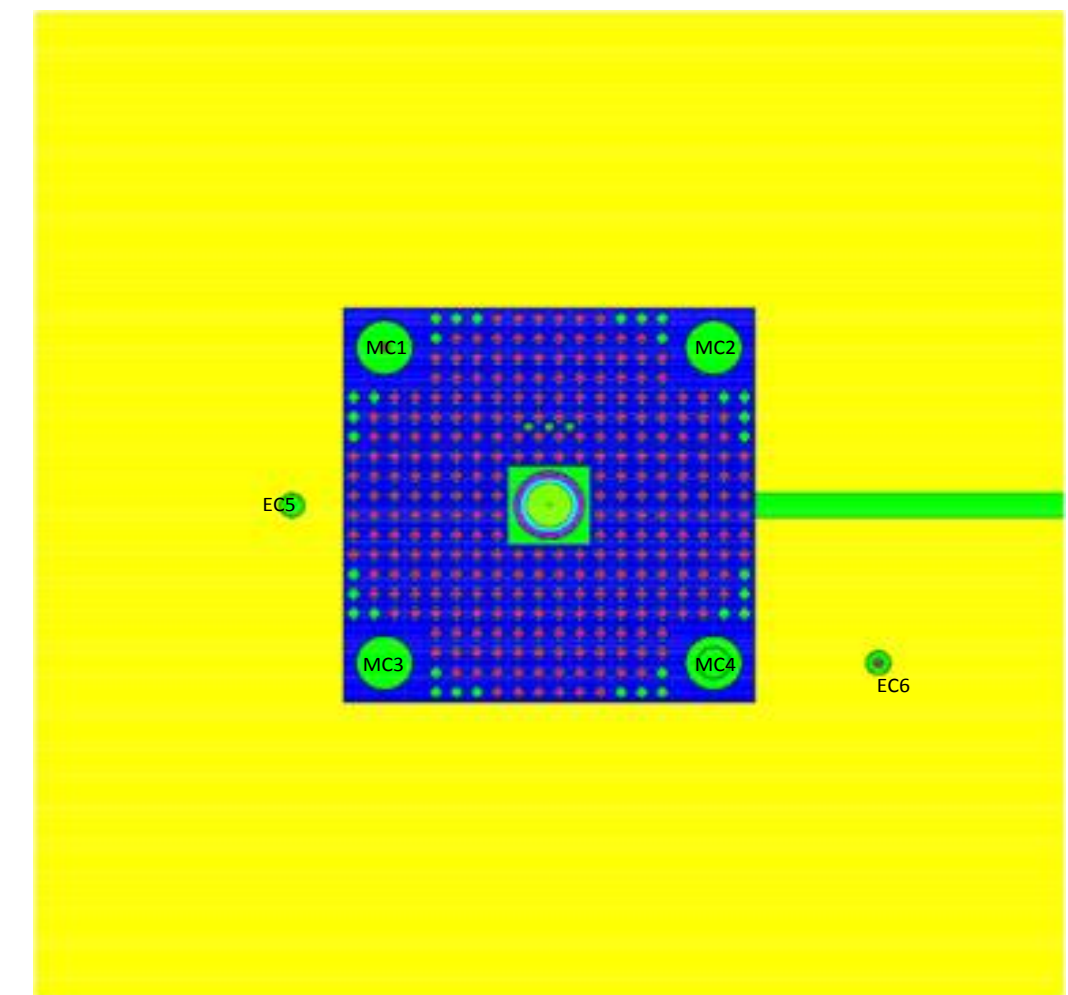

Figure 27. Monte Carlo model of the YALINA-thermal subcritical assembly configuration 18. 


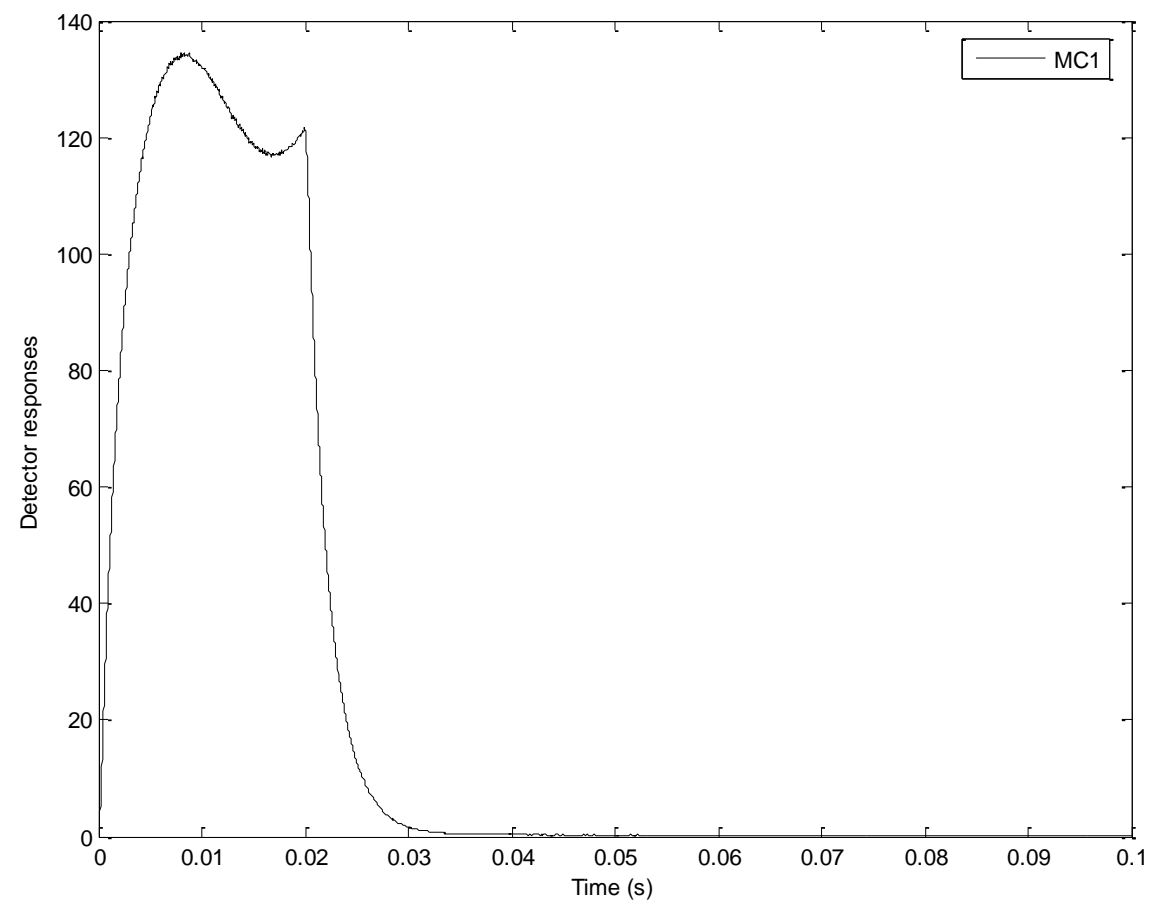

Figure 28. Monte Carlo simulation of the MC1 detector response $R_{T}$ in the YALINAthermal subcritical assembly using the external neutron source $S_{T}(t)$.

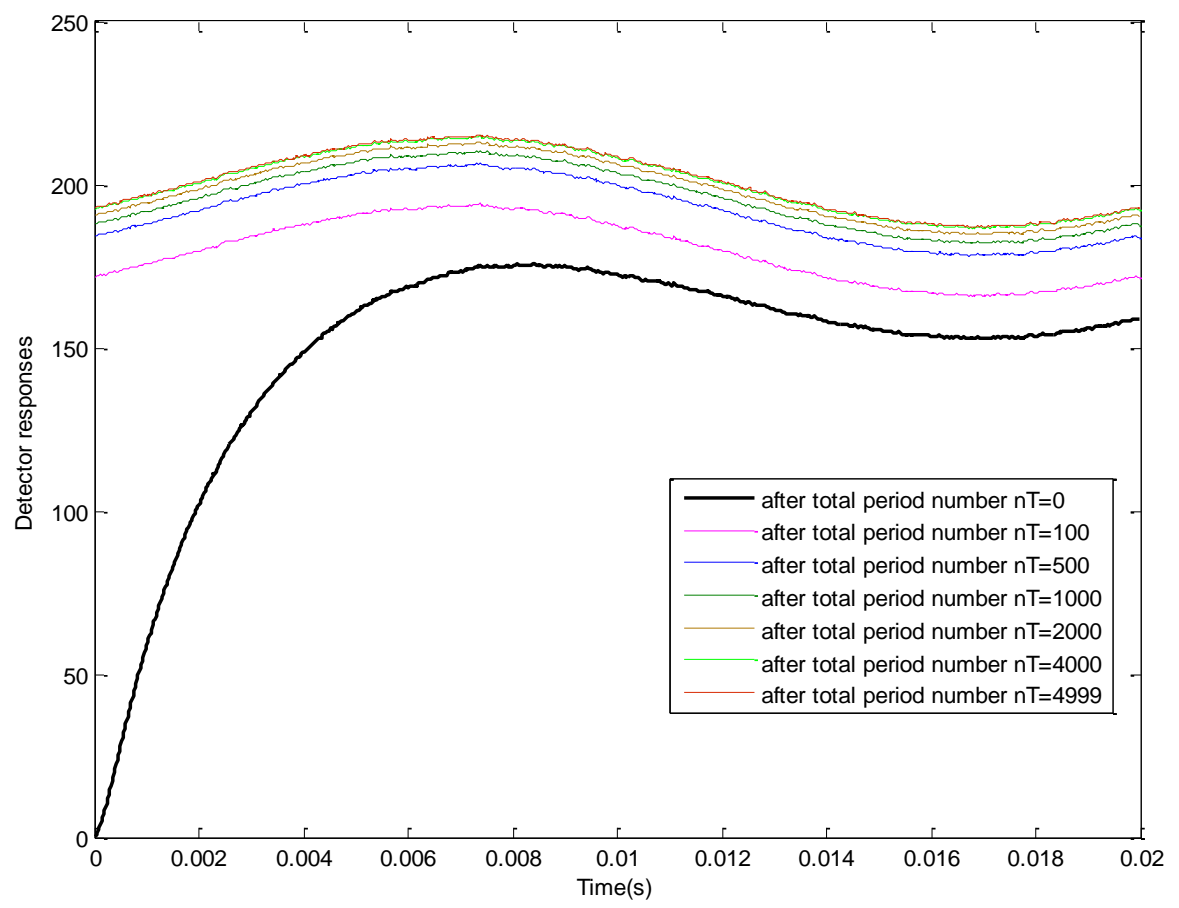

Figure 29. Calculated asymptotic detector responses at MC1 within one period with 1 to 5000 periods accumulated in the YALINA-thermal subcritical assembly. 
To apply the source-modulation method, as shown in Figure 30, the asymptotic detector responses are fitted with a sinusoidal function which has an undetermined amplitude variation factor $f_{z}$ and the phase shift $\psi$ over a source period:

$$
R(r, t)=\left[a_{0}+f_{z} \sin \left(\frac{2 \pi}{T} t+\psi\right)\right] \quad t \in[0, T)
$$

Table XIII lists the average detector count $a_{0}$, the amplitude variation $f_{z}$, the phase shift $\psi$ obtained from the fitting function of all the six detector responses. Two types of detectors $\mathrm{U}-235$ and short $\mathrm{He}-3$ detectors are assumed in the simulations without explicit simulation of the detector geometry. The calculated reactivities and $k_{\text {eff }}$ at each detector location were calculated and listed in Table XII. The "true" reactivities are obtained from the Monte Carlo k-eigenvalue calculations. Clearly, the source-modulation method has underestimated the absolute value of the reactivity by more than $50 \%$ at every detector location for each detector type.

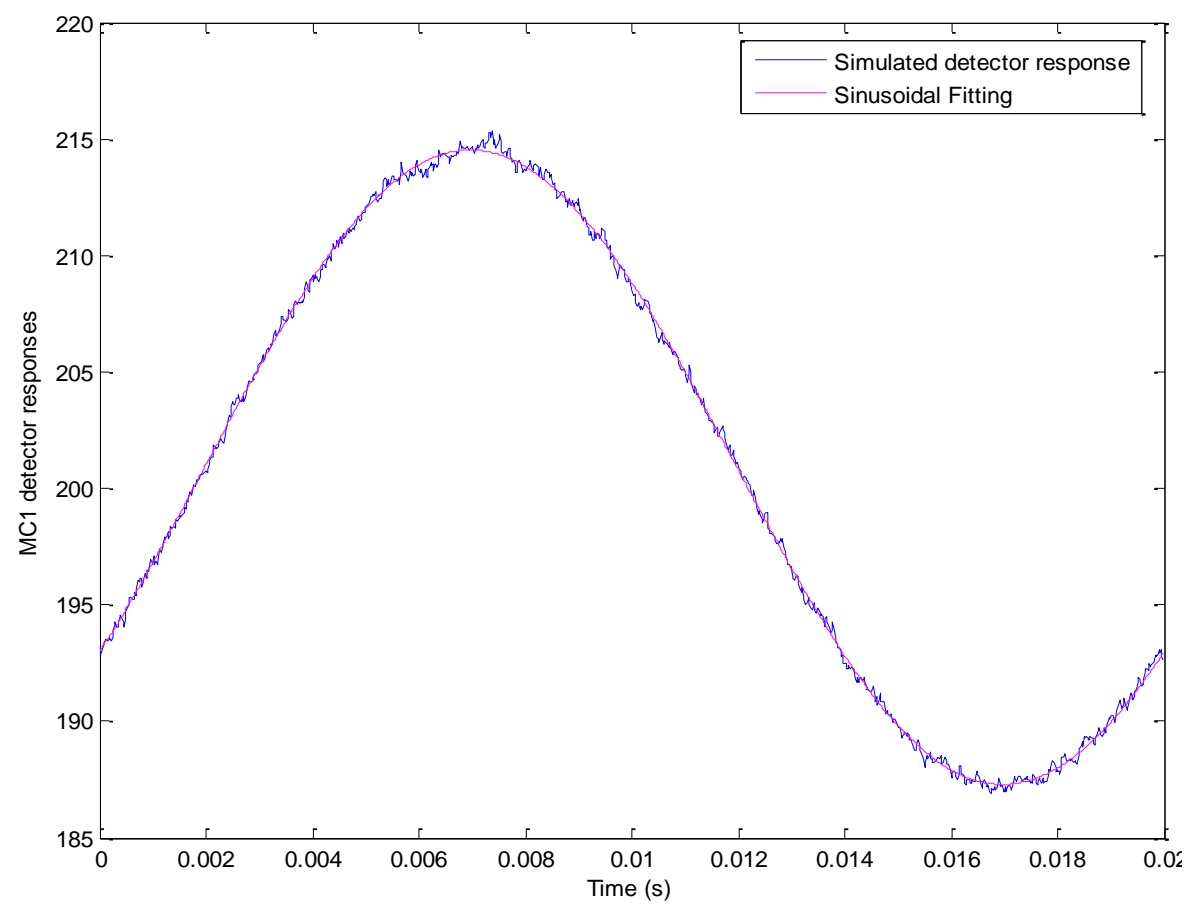

Figure 30. The simulated asymptotic detector response responses at MC1 position and its sinusoidal fitting in YALINA-thermal subcritical assembly.

The numerical simulations of the source-modulation method clearly show a spatial dependence in the phase shift at different detector positions in Table XII, which indicates that the high order spatial harmonics cannot be ignored in this problem. 
Table XII: Numerical simulations of the source modulation method for the YALINA-thermal subcritical assembly (Monte Carlo calculated parameters $\beta_{\text {eff }}=0.0073$,

\begin{tabular}{|c|c|c|c|c|c|c|c|}
\hline \multicolumn{2}{|l|}{ Detector } & MC1 & MC2 & MC3 & MC4 & EC5 & EC6 \\
\hline \multirow{2}{*}{$f_{z}$} & U-235 & 10.41 & 13.61 & 13.71 & 13.61 & 8.64 & 4.37 \\
\hline & $\mathrm{He}-3$ & 97.59 & 127.24 & 128.17 & 127.31 & 81.05 & 41.16 \\
\hline \multirow{2}{*}{$a_{0}$} & U-235 & 153.66 & 200.90 & 203.47 & 200.96 & 130.21 & 67.00 \\
\hline & $\mathrm{He}-3$ & 1440.50 & 1878.50 & 1902.50 & 1879.40 & 1221.80 & 630.72 \\
\hline \multirow{2}{*}{$\begin{array}{c}\psi \\
\text { (degree) }\end{array}$} & U-235 & --34.90 & -35.52 & -36.28 & -35.85 & -42.31 & -47.92 \\
\hline & $\mathrm{He}-3$ & -34.85 & -35.49 & -36.23 & -35.81 & -42.16 & -47.74 \\
\hline \multirow{2}{*}{$\begin{array}{c}f= \\
\frac{f_{z}}{a_{0} \Delta Q}\end{array}$} & U-235 & 0.68 & 0.68 & 0.67 & 0.68 & 0.66 & 0.65 \\
\hline & $\mathrm{He}-3$ & 0.68 & 0.68 & 0.67 & 0.68 & 0.66 & 0.65 \\
\hline \multirow{2}{*}{$\rho(\$)^{*}$} & U-235 & -2.101 & -2.099 & -2.064 & -2.099 & -1.969 & -1.878 \\
\hline & $\mathrm{He}-3$ & -2.101 & -2.099 & -2.065 & -2.100 & -1.971 & -1.878 \\
\hline \multirow{2}{*}{$k_{e f f}$} & U-235 & 0.9849 & 0.9849 & 0.9852 & 0.9849 & 0.9858 & 0.9865 \\
\hline & $\mathrm{He}-3$ & 0.9849 & 0.9849 & 0.9852 & 0.9849 & 0.9858 & 0.9865 \\
\hline
\end{tabular}

Equation (25) also indicates that the source-modulation method is very sensitive to the experimental errors or the spatial corrections made to the experimental measurements. For instance, if defining the flux-to-current variation ratio $f$ as: $f=\frac{\Delta \phi}{\phi} / \frac{\Delta S}{S}$, Equation (25) can be reformulated as follows:

$$
\rho(\$)=\frac{f}{f-1}
$$

Considering the reactivity of the subcritical systems ranging from $-15 \$$ to $-3 \$, 1 \%$ increment or spatial corrections made to the flux-to-current variation ratio will lead to the corrections of the reactivity ranging from $19 \%$ to $4 \%$ respectively, depending on the reactivity of the subcritical system. Therefore, the above numerical analysis shows that the source-modulation method seems not reliable in determining the absolute reactivity of the subcritical system at the reference states. 


\section{Appendix B: Monte Carlo Sampling of the Modulated External Source}

\section{A. Sampling algorithm:}

For the sinusoidal source:

$$
S(r, t)=S_{0}(r)+f S_{0}(r) \sin \left(\frac{2 \pi}{T} t\right)=S_{0}(r)\left[1+f \sin \left(\frac{2 \pi}{T} t\right)\right] .
$$

Within one source period, the total area of the source is calculated to be:

$$
S_{\text {total }}=\int_{0}^{T} S(r, t) d t=S_{0}(r) T .
$$

The area in each quadrant is:

$$
\begin{aligned}
& S_{1}=\int_{0}^{\frac{T}{4}} S(r, t) d t=S_{0}(r) T\left[\frac{1}{4}+\frac{f}{2 \pi}\right], \\
& S_{2}=\int_{\frac{T}{4}}^{\frac{T}{2}} S(r, t) d t=S_{0}(r) T\left[\frac{1}{4}+\frac{f}{2 \pi}\right], \\
& S_{3}=\int_{\frac{T}{2}}^{\frac{3 T}{4}} S(r, t) d t=S_{0}(r) T\left[\frac{1}{4}-\frac{f}{2 \pi}\right], \\
& S_{4}=\int_{\frac{3 T}{4}}^{T} S(r, t) d t=S_{0}(r) T\left[\frac{1}{4}-\frac{f}{2 \pi}\right] .
\end{aligned}
$$

Selecting random number $\epsilon_{1} \in[0,1]$ to determine the quadrant of the sampling time point first:

$$
\text { if } \begin{cases}\epsilon_{1} \leq s_{1} & 1^{\text {st }} \\ s_{1}<\epsilon_{1} \leq\left(s_{1}+s_{2}\right) & 2^{\text {nd }} \\ \left(s_{1}+s_{2}\right)<\epsilon_{1} \leq\left(s_{1}+s_{2}+s_{3}\right) & 3^{\text {rd }} \\ \left(s_{1}+s_{2}+s_{3}\right)<\epsilon_{1} & 4^{\text {th }}\end{cases}
$$

In the first quadrant, if assuming the current time is at $t_{1}$, then the accumulative area between $T\left[0, t_{1}\right]$ can be calculated as: 


$$
S_{1}\left(t_{1}\right)=\int_{0}^{t_{1}} S(r, t) d t=S_{0}(r) T\left[t_{1}+\frac{f}{2 \pi}\left(1-\cos \left(2 \pi t_{1}\right)\right] .\right.
$$

Selecting random number $\epsilon_{2} \in[0,1]$, the time sampling of $t_{1}$ can be calculated with:

$$
\epsilon_{2}=\frac{S_{1}\left(t_{1}\right)}{S_{1}}=\frac{\left[t_{1}+\frac{f}{2 \pi}\left(1-\cos \left(2 \pi t_{1}\right)\right]\right.}{\frac{1}{4}+\frac{f}{2 \pi}} .
$$

Correspondingly, if the sampling point is at the second quadrant, the time point can be obtained as:

$$
t_{2}=\left[\frac{1}{2}-t_{1}\right] T
$$

When the sampling time point is in the third quadrant:

$$
S_{3}\left(t_{3}\right)=\int_{\frac{T}{2}}^{t_{3}} S(r, t) d t=S_{0}(r) T\left[t_{3}-\frac{1}{2}-\frac{f}{2 \pi}\left(1-\cos \left(2 \pi\left(t_{3}-\frac{1}{2}\right)\right] .\right.\right.
$$

Similarly, selecting random number $\epsilon_{2} \in[0,1]$, the time sampling $t_{3}$ can be calculated as:

$$
\epsilon_{2}=\frac{S_{3}\left(t_{3}^{\prime}\right)}{S_{3}}=\frac{\left[t_{3}^{\prime}-\frac{f}{2 \pi}\left(1-\cos \left(2 \pi t_{3}^{\prime}\right)\right]\right.}{\frac{1}{4}-\frac{f}{2 \pi}} .
$$

And:

$$
t_{3}=\left[\frac{1}{2}+t_{3}^{\prime}\right] T
$$

Similarly, the corresponding sampling point if it is in the fourth quadrant can also be obtained as:

$$
t_{4}=T-t_{3}^{\prime} .
$$




\section{B. Sampling Matlab program and Fortran program in the MCNPX code package:}

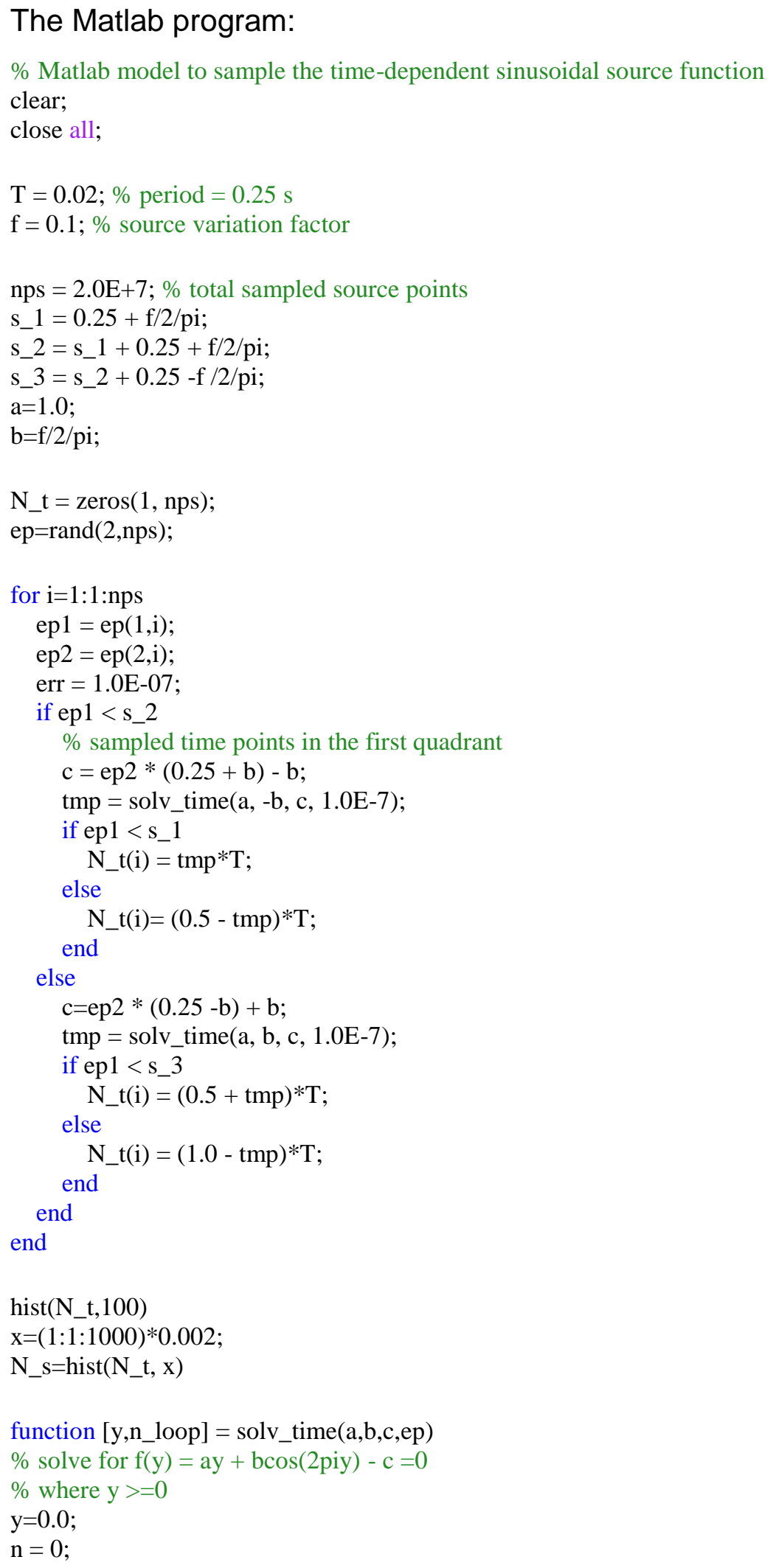




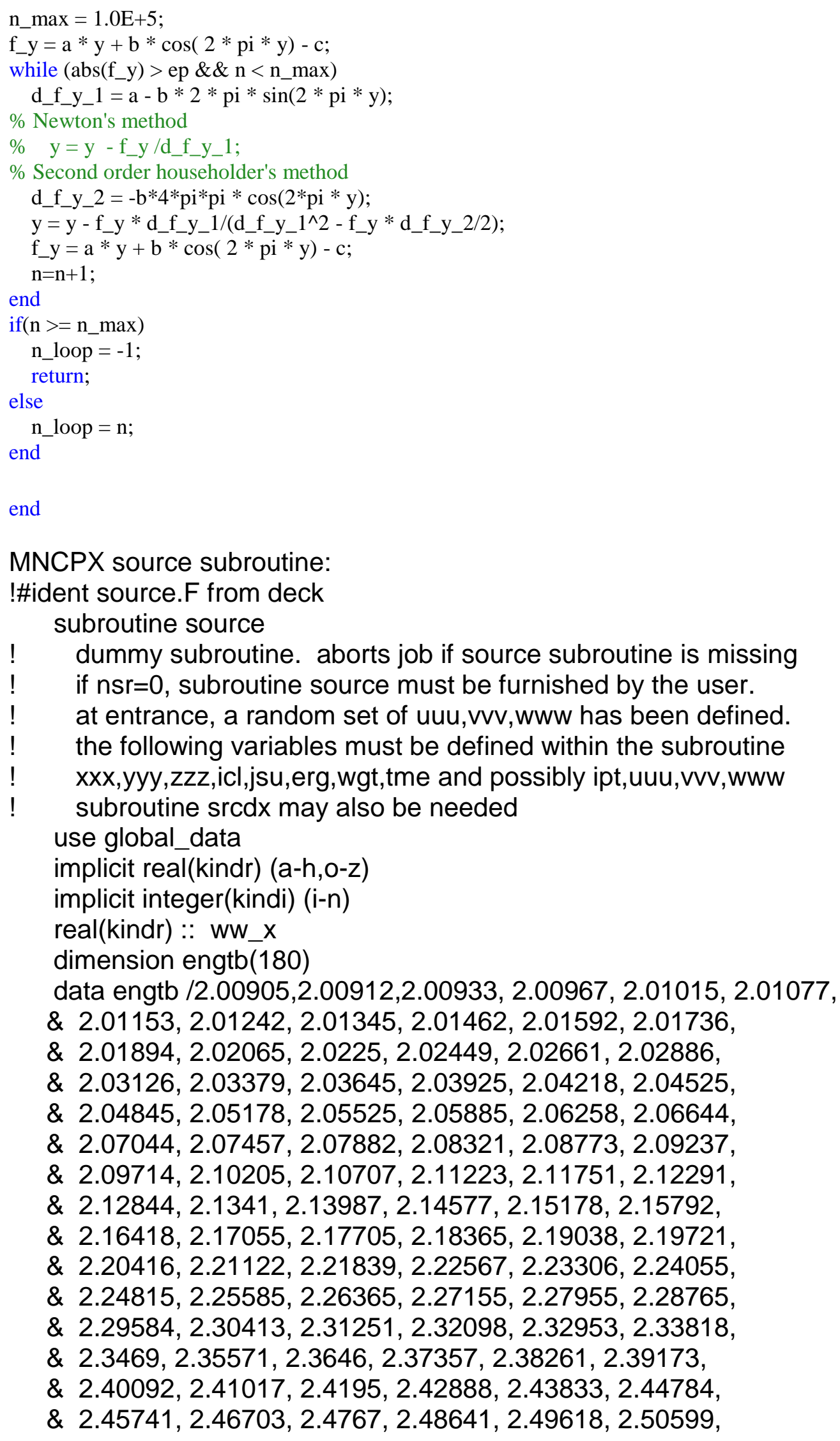


\& $2.51584,2.52572,2.53564,2.54559,2.55557,2.56557$,

\& 2.5756, 2.58564, 2.5957, 2.60578, 2.61586, 2.62594,

\& 2.63603, 2.64612, 2.6562, 2.66628, 2.67634, 2.68639,

\& 2.69641, 2.70642, 2.7164, 2.72635, 2.73627, 2.74614,

\& $2.75598,2.76578,2.77552,2.78521,2.79485,2.80442$,

\& 2.81394, 2.82338, 2.83275, 2.84205, 2.85127, 2.86041,

\& 2.86945, 2.87841, 2.88728, 2.89604, 2.90471, 2.91327,

\& 2.92172, 2.93006, 2.93828, 2.94638, 2.95435, 2.9622,

\& 2.96992, 2.97751, 2.98495, 2.99226, 2.99942, 3.00643,

\& $3.01329,3.02,3.02655,3.03294,3.03917,3.04523$,

\& $3.05112,3.05684,3.06238,3.06775,3.07294,3.07794$,

\& 3.08276, 3.08739, 3.09183, 3.09609, 3.10014, 3.104,

\& $3.10767,3.11113,3.11439,3.11745,3.12031,3.12296$,

\& 3.1254, 3.12763, 3.12966, 3.13147, 3.13308, 3.13447,

\& $3.13565,3.13661,3.13736,3.1379,3.13822,3.13833 /$

!

wgt $=1.0$

jsu $=0$

icl $=0$

$\mathrm{jt}=0$

z-cylinder source

sample position from the RDUM parameter

! rdum =[radius, height/2, center_x, center_y, center_z,amp, prd] $r=\operatorname{rdum}(1)^{*}$ sqrt(rang ()$)$

$\mathrm{TH}=2$. ${ }^{*}$ pie*rang()

$\mathrm{xxX}=\operatorname{rdum}(3)+\mathrm{r}^{*} \cos (\mathrm{TH})$

yyy=rdum $(4)+r^{*} \sin (\mathrm{TH})$

$\mathrm{zzZ}=\mathrm{rdum}(5)+\mathrm{rdum}(2)^{*}\left(2 .{ }^{*}\right.$ rang()-1.0)

! sampling the cosine angle from distribution 1

call smpsrc(www, 1, IB, FI)

$\mathrm{TH}=2 .{ }^{*}$ pie*rang()

$w w \_x=\operatorname{sqrt}\left(1-w w w^{\star *} 2\right)$

uuu $=\mathrm{ww} \_\mathrm{x}^{*} \cos (\mathrm{TH})$

$v V V=w w \_x^{*} \sin (T H)$

erg=engtb $\left(180\right.$-int $\left(\operatorname{acos}(w w w) /\right.$ pie $\left.\left.^{*} 180.0\right)\right)$

icl=namchg( 1 ,idum(1))

if (idum(2) .eq. 0) call smptmsn

if (idum(2) .eq. 1) call smptmsqur

if (idum(2) .eq. 2) call smptmunf

call smptm

call smptmsqur

return

end

subroutine smptmsqur

! sample a time dependent source with the following proba form

! $s(r, t)=s \_0(r)+f \_a m p^{*} u\left(t+n^{*} p r d\right)$ 


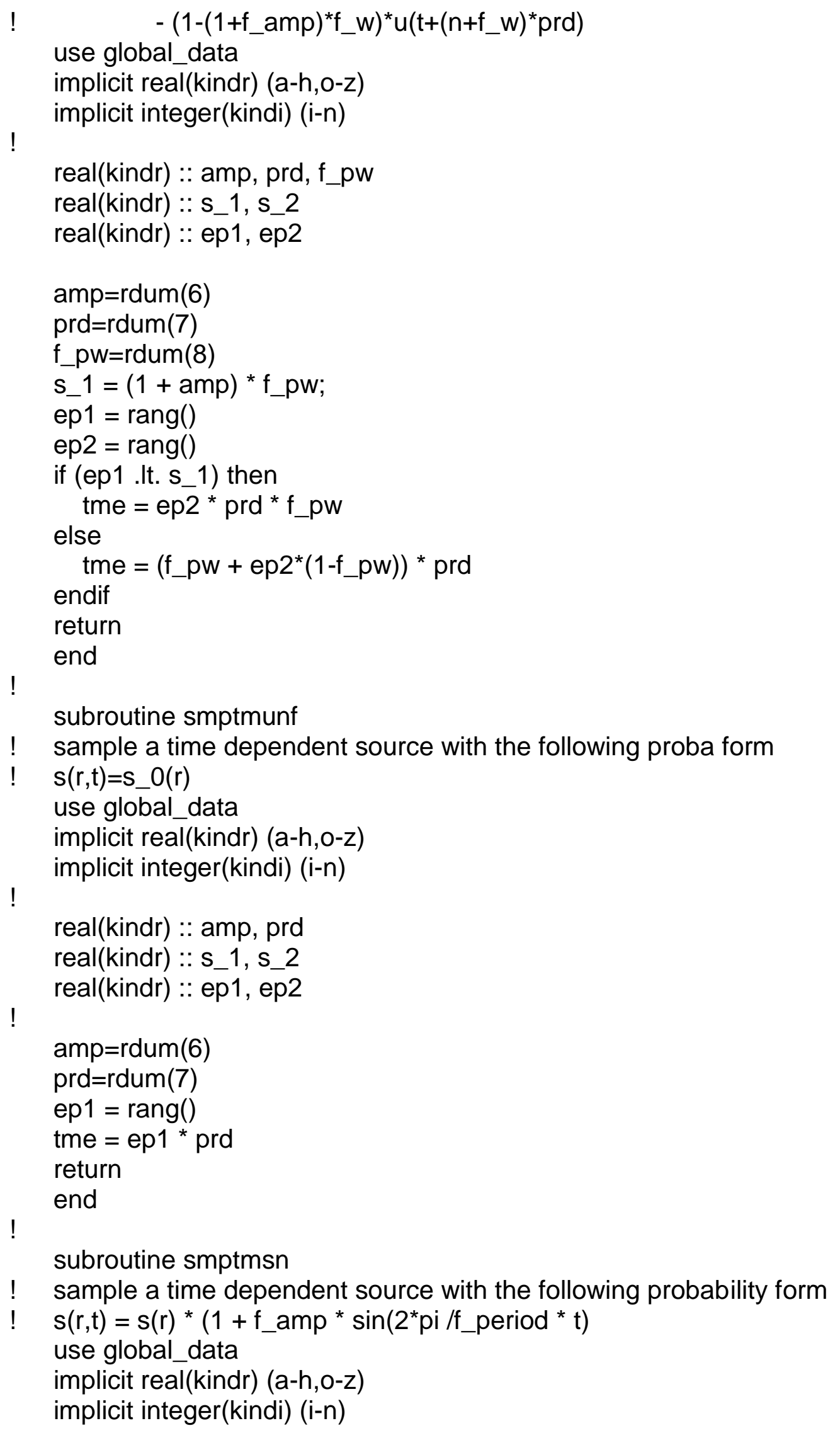




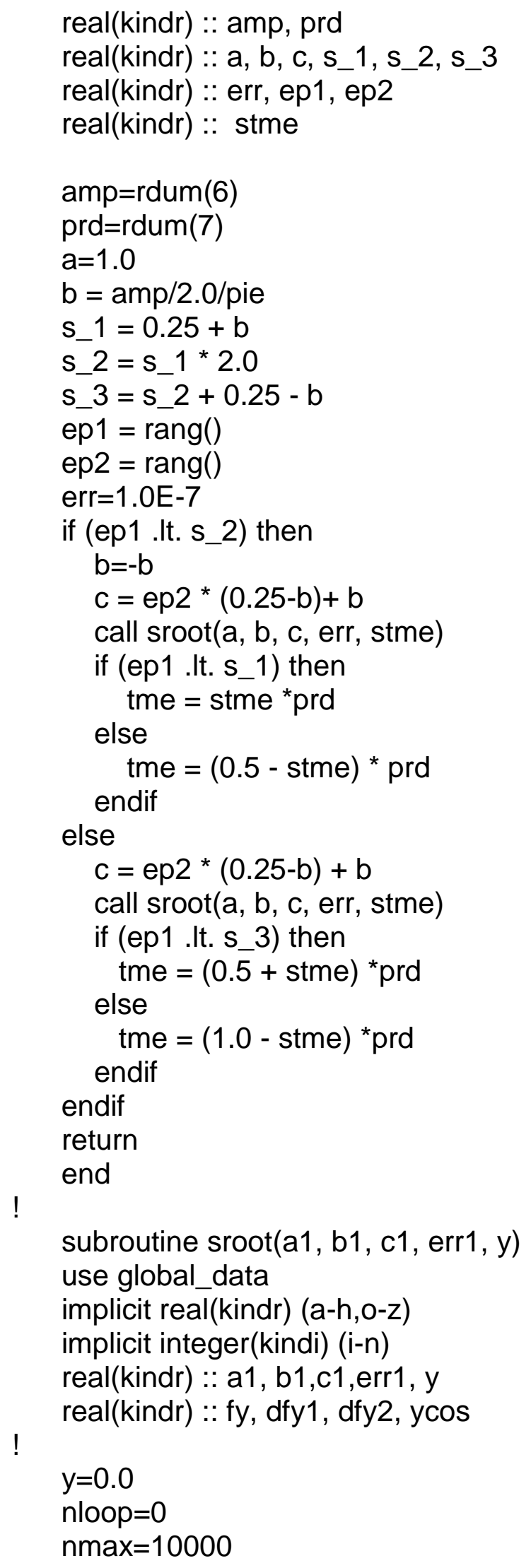




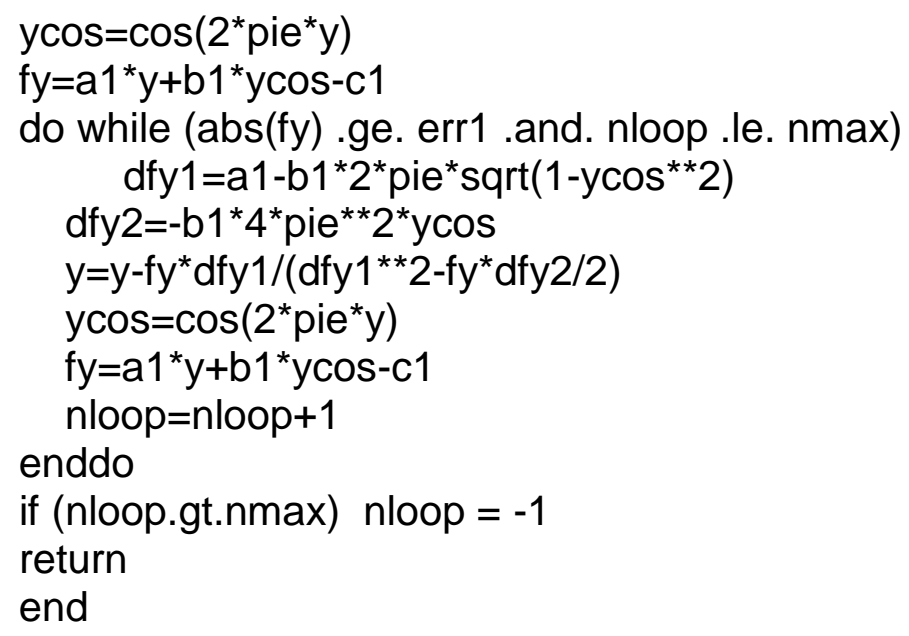




\section{Argonne}

Nuclear Engineering Division

Argonne National Laboratory

9700 South Cass Avenue, Bldg. 208

Argonne, IL 60439

www.anl.gov 